\title{
Heavy-Metal Contamination on Training Ranges at the Grafenwöhr Training Area, Germany
}

by S.D. Zellmer and J.F. Schneider

Reclamation Engineering and Geosciences Section, Energy Systems Division, Argonne National Laboratory, 9700 South Cass Avenue, Argonne, Illinois 60439

May 1993

Work sponsored by the Department of the Army, U.S. Army 7th Army Training Center, 100th Area Support Group, Directorate of Engineering and Housing, Environmental Division, Grafenwöhr, Germany 


\section{Contents}

Acknowledgments................................................................ vi

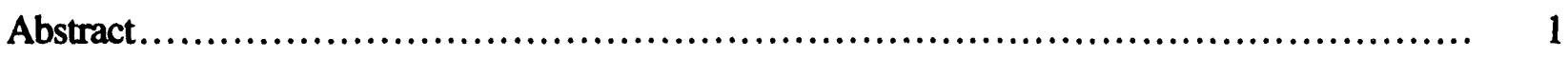

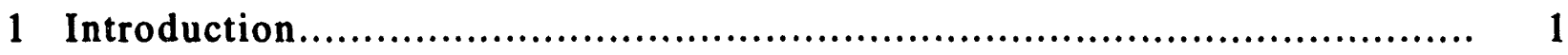

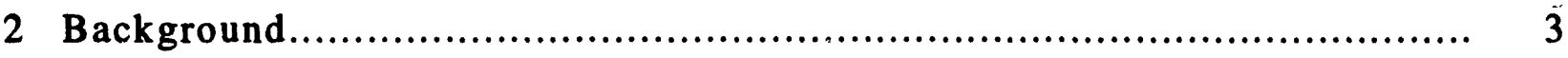

3 Goal, Objectives, and Approach........................................... 10

4 Materials and Methods........................................................ 12

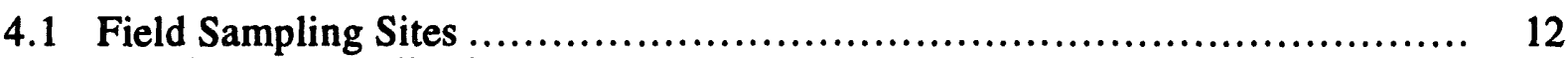

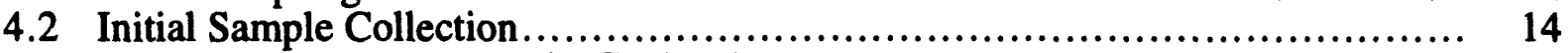

4.3 Primary Data and Sample Collection............................................. 18

4.3.1 Data and Sample Collection Plan......................................... 18

4.3.2 X-Ray Fluorescence Principle and Data Collection ..................... 20

4.3.3 Soil, Vegetation, and Water Sample Collection.......................... 22

4.4 Laboratory Analytical Methods ................................................ 24

4.4.1 Soil Analyses for Heavy Metals........................................ 24

4.4.2 Soil Analysis for Explosives .......................................... 26

4.4.3 Soil Analyses for Physical and Chemical Characteristics............... 27

4.4.4 Vegetation Analysis for Heavy Metals..................................... 27

4.4.5 Water Analysis for Heavy Metals ................................... 27

5 Results and Discussion ................................................... 28

5.1 Analytical Results for Initial Samples......................................... 28

5.1 .1 Heavy Metals ........................................................ 28

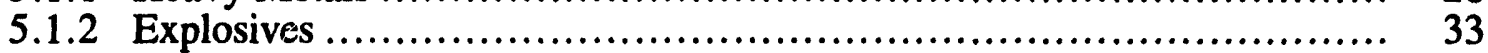

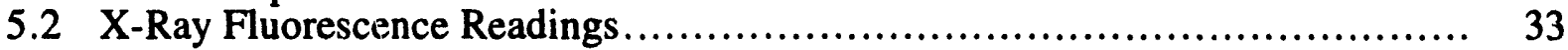

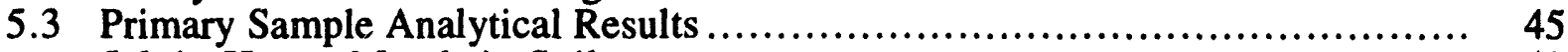

5.3 .1 Heavy Metals in Soils ................................................. 45

5.3 .2 Heavy Metals in Vegetation............................................. 53

5.3.3 Heavy Metals in Surface Water.......................................... 53

5.4 Comparison of X-Ray Fluorescence and Laboratory Analytical Data........... 55

5.4 .1 Lead Data.............................................................. 56

5.4 .2 Other Heavy-Metal Data ................................................. 57

5.5 Potential Heavy-Metal Transport ........................................... 58

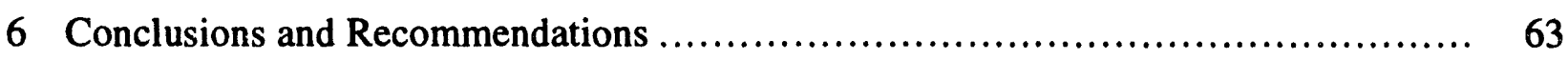

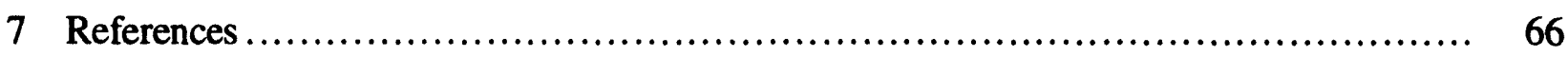




\section{Figures}

1 Location of the Grafenwöhr Training Area in Germany....................... 12

2 Location of the Three Training Ranges Selected for Investigation at GTA......... 13

3 Features and Sampling-Transect Locations at Range 122 at GTA............... 15

4 Features and Sampling-Transect Locations at Range 124 at GTA................ 16

$5 \quad$ Features and Sampling-Transect Locations at Range 111 at GTA............... 17

6 Excavation of the Trench in the Berm at Range 124 at GTA during

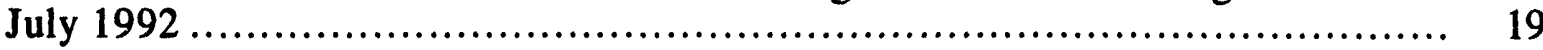

7 Hand-Held XRF Unit and Soil-Sampling Supplies Used at GTA during July 1992

8 Taking an XRF Reading at GTA during July 1992

9 XRF Spectrum 1: Sample with $0 \mathrm{mg} \mathrm{kg}^{-1}$ Lead Collected from Range 124 at GTA during July 1992 .

10 XRF Spectrum 2: Sample with $1,796 \mathrm{mg} \mathrm{kg}^{-1}$ Lead Collected from Range 124 at GTA during July 1992 ....

11 XRF Spectrum 3: Sample with 4,569 $\mathrm{mg} \mathrm{kg}^{-1}$ Lead Collected from Range 124 at GTA during July 1992

\section{Tables}

1 Concentration of Heavy Metals in Soils and Plant Leaves.......................... 5

2 Dutch List of Heavy Metals with Category Contamination Levels for Soil and Groundwater.

3 Suggested Maximum Heavy-Metal Concentrations in Drinking Water.............. 8

4 TCLP Limits for Heavy Metals and the Minimum Soil Concentrations Needed to Yield a Hazardous TCLP Classification ...

5 Heavy-Metal Concentrations Determined by ICP-AES Method for Soils Collected at GTA during April 1992

6 Heavy-Metal Concentrations in TCLP Extracts from Soils Collected at GTA during April 1992 


\section{Tables (Cont.)}

7 Minimum Heavy-Meta! Concentrations Needed to Yield a Hazardous

TCLP Concentration as Calculated from TCLP Extracts for Soils

Collected at GTA during April 1992.

8 X-Ray Fluorescence Readings Taken at Range 122 at GTA during July 1992

9 X-Ray Fluorescence Readings Taken at Range 124 at GTA during July 1992

10 X-Ray Fluorescence Readings Taken at Range 111 at GTA during July 1992

11 Heavy-Metal Concentrations Determined by the ICP-AES Method for Soils Collected at GTA during July 1992

12 Heavy-Metal Concentrations Determined by the TCLP Method for Soils Collected at GTA during July 1992.

13 Heavy-Metal Concentrations in Vegetation Collected at GTA during July 1992

14 Heavy-Metal Concentrations in Surface Water Collected at GTA during July 1992

15 XRF Lead Readings and Corresponding ICP-AES Lead Values for Two Soil Samples Collected from Range 124 at GTA during July 1992

16 Heavy-Metal Concentrations for Samples Collected at XRF Locations from Range 124 at GTA during July 1992.

17 Physical and Chemical Characteristics of Soils Collected at GTA during July 1992 


\section{Acknowledgments}

This study of heavy-metal contamination on training ranges at the Grafenwöhr Training Area in Germany was possible only because of the contributions and cooperation of a number of individuals and organizations. The authors acknowledge the assistance of the following:

Manfred Rieck, Environmental Branch, Directorate of Engineering and Housing, Grafenwöhr Training Area, for his interest, organizational support, and assistance during the planning and execution of the study and for his participation during field data and sample collection;

Training-range maintenance personnel, Grafenwöhr Training Area, for information on use of the ranges and excavation of the trenches in the berms;

Guenter Conzelmann, Argonne National Laboratory, Environmental Assessment and Information Sciences Division, for the translation of documents from German into English;

Dean Bass, Edmund Huff, and Lynn TenKate, Argonne National Laboratory, Chemical Technology Division/Analytical Chemistry Laboratory, for providing the analyses of soils by the inductively-coupled plasma atomic-emission spectroscopy method;

John Taylor, Melvin Findlay, Nancy Tomczyk, and Laura Skubal, Argonne National Laboratory, Reclamation Engineering and Geosciences Section analytical laboratory, for sample processing, analyses of soils by the toxic characterization leaching procedure, and analyses of vegetation and water samples;

Sandra Spurgash, Argonne National Laboratory, Environmental Research Division, for the analyses of soils for explosives using high-pressure liquid chromatography; and

Department of the Army, U.S. Army 7th Army Training Center, 100th Area Support Group, Directorate of Engineering and Housing, Environmental Division, for providing the necessary funding for the study. 


\title{
Heavy-Metal Contamination on Training Ranges at the Grafenwöhr Training Area, Germany
}

by

\author{
S.D. Zellmer and J.F. Schneider
}

\begin{abstract}
Large quantities of lead and other heavy metals are deposited in the environment of weapons ranges during training exercises. This study was conducted to determine the type, degree, and extent of heavy-metal contamination on selected handgun, rifle, and hand-grenade ranges at Grafenwöhr Training Area, Germany. Soil, vegetation, and surface-water samples were collected and analyzed using the inductively-coupled plasma atomic-emission spectroscopy (ICP-AES) method and the toxic characterization leaching procedure (TCLP). The ICP-AES results show that above-normal levels of lead and copper are in the surface soil at the handgun rang:, high concentrations of lead and copper are in the berm and soil surface at the rifle range, and elevated levels of cadmium and above-normal concentrations of arsenic, copper, and zinc are present in the surface soil at the hand-grenade range. The TCLP results show that surface soils can be considered hazardous waste because of lead content at the rifle range and because of cadmium concentration at the hand-grenade range. Vegetation at the handgun and rifle ranges has above-normal concentrations of lead. At the hand-grenade range, both vegetation and surface water have high levels of cadmium. A hand-held X-ray fluorescence (XRF) spectrum analyzer was used to measure lead concentrations in soils in a field test of the method. Comparison of XRF readings with ICP-AES results for lead indicate that the accuracy and precision of the hand-held XRF unit must improve before the unit can be used as more than a screening tool. Results of this study show that heavy-metal contamination at all three ranges is limited to the surface soil; heavy metals are not being leached into the soil profile or transported into adjacent areas.
\end{abstract}

\section{Introduction}

Military training exercises during the past several decades at the Grafenwöhr Training Area (GTA) have included firing of a variety of weapons and weapon systems on a number of firing ranges and target areas. The types of weapons used during these live-fire exercises range from small arms and hand grenades to artillery, tanks, and helicopter gunships. One environmental consequence of these firing exercises is the deposition of potentially large quantities of heavy metals (e.g., lead, copper, zinc) and explosive residue onto the soils of firing ranges and target areas at GTA. Thus, elevated concentrations of some heavy metals and explosive residue may be 
present in these soils. It is also conceivable that some heavy metals could be incorporated into food webs through uptake by vegetation. Equally important, it is possible, given certain circumstances, that significant quantities of heavy metals could be introduced into the local surface waters and/or leached from the soil into groundwater supplies. These conditions could provide an effective mechanism for transporting heavy metals to surrounding nonmilitary areas, producing significant adverse environmental impacts affecting the local German population. The type, degree, and extent of heavy-metal and explosive-residue contamination from current and past training exercises need to be determined, and the probability of off-site transport of heavy-metal contaminants must be evaluated.

This investigation was undertaken to provide the U.S. Army with documentation on the type, degree, and extent of heavy-metal and explosive-residue contamination on three types of training ranges and their environs at GTA in Germany. Current and past training exercises requiring the use of small arms and other munitions have resulted in the deposition of heavy metals onto the soils of training ranges. Potential contamination of the local environment by the introduction of heavy metals into the local surface waters or groundwater supplies was assessed. 


\section{Background}

The metals inventoried in this investigation are arsenic (As), barium (Ba), cadmium (Cd), chromium $(\mathrm{Cr})$, cobalt $(\mathrm{Co})$, copper $(\mathrm{Cu})$, lead $(\mathrm{Pb})$, mercury $(\mathrm{Hg})$, nickel $(\mathrm{Ni})$, tin $(\mathrm{Sn})$, and zinc $(\mathrm{Zn})$. All of these metals, with the exception of barium, meet the definition of a heavy metal: a metallic element with a specific gravity of $5.0 \mathrm{~g} \mathrm{~cm}^{-3}$ or more that is generally toxic in relatively low concentrations to plants and/or humans and animals. These heavy metals were inventoried because they are present in various components of small-arms ammunition or hand grenades.

The three training ranges at GTA selected for investigation were a handgun range (Range 122), a rifle range (Range 124), and a hand-grenade range (Range 111). Range 122 is used for handgun practice primarily by military police units, and Range 124 is used by combat units for checking the accuracy of the sights on their rifles. Both Ranges 122 and 124 are considered small-arms ranges. The following information on the chemical composition of smallarms ammunition is from Heath et al. (1991). A typical round of small-arms ammunition consists of a bullet or ball and a cartridge case containing the propellant and ignition cap. Bullets are either solid or filled (with tracer or incendiary materials) and may or may not have an outer metal jacket. The bullet is usually made of a lead alloy consisting of copper, sometimes tin, and up to $15 \%$ antimony, which is added for hardness. Unjacketed or bare balls are used in several types of revolver cartridges. Jacketed bullets are used in high-velocity and automatic weapons. The metal jacket consists of either copper-plate or a thin layer of gilding metal having copper and zinc as the major components. Bullets at high-velocity may shatter upon impact, exposing the lead, copper, zinc, and antimony of the bullet core and jacket. Tracer munitions are used to determine the direction of rapid fire. Tracer materials are made from compounds containing strontium, magnesium, barium, zinc, and potassium. The ignition cap or primer for small-arms ammunition generally contains compounds of lead, barium, antimony, and potassium. Potential sources of heavy-metal contamination in the soils at small-arms ranges consist of the heavy metals contained in the bullet, bullet jacket, tracer materials, and primer.

Range 111 at GTA is used for high-explosive hand-grenade training by U.S. and German Army combat units. The U.S. Army M67 fragmentation hand grenade consists of the body, an explosive charge, a delay fuse to detonate the explosive, and several safety devices. The grenade is about $9 \mathrm{~cm}(3.5 \mathrm{in}$.) in length by $6.4 \mathrm{~cm}(2.5 \mathrm{in}$.) in diameter and has a total weight of approximately $397 \mathrm{~g}(14 \mathrm{oz})$. The grenade body is a $6.4-\mathrm{cm}(2.5-\mathrm{in}$.) diameter sphere made from steel that is designed to burst into numerous fragments when the explosive is detonated. The body of the grenade is filled with approximately $184 \mathrm{~g}(6.5 \mathrm{oz})$ of high explosive, Composition B, consisting of 60\% RDX (hexahydro-1,3,5-trinitro-1,3,5-triazine) and 40\% TNT (2,4,6-trinitrotoluene). Because Composition B is highly corrosive, the internal surface and components of the grenade may be coated with cadmium or other metal alloys to prevent corrosion. The fuse and primer contain lead azide, lead styphnate, and RDX. Safety devices consist of steel pull ring, safety pin, and safety clip (Green 1992). Potential sources of heavy-metal contamination in the soils at Range 111 consist of the explosive residue and the metals contained in the grenade body, internal components and coatings, the fuse and primer, and safety devices. 
All of the heavy metals included in this investigation occur naturally in most soils and are taken up to some degree by plants. Cobalt, copper, and zinc are considered essential in the growth and development of higher plants, and the other heavy metals may benefit normal plant growth if available in very low concentration (Mengel and Kirkby 1978). All of these heavy metals, with the exception of barium and mercury, are necessary in very small amounts for the normal growth of humans and animals (Anke et al. 1984). The heavy metals included in this investigation are also considered a health hazard if present and available in the environment at levels in excess of their normal concentrations. Table 1 gives the average concentration of several heavy metals in soils, the normal range of concentration in soils, and the normal range in plant leaves.

There is no evidence that arsenic is essential for plant growth, but stimulation of root growth in solution cultures with the addition of small amounts of arsenic has been noted. Arsenic can be toxic to plants, and arsenic compounds were commonly used as insecticides and herbicides in agriculture until their replacement by organics (Lisk 1972). It has been reported that soil productivity is reduced where arsenic from sprays has accumulated in orchard soils (Liebig 1966). Arsenic has been added to the list of essential elements in the diet of mini-pigs, goats, and rats (Anke et al. 1984). Both acute and chronic exposure to arsenic may cause poisoning in humans and animals, but acute poisoning is rare today. Chronic poisoning usually results from exposure to contaminated air or drinking water or ingestion of arsenic in drugs or food. Arsenic poisoning among industrial workers is characterized by perforation of the nasal septum, skin changes, and peripheral neuritis. There is also evidence that arsenic may cause lung cancer (Ishinishi et al. 1986).

Barium is not considered essential for plants or animals. It is not reported to be toxic to plants, and the uptake of barium by plants does not correlate with the total amount in the soil (Vanselow 1966a). Barium is toxic to humans and animals because all water- and acid-soluble barium compounds are poisonous. Occupational poisoning by soluble barium salts is virtually unknown, but accidental poisoning with barium-containing household and medical products has been reported (Reeves 1986).

Cadmium is not an essential element for plants, and it can be toxic to plants, animals, and humans. Some studies indicate plant growth is severely depressed with a relatively low accumulation of cadmium in plants (Allaway 1968). New research suggests cadmium is essential for rats and goats (Anke et al. 1984). Studies done in Japan indicate cadmium from polluted soils and water can be incorporated into the food web in sufficient quantities to be toxic to humans (Yamagata and Sigematsu 1970). Cadmium in the environment also has been implicated in human hypertension and cardiovascular problems (Luckey et al. 1975).

There is no conclusive evidence that chromium is essential for plants, but plant-growth stimulation in solution cultures with the application of low levels of chromium salts has been seen. High levels of chromium in the soil can severely stunt or kill plants (Pratt 1966). Chromium is a recent addition to the list of elements essential for humans and animals, but at high levels in the diet, it can be toxic (Anke et al. 1984). Chronic exposure to chromate dust has been correlated with lung cancer, and oral intake has been associated with growth depression and liver and kidney damage in experimental animals (Anderson 1987). 
TABLE 1 Concentration of Heavy Metals in Soils and Plant Leaves

\begin{tabular}{lccc}
\hline Heavy Metal & $\begin{array}{c}\text { Average Concentration } \\
\text { in Soils } \\
\left(\mathrm{mg} \mathrm{kg} \mathbf{~ k}^{-1}\right)\end{array}$ & $\begin{array}{c}\text { Normal Range } \\
\text { in Soils } \\
\left(\mathrm{mg} \mathrm{kg}^{-1}\right)\end{array}$ & $\begin{array}{c}\text { Normal Range } \\
\text { in Plant Leaves } \\
\left(\mathrm{mg} \mathrm{kg}^{-1}\right)\end{array}$ \\
\hline Arsenic (As) & 5.0 & $1-50$ & $0.01-1.0$ \\
Barium (Ba) & 500 & $100-3,000$ & $10-100$ \\
Cadmium (Cd) & 0.5 & $0.01-0.70$ & $0.05-0.20$ \\
Chromium (Cr) & 200 & $5-1,000$ & $0.1-0.5$ \\
Cobalt (Co) & 8.0 & $1-40$ & $0.01-0.30$ \\
Copper (Cu) & 20.0 & $2-100$ & $3-40$ \\
Lead (Pb) & 10 & $2-200$ & $0.1-5.0$ \\
Mercury (Hg) & 0.03 & $0.03-0.3$ & $0.001-0.01$ \\
Nickel (Ni) & 40 & $5-500$ & $0.1-1.0$ \\
Tin (Sn) & 10 & $2-200$ & - \\
Zinc (Zn) & 20.0 & $2-100$ & $15-150$ \\
\hline
\end{tabular}

Source: Baker and Chesnin (1975).

It has been known for some time that cobalt is essential for microorganisms that fix nitrogen in the nodules of legumes, but recent research indicates that it is also necessary for the growth of higher plants (Mengel and Kirkby 1978). Results from other studies show that cobalt can be toxic to plants when the concentration in the soil is relatively low (Vanselow 1966b). Cobalt is an essential element for humans and animals because it is required for the production of vitamin $B_{12}$ (Baker and Chesnin 1975). Cobalt is not considered highly toxic to humans or animals, but the addition of cobalt to beer has caused endemic outbreaks of cardiomyopathy among heavy beer-drinkers, resulting in several fatalities. Animal studies also indicate cobalt may be a carcinogen (Elinder and Friberg 1986).

Copper is an essential element for both plants and animals. A moderate deficiency of copper in plants normally results in a reduction in growth or yield, while more acute deficiencies cause dieback at terminal growth points. Excess copper also reduces growth and may cause iron chlorosis symptoms resulting from a depression of the iron concentration in plant leaves. Copper solutions were also used for herbicides and fungicides in agriculture until their replacement by organics (Reuther and Labanauskas 1966). Copper is an essential element for humans and animals because it is required for the function of several essential enzymes. Ingestion of a large amount of copper salts causes gastrointestinal disturbances, and chronic copper exposure may cause liver and kidney damage (Aaseth and Norseth 1986).

Lead is not considered an essential element for plant growth, and no cases of lead deficiency in plants have been reported. Most observations of lead toxicity in plants are restricted to water-culture experiments, where acute toxic effects result in a reduction in growth, but acute toxicity is not generally seen in the field (Mengel and Kirkby 1978). Most research on lead in 
humans and animals deals with the toxic effect of this element, but recent research indicates that lead is essential in the diet of rats (Anke et al. 1984). Lead is a major pollutant in the environment, and no other pollutant has accumulated in man to average levels so close to those which are potentially clinically poisonous. One of the chief concerns of lead toxicity in humans is brain damage to children. There is evidence that elevated lead levels in the environment can induce aggressive behavior in animals. This evidence has implicated lead pollution as a causal factor for the increased rate of delinquency in large industrial cities (Mengel and Kirkby 1978).

Mercury is not considered an essential element for either plants or animals. The amount of mercury taken up by plants is small, and little is known about its reaction in the soil or its relationship to plant growth. Mercury is known to undergo microbiological transformation to methylmercury in the environment (Williams 1980). The hazards of long-term intake of methylmercury are associated with its accumulation in the brain. Chronic poisoning resu'ts in degeneration and atrophy of the sensory cerebral cortex and hearing and visual impairment (Berlin 1986).

Nickel is found in most plants. It is not considered an essential element, and nickel deficiency in plants has not been reported. Excess nickel produces a chlorosis in many plants that resembles the symptoms of iron deficiency (Vanselow 1966c). Nickel is now considered an essential element in the diet of chickens, rats, and goats (Anke et al. 1984). Dermatitis and lung reactions in the form of asthma have been attributed to sensitization caused by nickel. There is also evidence that some forms of nickel are carcinogenic (Norseth 1986).

Only limited information on tin in soils and plants has been published. There is no evidence that it is essential or beneficial to plants, and it has not been shown to be detrimental to plant growth under field conditions (Wallihan 1966). Relatively recent published information indicates that tin is an essential element in the diet of animals (Anke et al. 1984). The toxicity of tin after inhalation and ingestion is low, but acute gastrointestinal disturbances have been reported following the ingestion of relatively large amounts (Magos 1986).

Zinc is an essential element for both plants and animals. One of the most common micronutrient deficiencies in plants is zinc, and it is becoming increasingly significant in crop production. Plants suffering from zinc deficiency often show chlorosis in the interveinal areas of the leaf, and terminal growth is usually affected. An excess of zinc commonly produces iron chlorosis in plants (Mengel and Kirkby 1978). Zinc is necessary for the function of various enzymes in humans and animals. Symptoms and diseases related to zinc deficiency include acne, poor wound healing, loss of taste and smell, and poor growth in children. Large oral doses of zinc salts cause gastrointestinal disorders, but chronic zinc poisoning in humans has not been described (Elinder 1986).

Because explosives such as TNT and RDX are the products of man, they do not occur naturally in the environment. The production of TNT also results in a number of by-products, including 2,4,5-TNT, 2,4-dinitrotoluene (DNT), and 2,6-DNT. Degradation of TNT in the environment can result in the production of trinitrobenzene. Published information is limited on 
explosives entering the food chain via plant uptake. Concentrations of TNT at $500 \mathrm{mg} \mathrm{kg}^{-1}$ or more in soils are generally toxic to many agricultural crops, and the uptake of TNT from the soil by plants is low (Banwart and Hassett 1990). RDX in soils can be toxic to some agricultural crops, but other crops can accumulate RDX in plant tissues to higher levels than the soil in which they are growing (Banwart et al. 1991). Illness and death in munitions-plant workers from aplastic anemia and toxic hepatitis have resulted from exposure to TNT. There is limited evidence that TNT is carcinogenic, and much stronger evidence that dinitrotoluenes, especially 2,6-DNT, are carcinogens. RDX can have adverse effects on the central nervous system and may produce convulsion and/or unconsciousness following inhalation or ingestion (Rosenblatt et al. 1991).

Several national governments, including the United States, have developed guidelines and/or regulations defining hazardous levels of heavy-metal contamination in soils and groundwater. In 1988 the Netherlands published the "Dutch List" that gives concentrations for three categories of heavy-metal contamination: Category A-Baseline Concentration, Category BDetailed Investigation Needed, and Category C-Remedial Investigation Needed. As of this date, Germany has not by national law established standard action or cleanup levels for heavy-metalcontaminated soils and groundwater. However, the Bavarian state government has generally adopted the Dutch List as a guideline for assessing heavy-metal contamination. The heavy-metal concentrations in soil and groundwater listed for the three categories of the Dutch List are given in Table 2 for the metals included in this investigation.

Because of the potential health hazard associated with heavy metals in the environment, the World Health Organization has established guidelines for drinking-water quality that include concentrations of some heavy metals. Although the heavy-metal concentrations suggested in these guidelines are not established regulatory limits, these concentrations can be used to assess the general surface-water quality. Table 3 lists the heavy metals included in this inventory and their suggested maximum concentrations in drinking water.

The Toxicity Characteristic Leaching Procedure (TCLP) is one of the hazardous characteristics analyses of the Resource Conservation and Recovery Act designated by the U.S. Environmental Protection Agency (EPA) to determine if a waste material is hazardous. TCLP involves the extraction of the hazardous constituents (e.g., heavy metals) from the waste material. The extraction fluid is acid:s water emulating natural rainfall, and the waste material and extraction fluid are mixed in an end-over-end rotary agitation apparatus for 18 hours. For dry solids, such as soils, the mass ratio of extraction fluid to soil is 20 to 1 by weight. Following filtration, the extraction fluid is analyzed, and the concentration of the hazardous constituent in the extraction fluid determines if the waste material is hazardous. Because G'TA is operated by the U.S. Army, if soil that was removed from a range during renovation had high concentrations of heavy metals, this soil could be classified as a hazardous waste. Table 4 lists the TCLP limit for the heavy metals included in this inventory, along with the minimum concentration of these metals in soils needed to yield a hazardous TCLP classification. TCLP limits for cobalt, copper, nickel, tin, and zinc have not been established by the EPA. 
TABLE 2 Dutch List of Heavy Metals with Category Contamination Levels for Soil and Groundwater

\begin{tabular}{|c|c|c|c|c|c|c|}
\hline \multirow[b]{2}{*}{ Heavy Metal } & \multicolumn{3}{|c|}{ Concentration in Soil $\left(\mathrm{mg} \mathrm{kg}^{-1}\right)$} & \multicolumn{3}{|c|}{ Concentration in Groundwater $\left(\mu \mathrm{g} \mathrm{L}^{-1}\right)$} \\
\hline & Category A & Category B & Category C & Category A & Category B & Category C \\
\hline Arsenic & - & 30 & 50 & - & 30 & 100 \\
\hline Barium & 200 & 400 & 2,000 & 50 & 100 & 500 \\
\hline Cadmium & - & 5 & 20 & - & 2.5 & 10 \\
\hline Chromium & - & 250 & 800 & - & 50 & 200 \\
\hline Cobalt & 20 & 50 & 300 & 20 & 50 & 200 \\
\hline Copper & - & 100 & 500 & - & 50 & 200 \\
\hline Lead & - & 150 & 600 & - & 50 & 200 \\
\hline Mercury & - & 2 & 10 & - & 0.5 & 2 \\
\hline Nickel & - & 100 & 500 & - & 50 & 200 \\
\hline Tin & 20 & 50 & 300 & 10 & 30 & 150 \\
\hline Zinc & 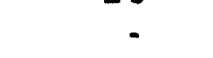 & 500 & 3,000 & - & 200 & 800 \\
\hline
\end{tabular}

Source: Staatsuitgeverij's-Gravenhage (1988).

TABLE 3 Suggested Maximum Heavy-Metal Concentrations in Drinking Water

\begin{tabular}{lllll}
\hline Heavy Metal & $\begin{array}{c}\text { Concentration } \\
\left(\mathrm{mg} \mathrm{L}^{-1}\right)\end{array}$ & & Heavy Metal & $\begin{array}{c}\text { Concentration } \\
\left(\mathrm{mg} \mathrm{L}^{-1}\right)\end{array}$ \\
Arsenic & 0.05 & & Lead & 0.05 \\
Barium & NMCSa & & Mercury & 0.001 \\
Cadmium & 0.005 & & Nickel & NMCS \\
Chromium & 0.05 & & Tin & NMCS \\
Cobalt & NMCS & Zinc & 5.0 \\
Copper & 1.0 & & \\
\hline
\end{tabular}

a NMCS = no max..num concentration suggested.

Source: Adapted from World Health Organization (1984). 
TABLE 4 TCLP Limits for Heavy Metals and the Minimum Soil Concentrations Needed to Yield a Hazardous TCLP Classification

\begin{tabular}{lcc}
\hline TCLP Constituent & $\begin{array}{c}\text { TCLP Limit } \\
\left(\mathrm{mg} \mathrm{L}^{-1}\right)\end{array}$ & $\begin{array}{c}\text { Minimum } \\
\text { Soil Concentration } \\
\left(\mathrm{mg} \mathrm{kg}^{-1}\right)\end{array}$ \\
\hline Arsenic & 5.0 & 100 \\
Barium & 100.0 & 2,000 \\
Cadmium & 0.5 & 20 \\
Chromium & 5.0 & 100 \\
Lead & 5.0 & 100 \\
Mercury & 0.2 & 4 \\
\hline
\end{tabular}

Source: Generalized from Conrad and Deever (1992). 


\section{Goal, Objectives, and Approach}

Argonne National Laboratory (ANL) conducted an investigation to provide the U.S. Army with documentation on the type, degree, and extent of heavy-metal and explosive-residue contamination on three training ranges at GTA. Current and past training exercises have required the use of small arms and other munitions that can result in the deposition of heavy metals and explosive residues on the soils of training ranges. Potential contamination of the adjacent areas can occur by the introduction of heavy metals into the local surface water and groundwater supplies. The following specific objectives were established:

- Icientify potential sources and types of heavy-metal and explosive-residue contamination on selected ranges at GTA,

- Assess the degree of heavy-metal contamination in the soils, vegetation, and water at the selected ranges,

- Relate the general pedologic, geologic, and geochemical conditions at the selected ranges to the mobility of the identified heavy-metal pollutants in the local environment, and

- Estimate the potential geographic extent of local and off-site heavy-metal contamination.

The initial task of the investigation involved the selection of three typical small-arms ranges at GTA. The three training ranges selected were a handgun range (Range 122), a rifle range (Range 124), and a hand-grenade range (Range 111). Background information on the physical characteristics, training activities, and munitions used at each range was assembled. A literature review was conducted to identify potential sources of heavy-metal and explosive-residue contamination on each range. These data were used to develop a safety plan for the field sampling effort.

During an initial field sampling effort, soil samples were collected from each of the three ranges and analyzed at ANL to determine the type of heavy-metal and explosive-residue contamination on each range. Analytical results for these soil samples were used to identify and confirm the presence of contaminants. This information was used to develop a detailed sampling plan for collecting the primary data and samples to assess the spatial distribution of heavy-metal contaminants at each of the selected ranges. During the second field sampling effort, an X-ray fluorescence spectrum analyzer was used to measure the concentrations of lead and other heavy metals in the soils at the three ranges. Soil samples were collected at selected measurement locations and analyzed at ANL to verify the field measurements made with the X-ray fluorescence spectrum analyzer. Vegetation and surface-water samples were also collected at selected locations and analyzed to assess heavy-metal contamination in the local environment. 
Available information on the general geological and geochemical characteristics of the selected ranges was compiled. Selected physical and chemical characteristics of the range soils were determined by laboratory analyses. Data from the field measurements and laboratory analyses for heavy metals were combined with the information on soils and on the geological and geochemical characteristics to estimate the potential geographic extent of local and off-range heavymetal contamination. 


\section{Materials and Methods}

\subsection{Field Sampling Sites}

Grafenwöhr Training Area is located in the Oberpfalz region of Bavaria, about $40 \mathrm{~km}$ $(25 \mathrm{mi})$ northeast of Nuremberg and approximately $35 \mathrm{~km}(22 \mathrm{mi})$ west of the German border with the Czech Republic (Figure 1). The Oberpfalz region has a humid mesothermal climate, and the winters are moderately cold; January temperatures average about $0^{\circ} \mathrm{C}\left(32^{\circ} \mathrm{F}\right)$, although winter temperatures may drop below freezing for a few days. Summers have warm days and cool nights, and temperatures average about $13^{\circ} \mathrm{C}\left(55^{\circ} \mathrm{F}\right)$ during July, the warmest month. Precipitation, mainly rain, is fairly evenly distributed throughout the year and averages about $960 \mathrm{~mm}$ (37.8 in.). Snowfall can occur during the winter, but snow cover is normally limited to a few days because of the above-freezing daytime winter temperatures. Soils at GTA are normally not frozen during the winter.

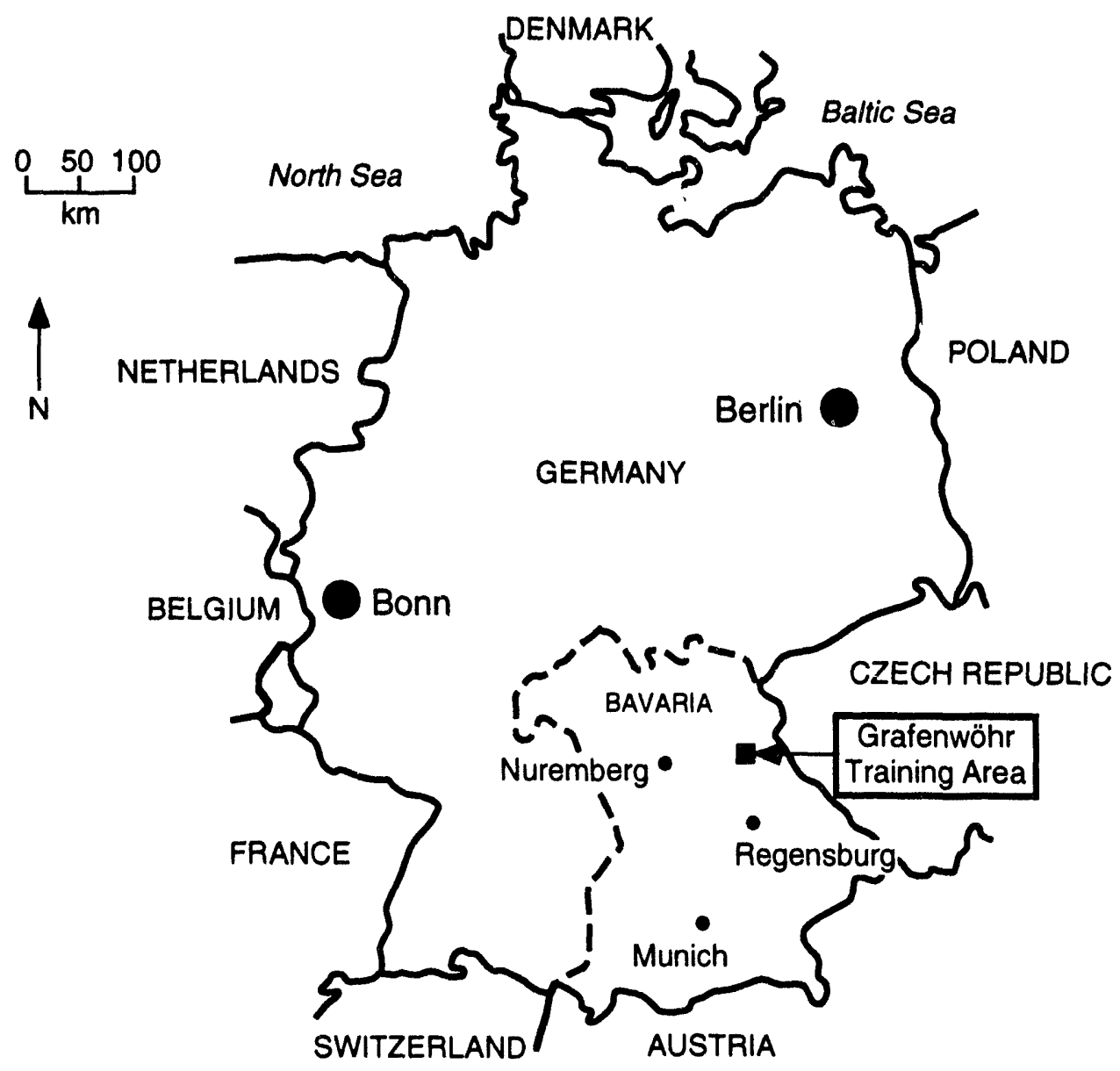

FIGURE 1 Location of the Grafenwöhr Training Area in Germany 
Portions of GTA have been used for military training activities since the early 1900s, when the Bavarian Army established an artillery training range. The installation was used for training German forces during both world wars and was acquired by the U.S. Army following World War II. GTA is operated by the U.S. Seventh Army Training Command, headquartered at GTA, and the current size of the installation is about 16,200 ha (40,000 acres). GTA is the major U.S. Army training area in Europe for conducting live-fire training exercises, and the weapons used during these exercises range from small arms and hand grenades to artillery, tanks, and helicopter gunships.

The three small-arms training ranges at GTA selected for this investigation were a handgun range (Range 122), a rifle range (Range 124), and a hand-grenade range (Range 111). These three ranges were selected by ANL staff members and U.S. Army representatives at GTA because they represent typical environmental conditions and different types of small-arms weapon-training areas at GTA. Locations of the three ranges in GTA are shown in Figure 2.

Range 122 is used for handgun practice mainly by military-police units, and the range has 10 firing points with a 7-m (23-ft) high earthen berm located about $55 \mathrm{~m}(180 \mathrm{ft})$ from the firing line. There are nine pop-up targets for each firing point: the first eight at distances ranging from

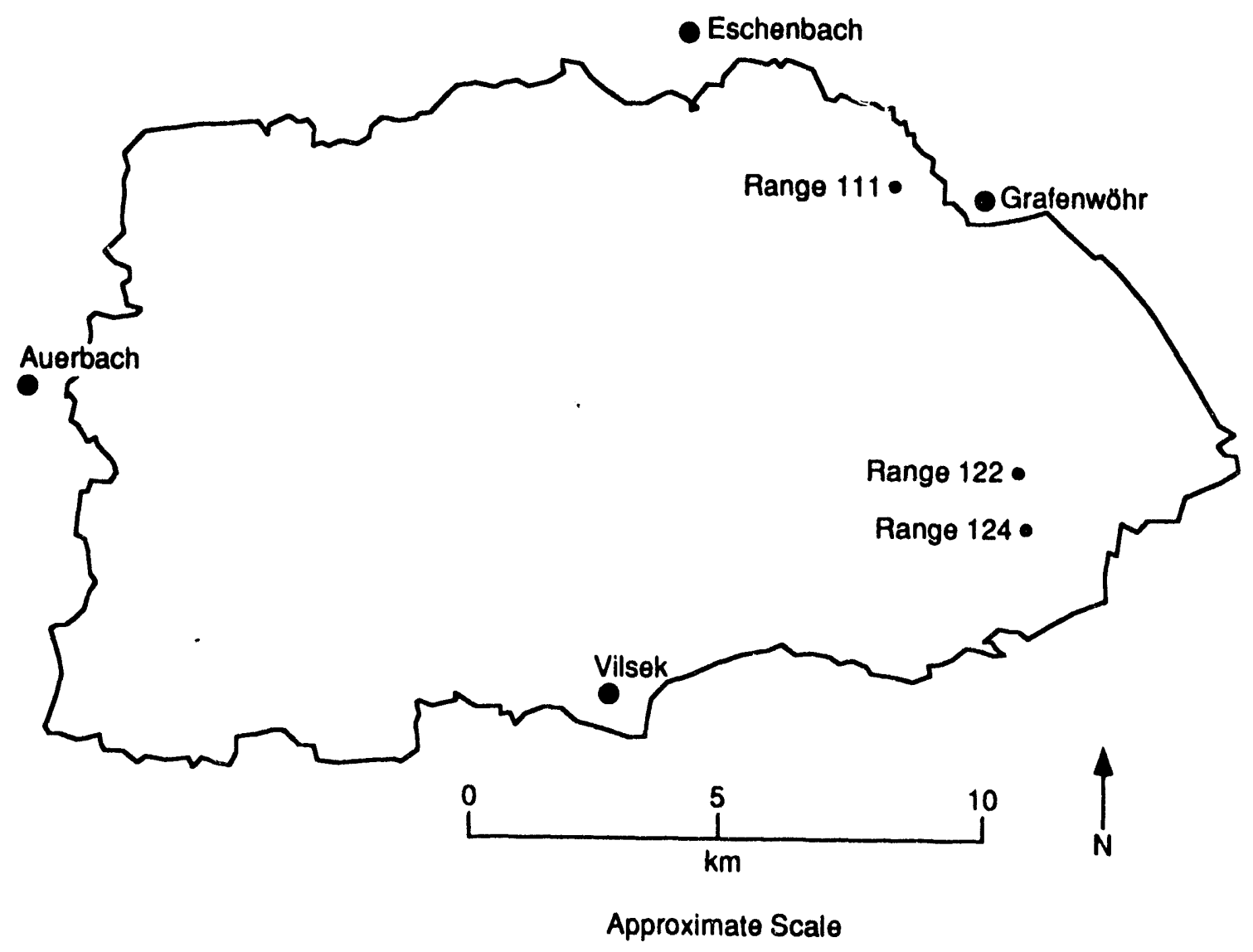

FIGURE 2 Location of the Three Training Ranges Selected for Investigation at GTA 
$10 \mathrm{~m}(32.8 \mathrm{ft})$ to $30 \mathrm{~m}(99 \mathrm{ft})$ and the ninth at $50 \mathrm{~m}(165 \mathrm{ft})$ from the firing line. A ditch that runs parallel to the berm between the eighth and ninth targets is designed to remove runoff water from the berm and range. The area around the targets is grass that is mowed short, and the ditch and berm are covered with a mixture of grasses and low shrubs. There are a large number of spent slugs on the soil surface behind the targets and on the berm. A tower behind the firing line is used for observation and safety control during firing exercises. The area on both sides and behind the range is forested. The area directly behind the berm has tall grass and shrub cover and is part of the GTA impact area. Range 122, as it exists now, was constructed about 10 years ago, but there has been a small-arms range at this area for a number of years. Figure 3 shows the layout and features of Range 122.

Range 124 is similar to Range 122 except that it is used by combat troops to check the accuracy of their rifle sights before rifle qualification on another range. Range 124 has 10 pads for firing from the prone position and 10 pits for firing from the standing position. There is a single small fixed target $25 \mathrm{~m} \mathrm{(82} \mathrm{ft)} \mathrm{from} \mathrm{each} \mathrm{firing} \mathrm{pad,} \mathrm{and} \mathrm{the} \mathrm{firing} \mathrm{pits} \mathrm{are} \mathrm{located} \mathrm{about}$ $5 \mathrm{~m}$ (16.4 ft) behind each firing pad. The area between the firing pads and the targets is mowed grass, and the 3-m (10-ft) high earthen berm generally lacks vegetative cover. There are no spent slugs on the soil surface or evident in the berm soil, but there is a depression (bullet pocket) in the berm behind each target. There is a shallow depression between the targets and the base of the berm for drainage. A tower behind the firing line is used for observation and safety control during range operations. The area behind the berm and to the right of the range is forested, and the parking lot for Range 126 is to the left. Although there had been small-arms ranges in the area for a number of years, the current Range 124 was constructed about 1977. Figure 4 shows the layout and features of Range 124.

Range 111 is used to provide combat troops with practical experience in the use of highexplosive hand grenades. This range consists of an open oval area about $50 \mathrm{~m}(165 \mathrm{ft})$ by $75 \mathrm{~m}$ $(245 \mathrm{ft})$ surrounded by an earthen berm approximately $1 \mathrm{~m}(3 \mathrm{ft})$ high. The area inside the berm

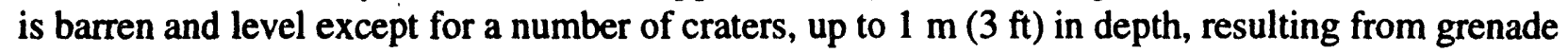
detonations, and some of the deeper craters contain standing water. There are two concrete and two log bunkers along the outer edge of the berm for the protection of the grenadier and the instructor during training exercises. Several other larger concrete structures are located in the area for the protection of troops during training exercises. There is some evidence of damage by grenade fragments to the signs, structures, and trees outside the berm. The area outside the berm has grass cover, and the surrounding area is forested. Figure 5 shows the layout and features of Range 111, which was constructed about 1985.

\subsection{Initial Sample Collection}

The initial soil-sample collection was made at each of the three ranges during April 1992. At Ranges 122 and 124, initial sampling locations were selected to represent different degrees of suspected heavy-metal and explosive-residue contamination. Several soil samples were collected from the berm directly behind targets (bullet pockets), while other samples were taken from other 


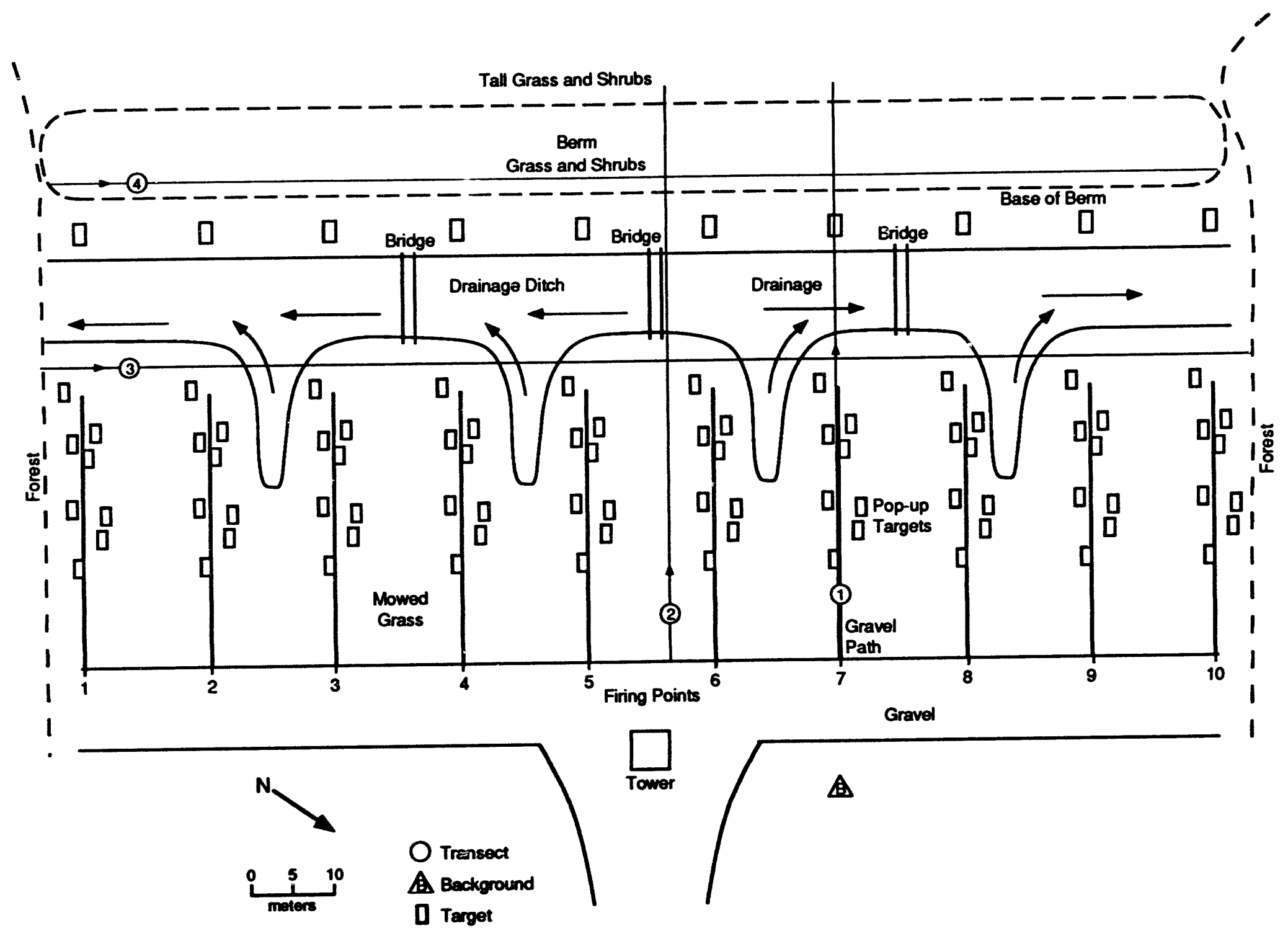

FIGURE 3 Features and Sampling-Transect Locations at Range 122 at GTA 


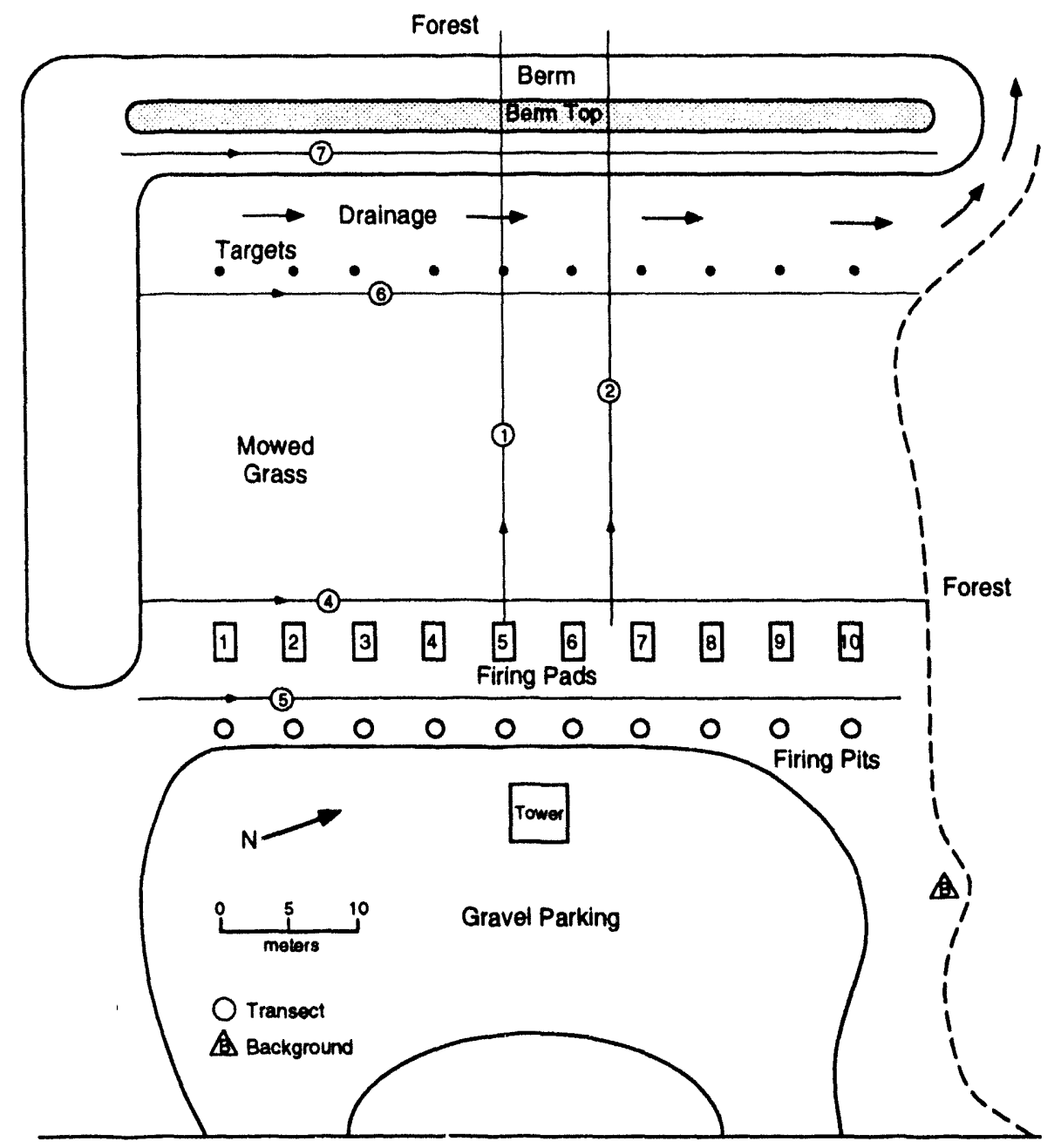

FIGURE 4 Features and Sampling-Transect Locations at Range 124 at GTA

parts of the berm and from the area between the firing line and the targets. Additional samples were collected from behind the firing line and outside the area of training impacts to provide background concentrations of heavy metals in the native soils. All samples were collected by means of a $2.5-\mathrm{cm}$ (1-in.) soil probe from depths of $0-15 \mathrm{~cm}(0-6 \mathrm{in}$.) and $15-30 \mathrm{~cm}(6-12$ in.). The purpose of sampling at the $15-30 \mathrm{~cm}$ depth was to assess potential leaching of heavy metals below the soil surface. A sediment sample from drainage of each range was collected to assess the transport of heavy metals into the adjacent environment. A total of 15 samples were collected from each of the two ranges.

At Range 111 (the hand-grenade range), 14 surface-soil samples were collected from within the berm area. Only surface samples were collected because grenade fragments and explosive residues were not expected to penetrate the soil to an appreciable depth. These samples were collected, by means of a stainless-steel spoon, at locations on the bottoms and sides of 


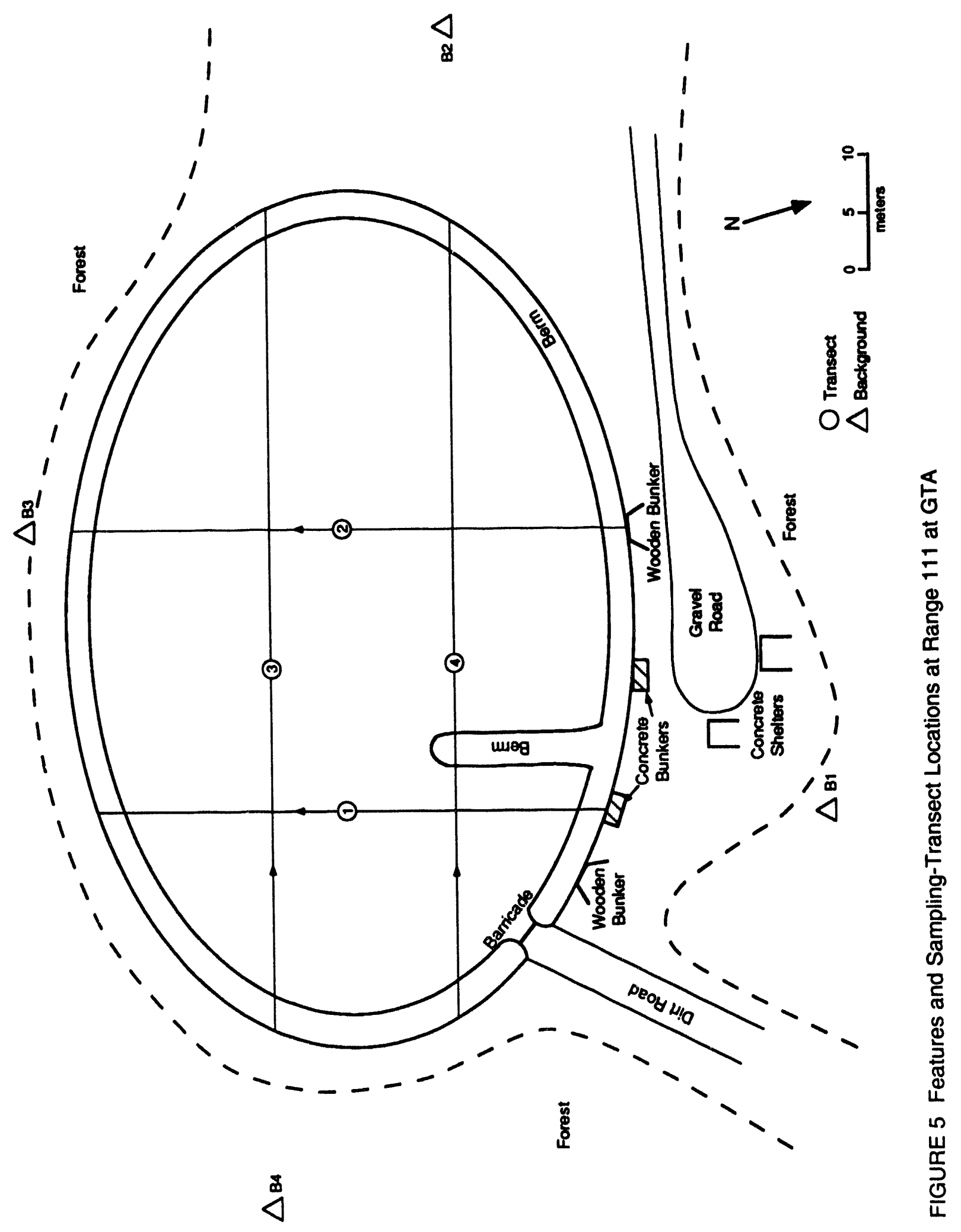


grenade craters and from areas between the craters. Additional samples were collected from the berm and from outside the berm to provide background levels of heavy metals in the native soil. These background soil samples were collected from depths of $0-15 \mathrm{~cm}(0-6 \mathrm{in}$.$) and 15-30 \mathrm{~cm}$ (6-12 in.) using the soil probe.

All samples were placed in precleaned, $250-\mathrm{mL}$, wide-mouth glass jars; the jars were sealed in plastic bags, and the bagged jars packed in a cooler for transport to ANL. This packaging was required to meet the U.S. Department of Agriculture (USDA) soil-import permit requirements. The soil samples were analyzed at ANL to determine heavy-metal and explosiveresidue concentrations. Details of the methods used for these analyses are given in Section 4.4. Analytical results from these samples were used to refine the primary data and sample collection plan.

\subsection{Primary Data and Sample Collection}

\subsubsection{Data and Sample Collection Plan}

Primary data and sample collection was made during July 1992 according to the following plan. At Range 122 (the handgun range), four sampling lines or transects were established. Transects 1 and 2 ran perpendicular to the firing line, with transect 1 running from firing point 7 through the high impact area (bullet pocket) on the face of the berm and down the backside of the berm. Data collection points were located at about 5-m (16.4-ft) intervals along this transect, starting at the firing line. Other data collection locations were adjacent to this transect about $3 \mathrm{~m}$ $(9.8 \mathrm{ft})$ behind each of the eight pop-up targets. Transect 2 was also perpendicular to the firing line, but this transect was located between firing points 5 and 6 . Transect 2 also ran from the firing line, through the target area, and down the backside of the berm. Data collection points on this transect were located at about 5-m (16.4-ft) intervals, starting at the firing line. GTA personnel, using a backhoe, excavated trenches about $1-\mathrm{m}(3.28-\mathrm{ft})$ deep from the top to the base of the berm adjacent to these two transects. These trenches provided access to the soil profile in the berm for data and sample collection. The interval between data collection points along the trenches was reduced to $1 \mathrm{~m}(3.28 \mathrm{ft})$ because of the potentially higher concentration of heavy metals in the berm soil. Data collection points were located at 15-cm (6-in.) depth intervals on the trench walls.

Two transects were also established parallel to the firing line at Range 122. Transect 3 was behind the eighth row of pop-up targets, $35 \mathrm{~m}$ (115 ft) from the firing line, and transect 4 was behind the last row of targets, $57 \mathrm{~m}(187 \mathrm{ft})$ from the firing line and about $3 \mathrm{~m}(9.8 \mathrm{ft})$ up the base of the berm. The initial data collection points were established at the forest edge on the left (south) side of the range, and additional points were established at about 5-m (16.4-ft) intervals along these two transects. A control or background data collection point was established about 
$18 \mathrm{~m}(57 \mathrm{ft})$ behind firing point 7 , in line with transect 1 . A pit was excavated by the backhoe to a depth of about $1 \mathrm{~m}(3.28 \mathrm{ft})$ to provide access to uncontaminated subsurface soil. Figure 3 shows the location of the transects and the background-data collection point at Range 122 .

Transect lscations and data and sample collection points established at Range 124 (the rifle range) were similar to those at Range 122, except that six sampling transects were established at Range 124. 'Transects 1 and 2 were located perpendicular to the firing line and extended across the range, over the berm, and into the forest behind the berm. Transect 1 started at firing pad 5 and ran through the bullet pocket behind its single target, while transect 2 started between firing pads 6 and 7. Trenches were excavated using a backhoe along these transects to provide access to the subsurface of the berm (Figure 6). Data collection points were at intervals of about 5-m (16.4- $\mathrm{ft}$ ) along these transects except on the face of the berm along the trenches, where the interval was $1 \mathrm{~m}(3.28 \mathrm{ft})$. As at Range 122, data collection points were established at 15-cm (6-in.) depth intervals on the trench walls.

Four transects were established parallel to the firing line: transect $4,1.5 \mathrm{~m}(4.9 \mathrm{ft})$ in front of the firing pads; transect $5,1.5 \mathrm{~m}(4.9 \mathrm{ft})$ in front of the firing pits; transect $6,24 \mathrm{~m}$ $(79 \mathrm{ft})$ from the firing line and $1 \mathrm{~m}(3.28 \mathrm{ft})$ in front of the targets; and transect $7,35 \mathrm{~m}(115 \mathrm{ft})$

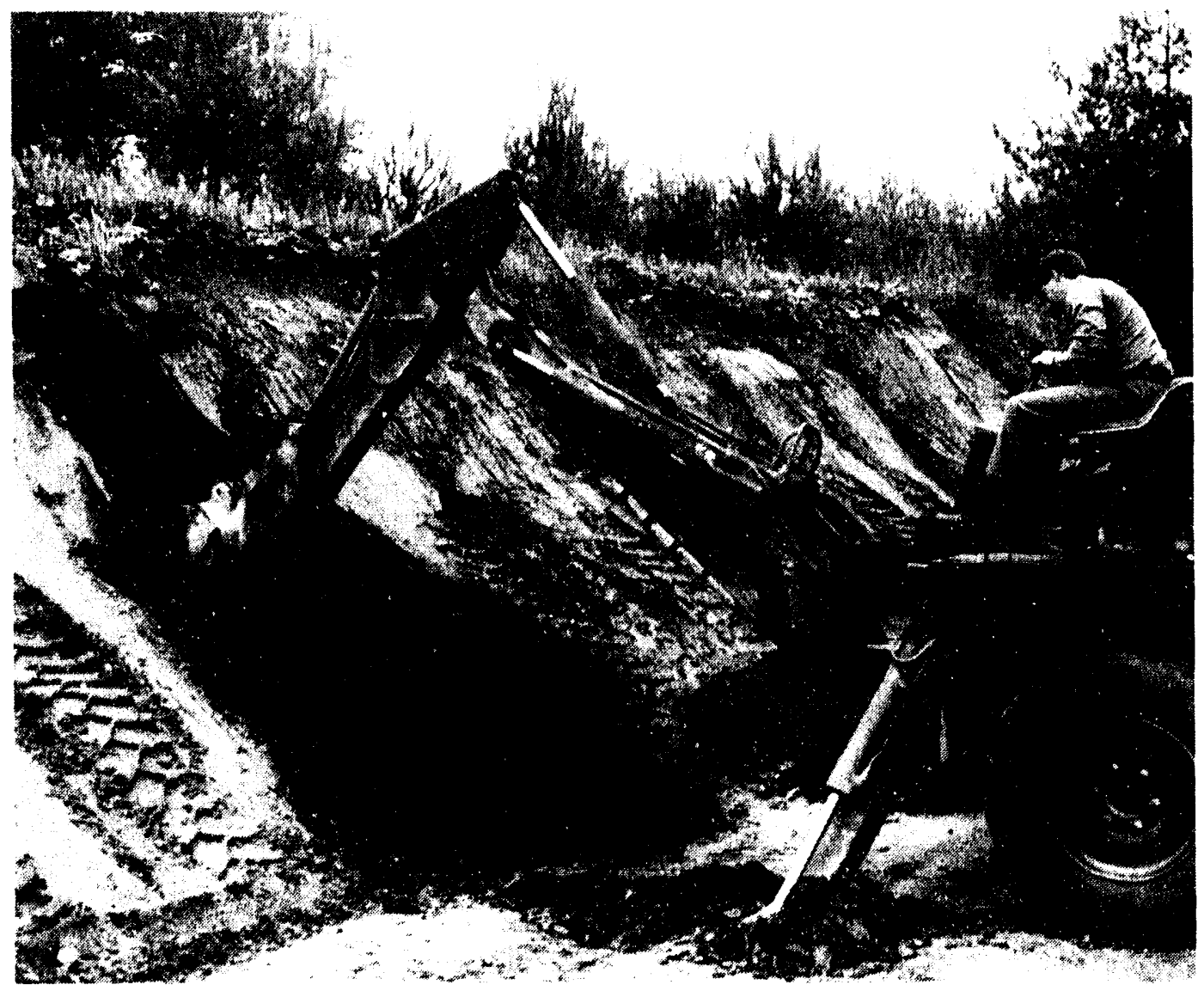

FIGURE 6 Excavation of the Trench in the Berm at Range 124 at GTA during July 1992 
from the firing line and in line with the bullet pockets on the berm. The initial data collection point on these transects was at the edge of the range on the left (south) side, and additional data collection points were established at about $5-\mathrm{m}(16.4-\mathrm{ft})$ intervals. A pit for the collection of background data and samples was excavated adjacent to the forest edge about $20 \mathrm{~m}(66 \mathrm{ft})$ behind firing pad 10. Figure 4 shows the location of the transects and the background-data collection point at Range 124.

Because the physical layout of Range 111 (the hand-grenade range) is somewhat different from that of Ranges 122 and 124, placement of the sampling transects was different. Transects 1 and 2 were parallel; each started at a bunker and extended to the berm on the other side of the open area. Transects 3 and 4 were perpendicular to the initial transects, extending across the open area from berm to berm starting at the left (east) berm. Data were collected at about 5-m (16.4-ft) intervals along each transect, and no excavation was made in the berm. Background or control sampling points were established in line with the transects, but 17 to $30 \mathrm{~m}$ (56 to $98 \mathrm{ft}$ ) beyond the outer edge of the berm. Excavations for the collection of background data and samples were done by hand. Figure 5 shows the location of the transects and background-data collection points at Range 111.

\subsubsection{X-Ray Fluorescence Principle and Data Collection}

Field measurements were taken at the data collection points using a portable energydispersive X-ray fluorescence (XRF) spectrum analyzer. $X$-ray fluorescence is the production of $\mathrm{X}$-rays in the electron orbitals. In atoms that have many electrons, the electrons are arranged in concentric shells at increasing distances from the nucleus. These shells are labeled $K, L, M, N$, etc., with the $\mathrm{K}$ shell being closest to the nucleus. In the process of XRF, gamma photons bombard the atom, and some of the gamma photons collide with the K- and L-shell electrons, dislodging them from their orbits. This leaves a vacant space in the shell, which is immediately filled by an electron from either the $\mathrm{L}, \mathrm{M}$, or $\mathrm{N}$ shell. The readjustment of the electrons is accompanied by the emission of an X-ray photon. The frequency (or energy) of the emitted X-ray is characteristic of a specific element, and the quantity of X-rays emitted is proportional to the concentration of that element.

$\mathrm{X}$-ray energy, measured in thousands of electron volts, is directly proportional to the frequency of the $X$-ray waves and inversely proportional to the wavelength. The fluorescent $X$-rays have sharply defined energies characteristic of the elements excited. The spectrum displays a graph of the fluoresced X-ray energy on the $\mathrm{x}$ axis versus the "count" or quantity on the $\mathrm{y}$ axis. The spectrum can be used to identify and quantitate lead and other metals in a sample.

The field-portable instrument used in this study is an energy-dispersive XRF spectrometer (Figure 7). The principal difference between a wavelength-dispersive and an energy-dispersive 


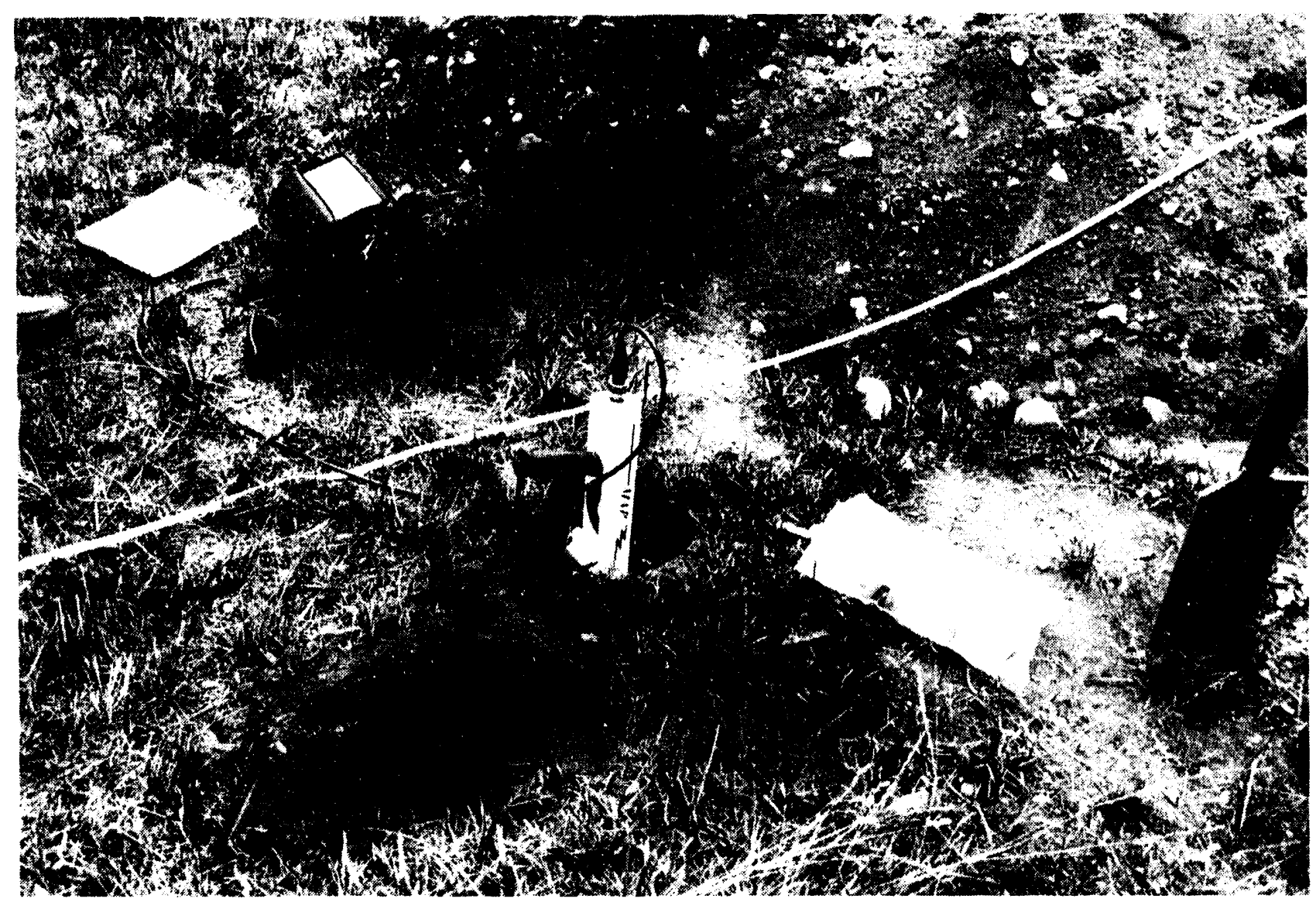

FIGURE 7 Hand-Held XRF Unit and Soil-Sampling Supplies Used at GTA during July 1992

instrument is the manner of resolving the fluorescent X-ray spectrum emitted by the excited atoms in the sample. A wavelength-dispersive instrument uses an optical assembly to sort the X-rays by wavelength, while an energy-dispersive instrument uses an electronic detector that responds to the energy of the X-ray being detected. Radioactive elements that produce a narrow band of characteristic energies are commonly used in portable XRF instruments.

The instrument used during this investigation was the MAP XRF spectrum analyzer produced by Scitec Corporation of Richland, Wash. This device contains a $0.025 \mathrm{Ci}{ }^{109} \mathrm{Cd}$ sealed source and was calibrated for lead in soil by the manufacturer. The detector is solid-state silicon with an active area of $25 \mathrm{~mm}^{2}$. The detection limit for lead in soil for this device is approximately $50 \mathrm{mg} \mathrm{kg}^{-1}$ using the standard 60-s measurement time. Detection limits for other metals in soil are not available from the manufacturer.

The MAP XRF spectrum analyzer measures the spectrum of energies of X-rays emitted from the sample. The spectrum of energies detected during a measurement is recorded, evaluated, and saved in the memory of the instrument. These spectra can be copied to a portable computer and analyzed at a later date to identify the presence of metals not targeted at the time of analysis. 
The spectrum not only reveals this information about the sampie, but it gives the analyst data to determine the nature of the soil matrix and to determine if the instrument is operating properly or if the reading for the targeted element is being affected by interference.

A validation standard was run to assure that the instrument was operating properly in the field. This validation standard was used to check the consistency of the device before use, periodically during the day, and at the end of each day. Field measurements were made using a 60-s time period to collect the spectra. Data recorded in the XRF analyzer were transferred to a portable computer, and backup copies of the data were made on a computer disk at the end of each workday. All operators of the XRF analyzer used in this study have been trained and have received certification from the manufacturer.

The procedure for taking measurements using the portable XRF spectrum analyzer (Figure 8) was as follows. Before a measurement was made, vegetation was removed without disturbing the soil surface, and a 60-s measurement was made in the cleared data collection point. If the surface measurement indicated that lead was present at a level above the detection limit of the instrument, several centimeters of soil were removed, and a second measurement was made on the bottom of the excavation. If this reading also indicated that lead was present, additional soil was excavated, and another measurement was made. This process was repeated until a reading below the detection limit was observed. At a number of data collection poinis, representing a range of lead concentrations in the soil, multiple readings were taken and used as replicates to determine the precision of the device. The range number, transect number, location on the transect, depth of reading, replicate number, and lead concentration of each measurement were recorded in a notebook. More than 200 XRF spectra were collected at Range 122, and at Range 124, over 165 XRF measurements were made. A majority of the XRF measurements taken at Range 111 were below the instrument detection limit for lead, and, as a result, only about $65 \mathrm{XRF}$ readings were taken at Range 111 .

\subsubsection{Soil, Vegetation, and Water Sample Collection}

A total of 17 soil sampies were collected from Range 122 at selected sampling points and depths to confirm the XRF measurements. The soil samples were taken by means of a stainlesssteel spoon at locations representing high, intermediate, and below-detection or zero readings of the XRF analyzer at a depth of about $5 \mathrm{~cm}(2 \mathrm{in}$.) below the soil surface. Each soil sample was identified with the same identification information assigned to the XRF measurement taken at that location. Soil samples were placed in precleaned, $250-\mathrm{mL}$, wide-mouth glass jars; the jars were sealed in plastic bags; and the bags were packed in a cocicr for transport to ANL. This packaging is required to meet the USDA soil-import permit requirements.

Five vegetation samples also were coilected at Range 122 to determine the extent of heavymetal contamination in plant materials. Grass blades and/or other plant leaves were clipped from the plant, with care taken to exclude root and soil materials, and the sample was placed in a 


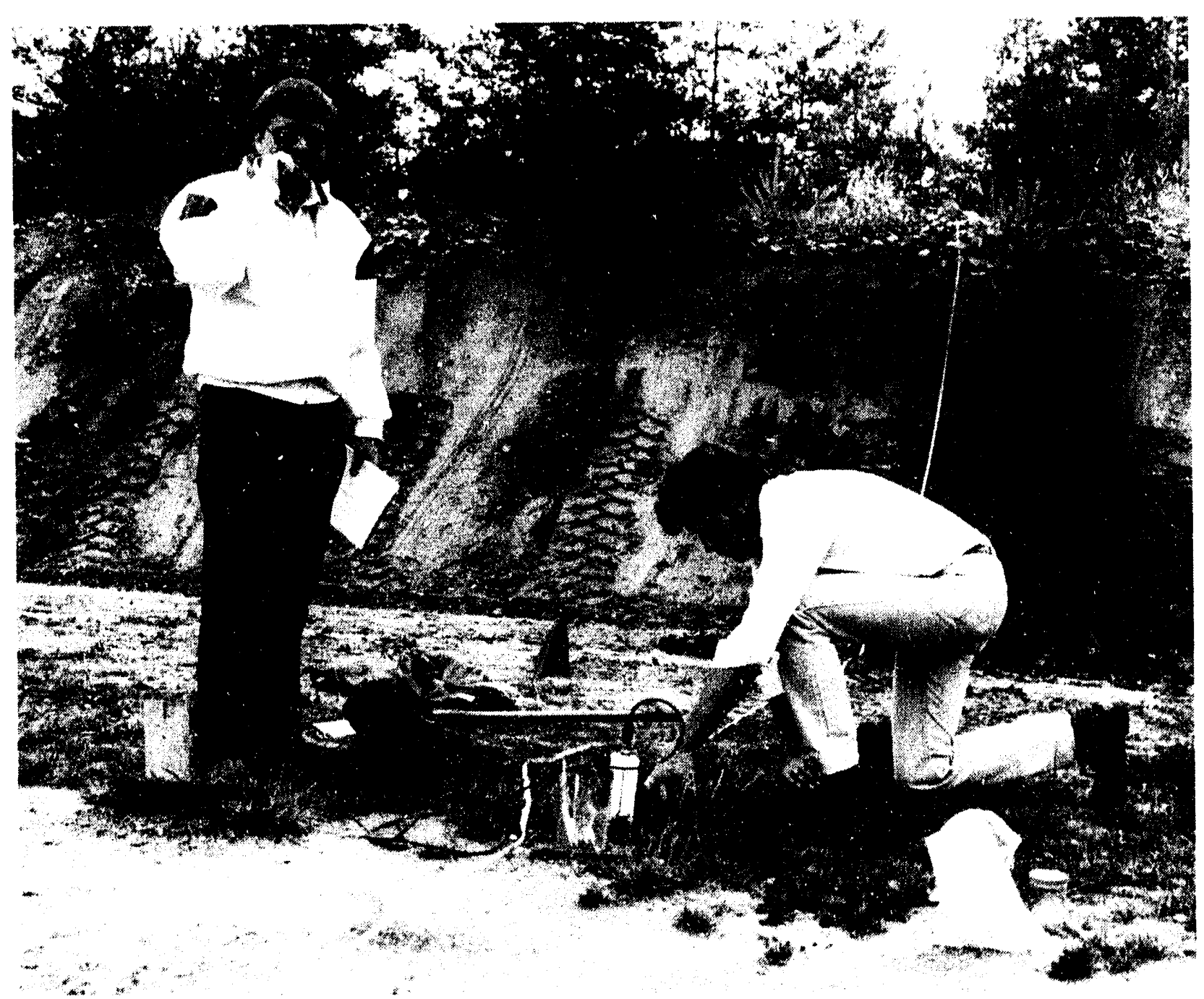

FIGURE 8 Taking an XRF Reading at GTA during July 1992

precleaned, 250-mL, wide-mouth glass jar. The jars were sealed in plastic bags and packed in a cooler to meet the USDA vegetation-import permit requirements for transport. Vegetation samples were collected adjacent to selected soil-sampling locations, and the identification assigned was identical to the adjacent soil sample, with the exception of the depth designation.

A single water sample was collected from a pool of standing water in the drainage area at the north end of the berm at Range 122. The water sample was collected in a precleaned, $250-\mathrm{mL}$, wide-mouth glass jar, and care was taken to exclude bottom sediments. The acidity of the sample was checked using standard $\mathrm{pH}$ paper, and nitric acid was added to acidify the sample to a $\mathrm{pH}$ of 2 or less. After acidification, the jar was sealed in a plastic bag and packed in a cooler for transport to ANL.

The procedures for collecting soil and vegetation samples at Ranges 124 and 111 were the sar:a as those used at Range 122. At Range 124, a total of 30 soil and 8 vegetation samples 
were collected. Due to the lack of standing water on or near Range 124, no water samples were collected there. At Range 111, a total of 27 soil and 7 vegetation samples were collected. Because of the lack of vegetation in the open area at Range 111, many of the vegetation samples were taken on or outside the berm. Six water samples were collected from the standing water in the craters in the open area at Range 111. These samples were collected using the procedures previously described, and care was taken to exclude bottom sediments and soil from the sides of the craters during collection.

\subsection{Laboratory Analytical Methods}

\subsubsection{Soil Analyses for Heavy Metals}

Soil samples from both the initial and primary collections were analyzed in two different laboratories at ANL using different procedures. The Analytical Chemistry Laboratory (ACL) at ANL used the inductively coupled plasma-atomic emission spectroscopy (ICP-AES) procedure to analyze the sampies for arsenic, barium, cadmium, chromium, cobalt, copper, lead, nickel, tin, and zinc. Samples were digested according to EPA Method 3050A (Acid Digestion of Sediments, Sludges, and Soils), followed by measurements according to EPA Method 6010 for ICP-AES (EPA 1986).

The digestion method consisted of heating 1-2 $\mathrm{g}$ of soil to $95^{\circ} \mathrm{C}$ in nitric acid and hydrogen peroxide. The samples were then refluxed in hydrochloric acid, filtered, and diluted to $200 \mathrm{~mL}$. The ICP-AES procedure uses a two-point calibration, with standards prepared by dilution of certified solutions. Measurements were made with an Instruments S.A., Inc., Model JY-86 spectrometer. This instrument consists of a 1-m JY-48 polychromator and a JY-38 scanningmonochromator sequential-analysis system. Quality-control samples were run in accordance with EPA methods. These methods included sample duplicates, laboratory control samples, spikes, spike duplicates, postdigestion spikes, serial dilutions, and calibration verifications.

Mercury concentration in selected soil samples was determined at the ACL by cold-vapor atomic absorption (CVAA) spectroscopy according to EPA Method 7471 (Soil) (EPA 1986). Quality-control samples were run in accordance with EPA methods, which included spiked samples, duplicate samples, and laboratory control samples.

The analytical laboratory of the Reclamation Engineering and Geosciences Section (RE\&G) of the Energy Systems Division at ANL analyzed selected soil samples using the toxic characterization leaching procedure (TCLP). This EPA-approved method was used to characterize the samples for barium, cadmium, chromium, copper, lead, tin, and zinc. Procedures for sample preparation, determination of the appropriate extraction fluid, preparation of the extraction fluids, and extraction of soil samples are from the (U.S.) 1990 Code of Federal Regulations. Samples were allowed to air dry for about four days, and then they were crushed using a mortar and pestle to pass a $6.35-\mathrm{mm}(0.25-\mathrm{in}$.) sieve. Bullets and stones that would not pass the sieve were 
removed. For selected samples, the bullets were returned to a portion of the original sieved sample for another extraction and analysis to determine the amount of heavy metals contributed by a bullet or bullet fragment.

The procedure to determine the appropriate extraction fluid was as follows:

1. A small portion of the sample is ground to a particle size of $<1 \mathrm{~mm}$.

2. Five grams of the ground sample is weighed into a 500-mL Erlenmeyer flask.

3. Reagent grade water $(96.5 \mathrm{~mL})$ is added, and the mixture is stirred for $5 \mathrm{~min}$.

4. The $\mathrm{pH}$ of the mixture is measured and recorded. If the $\mathrm{pH}$ is $<5.0$, the sample is extracted with fluid No. 1.

5. If the $\mathrm{pH}$ is $>5.0,3.5 \mathrm{~mL}$ of $1 \mathrm{~N} \mathrm{HCl}$ is added, and the flask is swirled briefly.

6. The mixture is heated to $50^{\circ} \mathrm{C}$, held at $50^{\circ} \mathrm{C}$ for $10 \mathrm{~min}$, and allowed to cool to room temperature.

7. After the suspension is cool, the $\mathrm{pH}$ is measured and recorded. If the $\mathrm{pH}$ is $<5.0$, extracting fluid No. 1 is used. If the $\mathrm{pH}$ is $>5.0$, the mixture is extracted with fluid No. 2.

The two extraction fluids were prepared according to the following procedures; all chemicals used, including water, were reagent grade.

Extraction fluid No. 1

1. Add $5.7 \mathrm{~mL}$ of glacial acetic acid to $500 \mathrm{~mL}$ of water.

2. Add $64.3 \mathrm{~mL}$ of $1 \mathrm{~N} \mathrm{NaOH}$, stir, and allow to cool.

3. Dilute to a volume of $1 \mathrm{~L}$ with water.

4. The $\mathrm{pH}$ of the solution should be $4.93 \pm 0.05$. 


\section{Extraction fluid No. 2}

1. Dilute $5.7 \mathrm{~mL}$ of glacial acetic acid to a volume of $1 \mathrm{~L}$ with water.

2. The $\mathrm{pH}$ of the solution should be $2.88 \pm 0.05$.

The procedure for extraction of a soil sample with the extraction fluid was as follows:

1. Fifty grams of sample is weighed into an extraction flask.

2. The required quantity of extraction solution is added to the flask. This is equal to 20 times the weight of the sample or $1,000 \mathrm{~mL}$.

3. The flask is secured to a rotary agitator and rotated, end over end, at 30 revolutions per minute for $18 \mathrm{~h}$. Temperature is maintained at $23^{\circ} \mathrm{C}$.

4. At the end of $18 \mathrm{~h}$, the suspension is filtered through a glass-fiber filter. The filtrate (liquid phase) is the TCLP extract.

5. The filtrate is acidified and stored in a refrigerator until analysis.

Heavy-metal analysis of the TCLP extracts was performed using flame atomic absorption (AA) spectroscopy, following the procedures given in Baker and Suhr (1982) and Franson (1989). All AA analyses were performed on a Buck Atomic Absorption Unit, Model 200A. Quality control in the RE\&G laboratory was in accordance with the TCLP method described in the 1990 Code of Federal Regulations. These procedures require a duplicate extraction for every 8 samples, one blank extraction for every 10 samples, and one split analysis for every 10 extracts. One split was analyzed "as-is," while the other split was spiked with a mixed standard. Concentrations in the spiked samples were in the midregion for the flame AA for each metal and at least five times the detection limit for that metal.

\subsubsection{Soil Analysis for Explosives}

Analysis for explosive compounds on selected soil samples from each of the three ranges were performed at ANL. The method used employed an acetonitrile extraction followed by analysis using high-pressure liquid chromatography (HPLC). This method is approved by the U.S. Army Toxic and Hazardous Materials Agency and can be used to detect concentrations as low as $1 \mathrm{mg} \mathrm{kg}^{-1}$ of TNT, RDX, and other explosives in soils (USATHAMA 1990). 


\subsubsection{Soil Analyses for Physical and Chemical Characteristics}

Several physical and chemical characteristics also were determined in the RE\&G laboratory for selected soil samples from each of the three ranges. The characteristics measured and the methods used were (1) soil pH, 1:1 in water (McLean 1982); (2) organic carbon by the WalkleyBlack method (Nelson and Sommers 1982); (3) cation exchange capacity of arid land soils (Rhoades 1982); and (4) particle-size distribution by hydrometer (Gee and Bauder 1982).

\subsubsection{Vegetation Analysis for Heavy Metals}

The 20 vegetation samples collected during July 1992 were analyzed for barium, cadmium, chromium, copper, lead, antimony, tin, and zinc content in the RE\&G laboratory. Samples were dried at $80^{\circ} \mathrm{C}$, ground to pass a $0.8-\mathrm{mm}(20$-mesh) sieve, and representative $0.5 \mathrm{~g}$ subsamples were weighed out for digestion. The wet-digestion procedure (Jones 1989) used involves dissolving the plant materials with concentrated nitric acid, followed by repeated additions of $30 \%$ hydrogen peroxide. The resultant solution is diluted to a known volume and analyzed for the heavy metals using flame AA spectroscopy following the same procedures used for the TCLP extracts.

\subsubsection{Water Analysis for Heavy Metals}

The seven water samples collected during July 1992 also were analyzed for barium, cadmium, chromium, copper, lead, antimony, tin, and zinc in the RE\&G laboratory. The water samples were prepared using the nitric acid-sulfuric acid digestion as given in Franson (1989). This digestion involves boiling a known volume of the acidified sample with small volumes of concentrated nitric acid and sulfuric acid until the solution is clear. The resultant solution is cooled, diluted to a known volume, and analyzed for heavy metals by using flame AA spectroscopy, following the procedures used for the TCLP extracts. 


\section{Results and Discussion}

\subsection{Analytical Results for Initial Samples}

\subsubsection{Heavy Metals}

The major objective of the analyses of the initial samples collected in April 1992 at GTA was to verify the existence and relative levels of heavy metals and explosive residues on the three training ranges. The history of the ranges and a review of the weapons used at the ranges were considered in identifying potential pollutants. Analytical results of the heavy-metal concentrations by the ICP-AES method for the initial soil samples are given in Table 5.

Only two samples for Range 122 have lead concentrations higher than the $150 \mathrm{mg} \mathrm{kg}^{-1}$ category B limit in the Dutch List, but both of these values are below the $600 \mathrm{mg} \mathrm{kg}^{-1}$ category $C$ value. One of these samples is sediment from the drainage ditch, which suggests that lead may be transported into adjacent areas with sediments. The other sample, from behind a target, is higher also in copper than the $100 \mathrm{mg} \mathrm{kg}^{-1}$ limit for category $\mathrm{B}$. The concentrations of all the heavy metals in the other Range 122 samples are below their respective category B values. These concentrations are generally within the normal range for heavy metals in soils (Table 1). Data for Range 122 in Table 5 show relatively low levels of heavy metals, with only potential lead and copper contamination.

Data in Table 5 for Range 124 show that all samples have lead concentrations higher than the $600 \mathrm{mg} \mathrm{kg}^{-1}$ category $\mathrm{C}$ value. In fact, one bullet-pocket sample is over $12 \%$ $\left(126,000 \mathrm{mg} \mathrm{kg}^{-1}\right)$ lead, while another sample, also from a bullet pocket, is almost $1.4 \%$ $\left(13,600 \mathrm{mg} \mathrm{kg}^{-1}\right)$ lead. The berm-backside sample, taken at the $15-30 \mathrm{~cm}$ depth, and the sediment sample also have lead levels higher than the category $\mathrm{C}$ limit. The elevated lead level in the sediment sample, which is similar to the elevated lead level in the sediment sample from Range 122, suggests that lead may be leaving Range 124 in sediments. Three of the six samples also have copper levels higher than the $500 \mathrm{mg} \mathrm{kg}^{-1}$ category $\mathrm{C}$ value. Only the berm-backside and sediment samples are below the $100 \mathrm{mg} \mathrm{kg}^{-1}$ category B value for copper. One bullet pocket has an arsenic concentration higher than the $50 \mathrm{mg} \mathrm{kg}^{-1}$ category $\mathrm{C}$ value. This sample is also higher than the $5 \mathrm{mg} \mathrm{kg}^{-1}$ category $B$ value for cadmium and the $50 \mathrm{mg} \mathrm{kg}^{-1}$ category B value for tin. Two other samples are higher in zinc than the $500 \mathrm{mg} \mathrm{kg}^{-1}$ category $B$ value. Concentrations of heavy metals from the other Range 124 samples are below the category B values and generally within the normal range for soils (Table 1). Data for Range 124 samples in Table 5 show that lead, copper, arsenic, cadmium, tin, and zinc may all be pollutants of potential concern.

A review of the cadmium values given in Table 5 for samples from Range 111 suggests that all the samples, except for the background sample, are higher than the $20 \mathrm{mg} \mathrm{kg}^{-1} \mathrm{cadmium}$ 
TABLE 5 Heavy-Metal Concentrations Determined by ICP-AES Method for Soils Collected at GTA during April 1992

\begin{tabular}{|c|c|c|c|c|c|c|c|c|c|c|c|c|c|c|}
\hline \multirow[b]{2}{*}{ Range } & \multirow[b]{2}{*}{ Sample } & \multirow[b]{2}{*}{ Location } & \multirow[b]{2}{*}{$\begin{array}{l}\text { Depth } \\
(\mathrm{cm})\end{array}$} & \multicolumn{11}{|c|}{ Heavy-Metal Concentration (mg kg-1) } \\
\hline & & & & As & $\mathrm{Ba}$ & Cd & $\mathrm{Cr}$ & Co & $\mathrm{Cu}$ & $\mathbf{P b}$ & $\mathrm{Hg}^{2}$ & $\mathrm{Ni}$ & Sn & Zn \\
\hline 122 & S016 & Behind target & $0-15$ & $\mathrm{BDL}^{\mathrm{b}}$ & 63.2 & $\mathrm{BDL}$ & 7.9 & $\mathrm{BDL}$ & 146 & 398 & 0.06 & 6.9 & $\mathrm{BDL}$ & 48.2 \\
\hline 122 & S017 & Behind target & $15-30$ & $\mathrm{BDL}$ & 63.3 & $\mathrm{BDL}$ & 4.6 & $\mathrm{BDL}$ & 28.6 & 41.2 & 0.08 & 7.7 & $B D L$ & 26.0 \\
\hline 122 & S022 & Bullet pocket & $0-15$ & $\mathrm{BDL}$ & 83.4 & $\mathrm{BDL}$ & 3.0 & $\mathrm{BDL}$ & 57.0 & 123 & 0.06 & 4.9 & $\mathbf{B D L}$ & 23.8 \\
\hline 122 & S026 & Berm & $0-15$ & $\mathrm{BDL}$ & 48.6 & $\mathrm{BDL}$ & 3.5 & $\mathrm{BDL}$ & 51.1 & 55.0 & 0.17 & $\mathrm{BDL}$ & $\mathrm{BOL}$ & 30.2 \\
\hline 122 & S029 & Background & $15-30$ & $\mathrm{BDL}$ & 71.6 & $\mathrm{BDL}$ & 5.5 & BDL & 23.7 & 31.6 & 0.06 & 11.5 & $B D L$ & 23.0 \\
\hline 122 & S030 & Sediment & Surface & $B D L$ & 97.9 & $\mathrm{BDL}$ & 39.2 & 13.0 & 32.6 & 314 & 0.06 & 47.8 & $\mathrm{BD}$ & 72.7 \\
\hline 124 & S003 & Bullet pocket & $0-15$ & 19.4 & 51.8 & 1.2 & 7.5 & $\mathrm{BDL}$ & 271 & 7,870 & 0.06 & 7.3 & $\mathrm{BDL}$ & 77.6 \\
\hline 124 & SO04 & Bullet pocket & $15-30$ & 145 & 37.1 & 7.6 & 5.6 & 7.2 & 798 & 126,000 & 0.05 & 8.2 & 71.3 & 125 \\
\hline 124 & S007 & Berm & $0-6$ & $\mathrm{BDL}$ & 57.3 & $\mathrm{BDL}$ & 7.2 & 6.7 & 6.420 & 4,800 & 0.05 & 11.2 & $\mathrm{BDL}$ & 700 \\
\hline 124 & S009 & Bullet pocket & $0-6$ & $\mathrm{BDL}$ & 53.7 & 2.1 & 10.1 & 6.0 & 13,200 & 13,600 & 0.07 & 6.1 & $\mathbf{B O L}$ & 1,350 \\
\hline 124 & S014 & Berm backside & $15-30$ & $\mathrm{BDL}$ & 28.9 & $\mathrm{BDL}$ & 6.6 & BDL & 29.9 & 1,800 & 0.08 & $\mathrm{BDL}$ & $\mathrm{BDL}$ & 105 \\
\hline 124 & S015 & Sediment & Surface & $\mathrm{BDL}$ & 34.4 & $\mathrm{BDL}$ & 6.0 & BDL & 35.0 & 648 & $\mathrm{BDL}$ & 6.7 & $\mathrm{BDL}$ & 39.6 \\
\hline 111 & S037 & Crater bottom & Surface & $\mathrm{BDL}$ & 97.3 & 31.1 & 34.8 & 9.0 & 276 & 112 & 0.05 & 37.7 & $B D L$ & 2,120 \\
\hline 111 & S038 & Crater wall & Surface & $\mathrm{BOL}$ & 115 & 32.3 & 41.8 & 7.7 & 370 & 152 & 0.05 & 47.5 & $\mathrm{BDL}$ & 5,680 \\
\hline 111 & S039 & Open area & Surface & $\mathrm{BDL}$ & 94.8 & 94.6 & 27.7 & 6.8 & 1,560 & 90.6 & 0.06 & 31.3 & 23.4 & 691 \\
\hline 111 & S041 & Open area & Surface & 22.6 & 164 & 32.5 & 44.4 & 12.8 & 364 & 70.1 & 0.06 & 55.2 & BDL & 976 \\
\hline 111 & S044 & Crater bottom & Surface & $\mathrm{BDL}$ & 92.0 & 73.6 & 25.8 & 5.8 & 322 & 70.1 & $\mathrm{BDL}$ & 29.5 & $\mathrm{BDL}$ & 703 \\
\hline 111 & S049 & Background & $15-30$ & BDL & 61.0 & $\mathrm{BDL}$ & 16.3 & 6.8 & 11.0 & 26.0 & $B D L$ & 7.9 & $B D L$ & 48.6 \\
\hline Detection & limit & & & 8.0 & 0.6 & 0.4 & 0.4 & 6.0 & 1.0 & 10.0 & 0.04 & 4.0 & 20.0 & 0.4 \\
\hline \multicolumn{15}{|c|}{ Dutch List soil contamination levels } \\
\hline Categor & ry A & & & - & 200 & - & - & 20 & - & - & - & - & 20 & - \\
\hline Categon & ory $B$ & & & 30 & 400 & 5 & 250 & 50 & 100 & 150 & 2 & 100 & $\begin{array}{r}50 \\
300\end{array}$ & $\begin{array}{r}500 \\
3000\end{array}$ \\
\hline Categon & ory C & & & 50 & 2,000 & 20 & 800 & 300 & 500 & 600 & 10 & 500 & & \\
\hline
\end{tabular}

a Mercury by cold-vapor atomic absorption.

b $B D L=$ below detection limit. 
value given for category $\mathrm{C}$. One sample has a copper concentration higher than the $500 \mathrm{mg} \mathrm{kg}^{-1}$ value for copper and one sample has a zinc concentration higher than the $3,000 \mathrm{mg} \mathrm{kg}^{-1}$ value for zinc given for category $\mathrm{C}$. In addition, all the other samples (except for the background sample) have concentrations of both copper and zinc that are higher than the $100 \mathrm{mg} \mathrm{kg}^{-1}$ value for copper and the $500 \mathrm{mg} \mathrm{kg}^{-1}$ value for zinc given for category $\mathrm{B}$. One sample has a lead concentration slightly higher than the $150 \mathrm{mg} \mathrm{kg}^{-1}$ value for category $\mathrm{B}$. Concentrations for all other heavy metals are below the category $B$ values and are usually within the normal range for soils (Table 1). These data suggest that cadmium, and possibly copper and zinc, are the heavy metals of concern at Range 111.

A split of the 18 samples listed in Table 5 was also analyzed using the TCLP procedure, and the results of these analyses are given in Table 6. Review of the results for the Range 122 samples shows that all samples have concentrations for barium, cadmium, chromium, and lead below the TCLP limits of detection listed in Table 4. TCLP limits for copper, tin, and zinc have not been established at this time. Lead concentrations for all the Range 124 samples are much higher than the $5.0 \mathrm{mg} \mathrm{L}^{-1}$ TCLP limit, but all barium and chromium concentrations are below TCLP limits. Cadmium concentrations in extracts from Range 111 samples, except for the control sample, are all higher than the $0.5 \mathrm{mg} \mathrm{L}^{-1}$ TCLP limit. These data suggest that the TCLP procedure is not leaching the total amount of heavy metals from the soil, but even so, these data show that high concentrations of lead in the soil of Range 124 and cadmium at Range 111 pose potential concerns.

The heavy-metal concentrations in the TCLP extracts were multiplied by a dilution factor of about 20 to calculate the minimum concentration in the Grafenwöhr soils that will yield a hazardous TCLP concentration. The results of these calculations are shown in Table 7. Comparison of these calculated values with the total heavy-metal concentrations determined by the ICP-AES method indicat: the degree to which heavy metals are leached from these soils by the simulated acidic rainwater used in the TCLP procedure.

Comparison of individual barium values in Table 5 with their corresponding values in Table 7 shows that the bulk of the total barium in the soil is extracted by the TCLP procedure as indicated by comparing the total barium concentrations in Table 5 with the calculated minimum barium concentrations in Table 7. These barium levels are not a concern, however, because both the total concentration by the ICP-AES method and extractable concentration by the TCLP procedure are below their respective regulatory limits. Review of these data suggests that tin reacts in a manner similar to barium, which suggests that barium and tin are more easily leached from the soils than the other metals.

The amount of cadmium extracted by the TCLP procedure is somewhat less than the amount of barium, as shown by a lower concentration of cadmium in an individual sample in Table 7 as compared with the concentration for the same sample in Table 5. Comparison of the chromium, copper, lead, and zinc concentrations for individual samples in Table 5 with their respective values in Table 7 suggests that these heavy metals respond in a manner similar to cadmium. These results suggest that some portion of these heavy metals is bound in the soil and 
TABLE 6 Heavy-Metal Concentrations in TCLP Extracts from Soils Collected at GTA during April 1992

\begin{tabular}{|c|c|c|c|c|c|c|c|c|c|c|}
\hline \multirow[b]{2}{*}{ Range } & \multirow[b]{2}{*}{ Sample } & \multirow[b]{2}{*}{ Location } & \multirow[b]{2}{*}{$\begin{array}{l}\text { Depth } \\
(\mathrm{cm})\end{array}$} & \multicolumn{7}{|c|}{ Heavy-Metal Concentration (mg $L^{-1}$ ) } \\
\hline & & & & $\mathrm{Ba}$ & Cd & $\mathrm{Cr}$ & $\mathrm{Cu}$ & $\mathbf{P b}$ & Sn & Zn \\
\hline 122 & S016 & Behind target & $0-15$ & 15.2 & $\mathrm{BDL}^{\mathbf{a}}$ & $\mathrm{BDL}$ & 0.42 & 1.89 & 9.12 & 0.26 \\
\hline 122 & S017 & Behind target & $15-30$ & 2.99 & BDL & BDL & 0.04 & 0.03 & 8.23 & 0.02 \\
\hline 122 & S022 & Bullet pocket & $0-15$ & 0.50 & BDL & BDL & 0.38 & 1.01 & 1.74 & 0.14 \\
\hline 122 & S026 & Berm & $0-15$ & BDL & $\mathbf{B D L}$ & BDL & 0.22 & BDL & 0.77 & 0.13 \\
\hline 122 & S029 & Background & $15-30$ & 3.94 & BDL & BDL & $B D L$ & BDL & 4.67 & $\mathrm{BDL}$ \\
\hline 122 & S030 & Sediment & Surface & 51.6 & 0.08 & BDL & 0.06 & 0.56 & 33.6 & 0.05 \\
\hline 124 & S003 & Bullet pocket & $0-15$ & 18.4 & 0.02 & $\mathrm{BDL}$ & 1.80 & 222 & 15.8 & 0.69 \\
\hline 124 & S004 & Bullet pocket & $15-30$ & 16.6 & 0.02 & $\mathrm{BOL}$ & 4.85 & 678 & 10.4 & 1.18 \\
\hline 124 & S007 & Berm & $0-6$ & 14.1 & $\mathbf{B D L}$ & BDL & 4.01 & 361 & 7.78 & 0.73 \\
\hline 124 & S009 & Bullet pocket & $0-6$ & 22.0 & $\mathrm{BDL}$ & $B D$ & 3.63 & 451 & 13.1 & 0.84 \\
\hline 124 & S014 & Berm backside & $15-30$ & 45.2 & 0.06 & $\mathbf{B D L}$ & 0.44 & 51.2 & 28.7 & 0.43 \\
\hline 124 & S015 & Sediment & Surface & 1.74 & $\mathrm{BOL}$ & $\mathrm{BDL}$ & 0.16 & 12.7 & 2.89 & 0.05 \\
\hline 111 & S037 & Crater bottom & Surface & 49.0 & 1.08 & 0.02 & 0.95 & 0.62 & 35.8 & 48.8 \\
\hline 111 & S038 & Crater wall & Surface & 52.5 & 1.29 & 0.02 & 1.27 & 0.75 & 37.1 & 76.2 \\
\hline 111 & S039 & Open area & Surface & 51.6 & 4.00 & 0.02 & 3.87 & 0.75 & 33.1 & 33.1 \\
\hline 111 & S041 & Open area & Suriace & 36.4 & 2.54 & BDL & 0.73 & 0.13 & 17.8 & 9.68 \\
\hline 111 & S044 & Crater bottom & Surface & 40.2 & 0.89 & BDL & 0.38 & 0.19 & 9.54 & 20.0 \\
\hline 111 & S049 & Background & $15-30$ & 1.00 & 0.38 & $\mathrm{BDL}$ & 0.04 & BDL & BDL & 0.08 \\
\hline \multicolumn{3}{|c|}{ Detection limit } & & 0.03 & 0.01 & 0.01 & 0.01 & 0.03 & 0.13 & 0.01 \\
\hline \multicolumn{3}{|c|}{ TCLP limit } & & 100.0 & 0.5 & 5.0 & - & 5.0 & - & - \\
\hline
\end{tabular}

a $\mathrm{BDL}=$ below detection limit. 
TABLE 7 Minimum Heavy-Metal Concentrations Needed to Yield a Hazardous TCLP Concentration as Calculated from TCLP Extracts for Soils Collected at GTA during April 1992

\begin{tabular}{|c|c|c|c|c|c|c|c|c|c|c|}
\hline \multirow[b]{2}{*}{ Range } & \multirow[b]{2}{*}{ Sample } & \multirow[b]{2}{*}{ Location } & \multirow[b]{2}{*}{$\begin{array}{l}\text { Depth } \\
\text { (cm) }\end{array}$} & \multicolumn{7}{|c|}{ Heavy Metal Concentration ( $\mathrm{mg} \mathrm{kg}^{-1}$ ) } \\
\hline & & & & $\mathbf{B a}$ & Cd & $\mathrm{Cr}$ & $\mathrm{Cu}$ & $\mathbf{P b}$ & Sn & $\mathrm{Zn}$ \\
\hline 122 & SO22 & Berm & $\begin{array}{r}15-50 \\
0-15\end{array}$ & 9.96 & $\begin{array}{l}\text { BDL } \\
\text { BDL }\end{array}$ & $\begin{array}{l}\text { BDL } \\
\text { BDL }\end{array}$ & $\begin{array}{l}0.75 \\
7.68\end{array}$ & 20.2 & 73.8 & 2.75 \\
\hline 122 & S026 & Berm & $0-15$ & BDL & $\mathrm{BDL}$ & $\mathrm{BDL}$ & 4.46 & BDL & 15.3 & 2.60 \\
\hline 122 & SO29 & Background & $15-30$ & 78.8 & BDL & BDL & $\mathrm{BDL}$ & BDL & 93.3 & BDL \\
\hline 122 & SO30 & Sediment & Surface & 1,032 & 1.61 & BDL & 1.20 & 11.2 & 671 & 1.04 \\
\hline 124 & S003 & Bullet pocket & $0-15$ & 607 & 0.38 & BDL & 35.9 & 4,440 & 316 & 13.7 \\
\hline 124 & S004 & Bullet pocket & $15-30$ & 369 & 0.38 & BDL & 96.9 & 13,600 & 209 & 23.6 \\
\hline 124 & SO07 & Berm & $0-6$ & 282 & BDL & $\mathrm{BDL}$ & 80.2 & 7,200 & 156 & 14.7 \\
\hline 124 & S009 & Bullet pocket & $0-6$ & 440 & BDL & BDL & 72.6 & 9,000 & 262 & 16.8 \\
\hline 124 & S014 & Berm backside & $15-30$ & 904 & 1.25 & BDL & 8.76 & 1,000 & 574 & 8.57 \\
\hline 124 & S015 & Sediment & Surface & 34.9 & BDL & BDL & 3.22 & 254 & 57.8 & 1.07 \\
\hline 111 & S037 & Crater bottom & Surface & 980 & 21.7 & 0.43 & 18.9 & 12.4 & 716 & 976 \\
\hline 111 & SO38 & Crater wall & Surface & 1,050 & 25.7 & 0.43 & 25.4 & 15.0 & 742 & 1,523 \\
\hline 111 & S039 & Open area & Surface & 1,032 & 80.0 & 0.43 & 73.4 & 15.0 & 662 & 662 \\
\hline 111 & SO41 & Open area & Surface & 728 & 50.8 & BDL & 14.6 & 2.51 & 356 & 193 \\
\hline 111 & S044 & Crater bottom & Surface & 804 & 17.3 & BDL & 7.68 & 3.77 & 191 & 400 \\
\hline 111 & SO49 & Background & $15-30$ & 19.9 & 0.38 & BDL & 0.75 & BDL & BDL & 1.68 \\
\hline $\begin{array}{r}\text { Minimu } \\
\text { hazar }\end{array}$ & $\begin{array}{l}\text { concentr: } \\
\text { lous TCLP }\end{array}$ & $\begin{array}{l}\text { tion in soil to yield } \\
\text { oncentration }\end{array}$ & & 2,000 & 20 & 100 & - & 100 & - & - \\
\hline
\end{tabular}

a $\mathrm{BDL}=$ below detection limit. 
also that concentrations of these heavy metals in runoff waters are lower than their concentrations in the range soils. However, if the concentration of one of these heavy metals in the soil is well above the soil regulatory limit, this heavy metal could be transported from the range in runoff waters.

Analytical results from the April 1992 collection of soil samples show that concentrations of heavy metals at Range 122 are below the Dutch List category B limits and the TCLP limits established by the EPA. These results suggest that heavy-metal contamination at Range 122 may not be a major concern. However, the lead concentration in the sediment sample is above the category B value, which suggests potential off-range contamination. The extremely high levels of lead and copper in the soils at Range 124 are a major concern. Several soil samples also had above normal concentrations of zinc. Although the concentrations of barium and tin in the soil are below the category B value, the higher proportion of these metals measured by the TCLP procedure than by the ICP-AES method suggests that these metals may be transported off the range in runoff waters. The major concerns at Range 111 are the high concentrations of cadmium and the above-normal levels of copper and zinc. In addition, potentially high levels of barium and tin may be present in runoff waters from Range 111 , because a high proportion of these heavy metals is extracted from the soil by the TCLP procedure.

\subsubsection{Explosives}

Selected samples collected during April 1992 from the three ranges were analyzed at ANL for TNT, RDX, and their explosive by-products. The potential for finding both TNT and RDX residues at Range 111 was high because both explosives are major components in hand grenades. Explosive residues were not expected at either Range 122 or Range 124 because these types of explosives are not components in most small-arms ammunition. No explosives were detected above the $1 \mathrm{mg} \mathrm{kg}^{-1}$ detection limit in any of the samples from any of the ranges.

\subsection{X-Ray Fluorescence Readings}

A major activity during the July 1992 primary data and sample collection effort was the collection of XRF readings at all three ranges. This activity was not included in the scope of the original study plan, but it was added because of the potential advantages of obtaining XRF data. Direct XRF readings can provide lead-contamination levels in soils at several locations and depths in a relatively short time. If the method is proven by field validation, XRF data can be used to determine lead contamination at a much lower cost than conventional soil sample collection and laboratory analyses. A disadvantage of the XRF method is that the minimum detection limit for lead in native soils has not been established. The XRF method has the potential to determine concentrations of other metals besides lead. In this study, however, the resolution of the portable XRF unit was too low to identify other metals. 
The 167 individual XRF readings for lead levels taken at Range 122, including the three replicate readings made at five locations, are listed in Table 8 . Of the 157 different locations and depths where readings were taken, samples from $129(82 \%)$ were below the $150 \mathrm{mg} \mathrm{kg}^{-1}$ category B value for lead in the Dutch List. Readings for 17 locations (11\%) were between the category B value and $600 \mathrm{mg} \mathrm{kg}^{-1}$, the category C lead value. Only 11 (7\%) readings were higher than the category $\mathrm{C}$ value.

Background-level readings at Range 122 were observed between targets (transect 2) and behind the eighth row of targets (transect 3 ) in the open area of the range. XRF readings between the category $B$ and category $C$ lead values were recorded behind the targets, next to the trench, and on the trench walls. The maximum depth at which any readings above the category $B$ value were found was at $16 \mathrm{~cm}$, suggesting that the interior of the berm is not contaminated with lead. The highest levels of lead contamination were observed behind targets (transect 1) and on the face of the berm (transect 4). Of the 11 readings higher than the category $C$ value, only two were from below the soil surface, at a maximum depth of $13 \mathrm{~cm}$. The XRF readings taken at Range 122 show lead contamination is limited to the surface soil.

The 222 individual XRF readings taken at Range 124, including the replicate readings at seven locations, are listed in Table 9. Distribution of the magnitude of the readings from the 210 different locations and depths is as follows: $57(27 \%)$ were below the category B value for lead, $20(10 \%)$ were between category B and category C values, and the remaining $133(63 \%)$ were higher than the category $\mathrm{C}$ value.

The lead-concentration pattern at Range 124 was not as well-defined as the pattern at Range 122. Generally, the only areas with surface-soil readings at background levels (lower than $150 \mathrm{mg} \mathrm{kg}^{-1}$ lead) were behind the firing pads (transect 5 and background locations). Other background-level readings were recorded at depths $5-15 \mathrm{~cm}$ below the soil surface between the firing pads and the berm. Readings higher than $150 \mathrm{mg} \mathrm{kg}^{-1}$ (the category B limit) were recorded on the soil surface throughout the range, on the berm, and on the trench walls.

The highest XRF readings recorded at Range 124 were on the berm face (transects 1,2 , and 7) and on the trench walls. Readings in the $3,000-7,000 \mathrm{mg} \mathrm{kg}^{-1}$ lead range were recorded on the trench wall to a depth of $75 \mathrm{~cm}$ below the soil surface. This depth of lead contamination on the trench walls was not observed at Range 122. The reasons for the difference between the degree of lead contamination at the two ranges were learned in discussions with Army personnel at GTA. The high-velocity rifle slugs disintegrate into small particles on impact, while the lowervelocity handgun slugs remain intact. Disintegration of the rifle slugs produced small lead particles that were easily incorporated into the soil surface, while the intact handgun slugs ricocheted off the soil surface. Thus, intact slugs were present at the handgun range (Range 122), but they were absent at the rifle range (Range 124). Impact from the high-velocity rifle slugs also produced a hole or bullet pocket behind the single fixed target on the face of the berm at Range 124, while bullet pockets do not develop behind the pop up targets at Range 122. At Range 124, the face of the berm is periodically graded, and soil is added to fill the bullet pockets. This grading has 
TABLE 8 X-Ray Fluorescence Readings Taken at Range 122 at GTA during July 1992

\begin{tabular}{|c|c|c|c|c|c|}
\hline Transect & $\begin{array}{l}\text { Location } \\
\text { (m) }\end{array}$ & $\begin{array}{l}\text { Depth } \\
(\mathrm{cm})\end{array}$ & $\begin{array}{l}\text { Replicate } \\
\text { Number }\end{array}$ & $\begin{array}{c}\mathrm{Pb} \\
\text { Reading } \\
\text { (mg kg-1) }\end{array}$ & Notes \\
\hline 1 & 1 & 0 & 1 & 0 & $1 \mathrm{~m}$ in front of firing point 7 \\
\hline 1 & 5 & 0 & 1 & 0 & \\
\hline 1 & 9 & 0 & 1 & 0 & $1 \mathrm{~m}$ in front of target 1 \\
\hline 1 & 13.7 & 0 & 1 & 125 & 3 in behind target 1 \\
\hline 1 & 15 & 0 & 1 & 279 & $3 \mathrm{~m}$ behind target 2 \\
\hline 1 & 15 & 0 & 2 & 331 & \\
\hline 1 & 15 & 0 & 3 & 309 & \\
\hline 1 & 15 & 15 & 1 & 0 & \\
\hline 1 & 20 & 0 & 1 & 0 & $3 \mathrm{~m}$ behind target 3 \\
\hline 1 & 21 & 0 & 1 & 362 & $3 \mathrm{~m}$ behind target 4 \\
\hline 1 & 21 & 10 & 1 & 0 & \\
\hline 1 & 25 & 0 & 1 & 13 & $3 \mathrm{~m}$ behind target 5 \\
\hline 1 & 29 & 0 & 1 & 43 & $3 \mathrm{~m}$ behind target 6 \\
\hline 1 & 29 & 12 & 1 & 0 & \\
\hline 1 & 32.5 & 0 & 1 & 0 & $3 \mathrm{~m}$ behind target 7 \\
\hline 1 & 34 & 0 & 1 & 183 & $3 \mathrm{~m}$ behind target 8 \\
\hline 1 & 34 & 11 & 1 & 0 & \\
\hline 1 & 38 & 0 & 1 & 43 & \\
\hline 1 & 44 & 0 & 1 & 0 & Bottom of ditch on sediment \\
\hline 1 & 49 & 0 & 1 & 0 & $1 \mathrm{~m}$ in front of target 10 \\
\hline 1 & 49 & 0 & 1 & 0 & $18 \mathrm{~m}$ behind target 8 \\
\hline 1 & 5.3 & 0 & 1 & 89 & $3 \mathrm{~m}$ behind target 10 \\
\hline 1 & 56 & 0 & 1 & 149 & Next to trench \\
\hline 1 & 56 & 15 & 1 & 0 & Trench wall \\
\hline 1 & 56 & 30 & 1 & 0 & \\
\hline 1 & 57 & 0 & 1 & 1,274 & Next to trench \\
\hline 1 & 57 & 12 & 1 & 0 & Trench wall \\
\hline 1 & 57 & 30 & 1 & 0 & \\
\hline 1 & 58 & 0 & 1 & 38 & Next to trench \\
\hline 1 & 58 & 15 & 1 & 0 & Trench wall \\
\hline 1 & 59 & 0 & 1 & 235 & Next to trench \\
\hline 1 & 59 & 15 & 1 & 128 & Trench wall \\
\hline 1 & 59 & 30 & 1 & 0 & \\
\hline 1 & 60 & 0 & 1 & 191 & Next to trench \\
\hline 1 & 60 & 15 & 1 & 14 & Trench wall \\
\hline 1 & 60 & 30 & 1 & 0 & \\
\hline 1 & 61 & 0 & 1 & 241 & Next to trench \\
\hline 1 & 61 & 15 & 1 & 265 & Trench wall \\
\hline 1 & 61 & 30 & 1 & 0 & \\
\hline 1 & 62 & 0 & 1 & 0 & Top of berm trench \\
\hline 1 & 62 & 15 & 1 & 0 & Trench wall \\
\hline 1 & 63 & 0 & 1 & 0 & Top of berm \\
\hline 1 & 65 & 0 & 1 & 0 & Backside of berm \\
\hline 1 & 67 & 0 & 1 & 0 & Backside of berm \\
\hline 1 & 71.5 & 0 & 1 & 0 & Backside of berm at base \\
\hline
\end{tabular}


TABLE 8 (Cont.)

\begin{tabular}{|c|c|c|c|c|c|}
\hline Transect & $\begin{array}{l}\text { Location }^{a} \\
\text { (m) }\end{array}$ & $\begin{array}{l}\text { Depth } \\
(\mathrm{cm})\end{array}$ & $\begin{array}{c}\text { Replicate } \\
\text { Number }\end{array}$ & $\begin{array}{c}\mathrm{Pb} \\
\text { Reading } \\
\left(\mathrm{mg} \mathrm{kg}^{-1}\right)\end{array}$ & Notes \\
\hline 2 & 1 & 0 & 1 & 0 & \\
\hline 2 & 5 & 0 & 1 & 0 & \\
\hline 2 & 10 & 0 & 1 & 0 & \\
\hline 2 & 15 & 0 & 1 & 6 & \\
\hline 2 & 15 & 0 & 2 & 64 & \\
\hline 2 & 15 & 0 & 3 & 6 & \\
\hline 2 & 15 & 7 & 1 & 0 & \\
\hline 2 & 20 & 0 & 1 & 81 & \\
\hline 2 & 20 & 7 & 1 & 0 & \\
\hline 2 & 25 & 0 & 1 & 0 & \\
\hline 2 & 30 & 0 & 1 & 0 & \\
\hline 2 & 35 & 0 & 1 & 0 & \\
\hline 2 & 39 & 0 & 1 & 0 & \\
\hline 2 & 44.5 & 0 & 1 & 0 & Bottom of ditch \\
\hline 2 & 49 & 0 & 1 & 0 & \\
\hline 2 & 55 & 0 & 1 & 1,408 & Next to trench \\
\hline 2 & 55 & 15 & 1 & 250 & Trench wall \\
\hline 2 & 55 & 30 & 1 & 0 & \\
\hline 2 & 56 & 0 & 1 & 0 & Next to trench \\
\hline 2 & 56 & 15 & 1 & 203 & Trench wall \\
\hline 2 & 56 & 30 & 1 & 0 & \\
\hline 2 & 57 & 0 & 1 & 0 & Next to trench \\
\hline 2 & 57 & 15 & 1 & 0 & Trench wall \\
\hline 2 & 58 & 0 & 1 & 0 & Next to trench \\
\hline 2 & 58 & 15 & 1 & 0 & Trench wall \\
\hline 2 & 59 & 0 & 1 & 0 & Next to trench \\
\hline 2 & 59 & 15 & 1 & 0 & Trench wall \\
\hline 2 & 59 & 30 & 1 & 0 & \\
\hline 2 & 60 & 0 & 1 & 0 & Next to trench \\
\hline 2 & 60 & 15 & 1 & 306 & Trench wall \\
\hline 2 & 61 & 0 & 1 & 0 & Next to trench \\
\hline 2 & 61 & 15 & 1 & 0 & Trench wall \\
\hline 2 & 63 & 0 & 1 & 0 & Top of berm \\
\hline 2 & 65 & 0 & 1 & 0 & Backside of berm \\
\hline 2 & 67 & 0 & 1 & 0 & Backside of berm \\
\hline 2 & 71 & 0 & 1 & 0 & Backside of herm at base \\
\hline 3 & 0 & 0 & 1 & 0 & Edge of range \\
\hline 3 & 5 & 0 & 1 & 0 & In line with firing point 1 \\
\hline 3 & 7.6 & 0 & 1 & 0 & \\
\hline 3 & 10 & 0 & 1 & 0 & \\
\hline 3 & 15 & 0 & 1 & 0 & \\
\hline 3 & 20 & 0 & 1 & 0 & In line with firing point 2 \\
\hline 3 & 25 & 0 & 1 & 0 & \\
\hline 3 & 31 & 0 & 1 & 0 & \\
\hline
\end{tabular}


TABLE 8 (Cont.)

\begin{tabular}{|c|c|c|c|c|c|}
\hline Transect & $\begin{array}{l}\text { Location }^{a} \\
(\mathrm{~m})\end{array}$ & $\begin{array}{l}\text { Depth } \\
(\mathrm{cm})\end{array}$ & $\begin{array}{c}\text { Replicate } \\
\text { Number }\end{array}$ & $\begin{array}{c}\mathrm{Pb} \\
\text { Reading } \\
\left(\mathrm{mg} \mathrm{kg}^{-1}\right)\end{array}$ & Notes \\
\hline 3 & 33 & 0 & 1 & 0 & \\
\hline 3 & 35 & 0 & 1 & 0 & In line with firing point 3 \\
\hline 3 & 40 & 0 & 1 & 0 & \\
\hline 3 & 45 & 0 & 1 & 0 & In line with firing point 4 \\
\hline 3 & 48 & 0 & 1 & 0 & \\
\hline 3 & 50 & 0 & 1 & 0 & \\
\hline 3 & 55 & 0 & 1 & 0 & \\
\hline 3 & 61 & 0 & 1 & 0 & In line with firing point 5 \\
\hline 3 & 63 & 0 & 1 & 0 & In line with target \\
\hline 3 & 63 & 7 & 1 & 0 & \\
\hline 3 & 66 & 0 & 1 & 0 & \\
\hline 3 & 71 & 0 & 1 & 0 & \\
\hline 3 & 76 & 0 & 1 & 0 & In line with firing point 6 \\
\hline 3 & 78.5 & 0 & 1 & 0 & In line with target \\
\hline 3 & 81 & 0 & 1 & 0 & \\
\hline 3 & 85 & 0 & 1 & 0 & \\
\hline 3 & 93.4 & 0 & 1 & 0 & In line with firing point 7 \\
\hline 3 & 95.5 & 0 & 1 & 0 & In line with target \\
\hline 3 & 100 & 0 & 1 & 0 & \\
\hline 3 & 105 & 0 & 1 & 0 & \\
\hline 3 & 110 & 0 & 1 & 489 & In line with firing point 8 \\
\hline 3 & 110 & 9 & 1 & 0 & \\
\hline 3 & 115 & 0 & 1 & 0 & \\
\hline 3 & 125 & 0 & 1 & 0 & In line with firing point 9 \\
\hline 3 & 130 & 0 & 1 & 0 & \\
\hline 3 & 135 & 0 & 1 & 0 & \\
\hline 3 & 140 & 0 & 1 & 0 & In line with firing point 10 \\
\hline 3 & 145 & 0 & 1 & 0 & Edge of range \\
\hline 4 & 0 & 0 & 1 & 0 & Edge of range \\
\hline 4 & 5 & 0 & 1 & 31 & In line with firing point 1 \\
\hline 4 & 10 & 0 & 1 & 0 & In line with target \\
\hline 4 & 15 & 0 & 1 & 47 & \\
\hline 4 & 20 & 0 & 1 & 734 & In line with firing point 2 \\
\hline 4 & 20 & 13 & 1 & 35 & \\
\hline 4 & 25 & 0 & 1 & 0 & \\
\hline 4 & 30 & 0 & 1 & 0 & \\
\hline 4 & 35 & 0 & 1 & 646 & In line with firing point 3 \\
\hline 4 & 35 & 12 & 1 & 9 & \\
\hline 4 & 35 & 12 & 2 & 7 & \\
\hline 4 & 35 & 12 & 3 & 16 & \\
\hline 4 & 40 & 0 & 1 & 0 & \\
\hline 4 & 45 & 0 & 1 & 0 & In line with firing point 4 \\
\hline
\end{tabular}


TABLE 8 (Cont.)

\begin{tabular}{|c|c|c|c|c|c|}
\hline Transect & $\begin{array}{l}\text { Locationa }^{a} \\
\text { (m) }\end{array}$ & $\begin{array}{l}\text { Depth } \\
(\mathrm{cm})\end{array}$ & $\begin{array}{c}\text { Replicate } \\
\text { Number }\end{array}$ & $\begin{array}{c}\mathrm{Pb} \\
\text { Reading } \\
\left(\mathrm{mg} \mathrm{kg}^{-1}\right)\end{array}$ & Notes \\
\hline 4 & 50.5 & 0 & 1 & 2,528 & In line with target \\
\hline 4 & 50.5 & 12 & 1 & 786 & \\
\hline 4 & 50.5 & 20 & 1 & 0 & \\
\hline 4 & 55 & 0 & 1 & 181 & \\
\hline 4 & 60 & 0 & 1 & 383 & In line with firing point 5 \\
\hline 4 & 65.3 & 0 & 1 & 3,987 & In line with target \\
\hline 4 & 65.3 & 13 & 1 & 708 & \\
\hline 4 & 65.3 & 13 & 2 & 659 & \\
\hline 4 & 65.3 & 13 & 3 & 688 & \\
\hline 4 & 65.3 & 19 & 1 & 0 & \\
\hline 4 & 70 & 0 & 1 & 210 & \\
\hline 4 & 75 & 0 & 1 & 149 & In line with firing point 6 \\
\hline 4 & 80 & 0 & 1 & 471 & \\
\hline 4 & 85 & 0 & 1 & 0 & \\
\hline 4 & 90 & 0 & 1 & 0 & In line with firing point 7 \\
\hline 4 & 94.5 & 0 & 1 & 971 & In line with target \\
\hline 4 & 94.5 & 16 & 1 & 512 & \\
\hline 4 & 94.5 & 28 & 1 & 0 & \\
\hline 4 & 100 & 0 & 1 & 0 & \\
\hline 4 & 105 & 0 & 1 & 0 & \\
\hline 4 & 110 & 0 & 1 & 0 & In line with firing point 8 \\
\hline 4 & 115 & 0 & 1 & 0 & \\
\hline 4 & 120 & 0 & 1 & 0 & \\
\hline 4 & 125 & 0 & 1 & 0 & In line with firing point 9 \\
\hline 4 & 130 & 0 & 1 & 2,271 & In line with target \\
\hline 4 & 130 & 16 & 1 & 60 & \\
\hline 4 & 135 & 0 & 1 & 0 & \\
\hline 4 & 140 & 0 & 1 & 1,936 & In line with firing point 10 \\
\hline 4 & 140 & 14 & 1 & 235 & \\
\hline 4 & 145 & 0 & 1 & 115 & Edge of range \\
\hline $\mathrm{Bkg}^{\mathrm{C}} 1$ & -12.5 & 0 & 1 & 0 & $12.5 \mathrm{~m}$ behind firing point 7 \\
\hline Bkg 1 & -12.5 & 0 & 2 & 0 & \\
\hline Bkg 1 & -12.5 & 0 & 3 & 0 & \\
\hline Bkg 1 & -16.5 & 0 & 1 & 0 & $16.5 \mathrm{~m}$ behind firing point 7 \\
\hline Bkg 1 & -16.5 & 15 & 1 & 0 & \\
\hline Bkg 1 & -16.5 & 30 & 1 & 0 & \\
\hline
\end{tabular}

Distance from starting point of transect.

b $\mathrm{Pb}$ reading of zero indicates concentration below detection limit.

C Bkg = background sample. 
TABLE 9 X-Ray Fluorescence Readings Taken at Range 124 at GTA during July 1992

\begin{tabular}{|c|c|c|c|c|c|}
\hline Transect & $\begin{array}{l}\text { Location }^{a} \\
\text { (m) }\end{array}$ & $\begin{array}{l}\text { Depth } \\
\text { (cm) }\end{array}$ & $\begin{array}{l}\text { Replicate } \\
\text { Number }\end{array}$ & $\begin{array}{c}\mathrm{Pb} \\
\text { Reading } \\
(\mathrm{mg} \mathrm{kg} \\
\left.\mathrm{kg}^{-1}\right)\end{array}$ & Notes \\
\hline 1 & 1 & 0 & 1 & 1,616 & $1 \mathrm{~m}$ in front of firing pad 5 \\
\hline 1 & 1.5 & 0 & 2 & 1,435 & \\
\hline 1 & 1.5 & 15 & 1 & 0 & Undisturbed subsoil \\
\hline 1 & 5 & 0 & 1 & 0 & \\
\hline 1 & 10 & 0 & 1 & 1,512 & \\
\hline 1 & 10 & 15 & 1 & 0 & Undisturbed subsoil \\
\hline 1 & 15 & 0 & 1 & 1,408 & \\
\hline 1 & 15 & 3 & 1 & 0 & Undisturbed subsoil \\
\hline 1 & 20 & 0 & 1 & 3,505 & \\
\hline 1 & 20 & 15 & 1 & 0 & Undisturbed subsoil \\
\hline 1 & 22.5 & 0 & 1 & 2,335 & \\
\hline 1 & 22.5 & 1 & 1 & 4,831 & \\
\hline 1 & 22.5 & 3 & 1 & 4,792 & \\
\hline 1 & 22.5 & 5.5 & 1 & 0 & Undisturbed subsoil \\
\hline 1 & 25 & 0 & 1 & 3,312 & $1 \mathrm{~m}$ behind target \\
\hline 1 & 25 & 5 & 1 & 2,898 & \\
\hline 1 & 25 & 17 & 1 & 3,025 & \\
\hline 1 & 25 & 19 & 1 & 43 & \\
\hline 1 & 25 & 22 & 1 & 5,308 & \\
\hline 1 & 29 & 0 & 1 & 0 & Bottom of ditch \\
\hline 1 & 33 & 0 & 1 & 3,712 & Next to trench \\
\hline 1 & 33 & 0 & 2 & 3,911 & \\
\hline 1 & 33 & 15 & 1 & 4,027 & Trench wall \\
\hline 1 & 33 & 30 & 1 & 230 & \\
\hline 1 & 33 & 45 & 1 & 1,613 & \\
\hline 1 & 33 & 60 & 1 & 0 & Undisturbed subsoil, trench wall \\
\hline 1 & 33 & 75 & 1 & 0 & \\
\hline 1 & 34 & 0 & 1 & 1,803 & Next to trench \\
\hline 1 & 34 & 15 & 1 & 2,852 & Trench wall \\
\hline 1 & 34 & 30 & 1 & 3,562 & \\
\hline 1 & 34 & 45 & 1 & 1,316 & \\
\hline 1 & 34 & 60 & 1 & 761 & \\
\hline 1 & 34 & 75 & 1 & 0 & Undisturbed subsoil, trench wall \\
\hline 1 & 34.5 & 0 & 1 & 3,174 & Bullet pocket, next to trench \\
\hline 1 & 34.5 & 30 & 1 & 5,984 & Bullet pocket, trench wall \\
\hline 1 & 34.5 & 35 & 1 & 7,859 & \\
\hline 1 & 35 & 0 & 1 & 594 & Next to trench \\
\hline 1 & 35 & 15 & 1 & 5,076 & Trench wall \\
\hline 1 & 35 & 30 & 1 & 3,764 & \\
\hline 1 & 35 & 45 & 1 & 0 & \\
\hline 1 & 35 & 60 & 1 & 1,144 & \\
\hline 1 & 35 & 75 & 1 & 1,830 & \\
\hline 1 & 36 & 0 & 1 & 1,564 & Next to trench \\
\hline 1 & 36 & 15 & 1 & 2,014 & Trench wall \\
\hline 1 & 36 & 30 & 1 & 898 & \\
\hline
\end{tabular}


TABLE 9 (Cont.)

\begin{tabular}{|c|c|c|c|c|c|}
\hline Transect & $\begin{array}{l}\text { Location }^{a} \\
(m)\end{array}$ & $\begin{array}{l}\text { Depth } \\
(\mathrm{cm})\end{array}$ & $\begin{array}{l}\text { Replicate } \\
\text { Number }\end{array}$ & $\begin{array}{c}\mathrm{Pb} \\
\text { Reading } \\
\left(\mathrm{mg} \mathrm{kg}^{-1}\right)\end{array}$ & Notes \\
\hline 1 & 36 & 45 & 1 & 7,732 & \\
\hline 1 & 36 & 60 & 1 & 3,005 & \\
\hline 1 & 36 & 75 & 1 & 2,375 & \\
\hline 1 & 36 & 90 & 1 & 0 & \\
\hline 1 & 37 & 0 & 1 & 5,688 & Next to trench \\
\hline 1 & 37 & 15 & 1 & 2,191 & Trench wall \\
\hline 1 & 37 & 30 & 1 & 5,271 & \\
\hline 1 & 37 & 45 & 1 & 1,957 & \\
\hline 1 & 37 & 60 & 1 & 0 & \\
\hline 1 & 38 & 0 & 1 & 4,314 & Top of berm \\
\hline 1 & 39 & 0 & 1 & 2,443 & Top of berm \\
\hline 1 & 39 & 15 & 1 & 6,822 & \\
\hline 1 & 41 & 0 & 1 & 2,759 & Top of berm \\
\hline 1 & 43 & 0 & 1 & 1,028 & Backside of berm \\
\hline 1 & 45 & 0 & 1 & 1,065 & At the base of the backside of the berm \\
\hline 1 & 51 & 0 & 1 & 2,235 & Behind berm \\
\hline 1 & 53.5 & 0 & 1 & 745 & Behind berm \\
\hline 1 & 53.5 & 18 & 1 & 0 & \\
\hline 2 & 1.5 & 0 & 1 & 391 & $1.5 \mathrm{~m}$ in front of firing pads \\
\hline 2 & 1.5 & 0 & 2 & 322 & \\
\hline 2 & 1.5 & 0 & 3 & 339 & \\
\hline 2 & 5 & 0 & 1 & 150 & \\
\hline 2 & 5 & 7 & 1 & 0 & \\
\hline 2 & 10 & 0 & 1 & 616 & \\
\hline 2 & 10 & 9 & 1 & 0 & Undisturbed subsoil \\
\hline 2 & 15 & 0 & 1 & 3,824 & \\
\hline 2 & 15 & 0 & 2 & 3,842 & \\
\hline 2 & 15 & 0 & 3 & 3,753 & \\
\hline 2 & 15 & 7 & 1 & 0 & Undisturbed subsoil \\
\hline 2 & 20 & 0 & 1 & 4,204 & \\
\hline 2 & 20 & 7 & 1 & 0 & \\
\hline 2 & 22.5 & 0 & 1 & 4,771 & \\
\hline 2 & 22.5 & 6 & 1 & 0 & Undisturbed subsoil \\
\hline 2 & 25 & 0 & 1 & 5,143 & \\
\hline 2 & 25 & 5 & 1 & 0 & Undisturbed subsoil \\
\hline 2 & 29 & 0 & 1 & 247 & Bottom of ditch \\
\hline 2 & 32 & 0 & 1 & 2,483 & Next to trench \\
\hline 2 & 32 & 15 & 1 & 1,269 & Trench wall \\
\hline 2 & 32 & 30 & 1 & 0 & Undisturbed subsoil, trench wall \\
\hline 2 & 32 & 45 & 1 & 0 & \\
\hline 2 & 33 & 0 & 1 & 3,083 & Next to trench \\
\hline 2 & 33 & 15 & 1 & 894 & Trench wall \\
\hline 2 & 33 & 30 & 1 & 0 & Undisturbed subsoil, trench wall \\
\hline 2 & 33 & 45 & 1 & 0 & \\
\hline 2 & 34 & 0 & 1 & 4,457 & Next to trench \\
\hline
\end{tabular}


TABLE 9 (Cont.)

\begin{tabular}{|c|c|c|c|c|c|}
\hline Transect & $\begin{array}{l}\text { Location }^{a} \\
(\mathrm{~m})\end{array}$ & $\begin{array}{l}\text { Depth } \\
(\mathrm{cm})\end{array}$ & $\begin{array}{l}\text { Replicate } \\
\text { Number }\end{array}$ & $\begin{array}{c}\mathrm{Pb} \\
\text { Reading } \\
\left(\mathrm{mg} \mathrm{kg}^{-1}\right)\end{array}$ & Notes \\
\hline 2 & 34 & 15 & 1 & 111 & Trench wall \\
\hline 2 & 34 & 30 & 1 & 4,896 & \\
\hline 2 & 34 & 45 & 1 & 1,466 & \\
\hline 2 & 34 & 60 & 1 & 1,888 & \\
\hline 2 & 34 & 75 & 1 & 1,454 & \\
\hline 2 & 34 & 90 & 1 & 103 & \\
\hline 2 & 35 & 0 & 1 & 3,620 & Next to trench \\
\hline 2 & 35 & 15 & 1 & 1,256 & Trench wall \\
\hline 2 & 35 & 30 & 1 & 5,630 & \\
\hline 2 & 35 & 45 & 1 & 4,716 & \\
\hline 2 & 35 & 60 & 1 & 5,120 & \\
\hline 2 & 35 & 75 & 1 & 0 & \\
\hline 2 & 35 & 90 & 1 & 0 & \\
\hline 2 & 36 & 0 & 1 & 2,591 & Next to trench \\
\hline 2 & 36 & 15 & 1 & 1,304 & Trench wall \\
\hline 2 & 36 & 30 & 1 & 2,148 & \\
\hline 2 & 36 & 45 & 1 & 6,925 & \\
\hline 2 & 36 & 60 & 1 & 8,494 & \\
\hline 2 & 36 & 75 & 1 & 0 & \\
\hline 2 & 37 & 0 & 1 & 1,123 & Next to trench \\
\hline 2 & 37 & 15 & 1 & 3,400 & Trench wall \\
\hline 2 & 37 & 30 & 1 & 6,180 & \\
\hline 2 & 37 & 45 & 1 & 2,979 & \\
\hline 4 & 0 & 0 & 1 & 0 & Edge of range \\
\hline 4 & 2 & 0 & 1 & 0 & \\
\hline 4 & 4 & 0 & 1 & 0 & \\
\hline 4 & 6 & 0 & 1 & 430 & $1.5 \mathrm{~m}$ in front of firing pad 1 \\
\hline 4 & 8.5 & 0 & 1 & 0 & \\
\hline 4 & 11 & 0 & 1 & 497 & $1.5 \mathrm{~m}$ in front of firing pad 2 \\
\hline 4 & 14 & 0 & 1 & 31 & \\
\hline 4 & 16.5 & 0 & 1 & 1,796 & $1.5 \mathrm{~m}$ in front of firing pad 3 \\
\hline 4 & 19 & 0 & 1 & 399 & \\
\hline 4 & 21.5 & 0 & 1 & 462 & $1.5 \mathrm{~m}$ in front of firing pad 4 \\
\hline 4 & 24 & 0 & 1 & 89 & \\
\hline 4 & 29 & 0 & 1 & 299 & \\
\hline 4 & 31 & 0 & 1 & 2,092 & $1.5 \mathrm{~m}$ in front of firing pad 6 \\
\hline 4 & 31 & 3 & 1 & 0 & \\
\hline 4 & 36.5 & 0 & 1 & 1,718 & $1.5 \mathrm{~m}$ in front of firing pad 7 \\
\hline 4 & 36.5 & 0 & 2 & 1,720 & \\
\hline 4 & 36.5 & 0 & 3 & 1,827 & \\
\hline 4 & 39 & 0 & 1 & 214 & \\
\hline 4 & 41.6 & 0 & 1 & 1,017 & $1.5 \mathrm{~m}$ in front of firing pad 8 \\
\hline 4 & 41.6 & 2 & 1 & 849 & \\
\hline 4 & 41.6 & 5 & 1 & 0 & \\
\hline 4 & 44 & 0 & 1 & 334 & \\
\hline
\end{tabular}


TABLE 9 (Cont.)

\begin{tabular}{|c|c|c|c|c|c|}
\hline Transect & $\begin{array}{l}\text { Location }^{a} \\
(\mathrm{~m})\end{array}$ & $\begin{array}{l}\text { Depth } \\
(\mathrm{cm})\end{array}$ & $\begin{array}{l}\text { Replicate } \\
\text { Number }\end{array}$ & $\begin{array}{c}\mathrm{Pb} \\
\text { Reading } \\
\left(\mathrm{mg} \mathrm{kg}^{-1}\right)\end{array}$ & Notes \\
\hline 4 & 46.7 & 0 & 1 & 2,369 & $1.5 \mathrm{~m}$ in front of firing pad 9 \\
\hline 4 & 49 & 0 & 1 & 603 & \\
\hline 4 & 51.6 & 0 & 1 & 1,246 & $1.5 \mathrm{~m}$ in front of firing pad 10 \\
\hline 4 & 53 & 0 & 1 & 1,190 & \\
\hline 4 & 55 & 0 & 1 & 0 & \\
\hline 4 & 57 & 0 & 1 & 0 & Edge of range \\
\hline 5 & 5.3 & 0 & 1 & 0 & $1 \mathrm{~m}$ in front of firing pit 2 \\
\hline 5 & 21.2 & 0 & 1 & 107 & $1 \mathrm{~m}$ in front of firing pit 4 \\
\hline 5 & 31.8 & 0 & 1 & 0 & $1 \mathrm{~m}$ in front of firing pit 6 \\
\hline 5 & 42.4 & 0 & 1 & 63 & $1 \mathrm{~m}$ in front of firing pit 8 \\
\hline 5 & 47.7 & 0 & 1 & 0 & $1 \mathrm{~m}$ in front of firing pit 9 \\
\hline 6 & 0 & 0 & 1 & 1,178 & Edge of range \\
\hline 6 & 2.3 & 0 & 1 & 825 & \\
\hline 6 & 5.5 & 0 & 1 & 213 & $1 \mathrm{~m}$ in front of target 1 \\
\hline 6 & 7.7 & 0 & 1 & 551 & \\
\hline 6 & 10 & 0 & 1 & 590 & $1 \mathrm{~m}$ in front of target 2 \\
\hline 6 & 12.2 & 0 & 1 & 5,080 & \\
\hline 6 & 15.8 & 0 & 1 & 2,013 & $1 \mathrm{~m}$ in front of target 3 \\
\hline 6 & 15.8 & 2 & 1 & 3,780 & \\
\hline 6 & 15.8 & 6 & 1 & 485 & \\
\hline 6 & 18.3 & 0 & 1 & 2,378 & \\
\hline 6 & 20.6 & 0 & 1 & 2,574 & $1 \mathrm{~m}$ in front of target 4 \\
\hline 6 & 23 & 0 & 1 & 1,626 & \\
\hline 6 & 25.2 & 0 & 1 & 319 & $1 \mathrm{~m}$ in front of target 5 \\
\hline 6 & 27.5 & 0 & 1 & 697 & \\
\hline 6 & 30.5 & 0 & 1 & 1,902 & $1 \mathrm{~m}$ in front of target 6 \\
\hline 6 & 30.5 & 8 & 1 & 0 & \\
\hline 6 & 33 & 0 & 1 & 2,203 & \\
\hline 6 & 35.6 & 0 & 1 & 5,498 & $1 \mathrm{~m}$ in front of target 7 \\
\hline 6 & 38 & 0 & 1 & 1,290 & \\
\hline 6 & 40.4 & 0 & 1 & 953 & $1 \mathrm{~m}$ in front of target 8 \\
\hline 6 & 42.5 & 0 & 1 & 1,277 & \\
\hline 6 & 45 & 0 & 1 & 440 & $1 \mathrm{~m}$ in front of target 9 \\
\hline 6 & 45 & 5 & 1 & 954 & \\
\hline 6 & 45 & 9 & 1 & 0 & \\
\hline 6 & 47 & 0 & 1 & 1,279 & \\
\hline 6 & 49.3 & 0 & 1 & 4,332 & $1 \mathrm{~m}$ in front of target 10 \\
\hline 6 & 52 & 0 & 1 & 1,783 & \\
\hline 6 & 54 & 0 & 1 & 4,076 & Edge of range \\
\hline 6 & 54 & 7 & 1 & 9,182 & \\
\hline 6 & 54 & 17 & 1 & 3,407 & \\
\hline 6 & 54 & 19 & 1 & 1,568 & \\
\hline 7 & 0 & 0 & 1 & 4,090 & $10 \mathrm{~m}$ behind targets, edge of range \\
\hline
\end{tabular}


TABLE 9 (Cont.)

\begin{tabular}{|c|c|c|c|c|c|}
\hline Transect & $\begin{array}{l}\text { Location } \\
\qquad(\mathrm{m})\end{array}$ & $\begin{array}{l}\text { Depth } \\
(\mathrm{cm})\end{array}$ & $\begin{array}{l}\text { Replicate } \\
\text { Number }\end{array}$ & $\begin{array}{c}\text { Pb } \\
\text { Reading }^{\mathrm{b}} \\
\left(\mathrm{mg} \mathrm{kg}^{-1}\right)\end{array}$ & Notes \\
\hline 7 & 0 & 0 & 1 & 0 & Base of berm, edge of range \\
\hline 7 & 2.5 & 0 & 1 & 3,144 & \\
\hline 7 & 5 & 0 & 1 & 1,685 & $10 \mathrm{~m}$ behind target 1 \\
\hline 7 & 7.3 & 0 & 1 & 2,972 & \\
\hline 7 & 10 & 0 & 1 & 7,363 & $10 \mathrm{~m}$ behind target 2 \\
\hline 7 & 10 & 13 & 1 & 6,397 & \\
\hline 7 & 13 & 0 & 1 & 2,686 & \\
\hline 7 & 16 & 0 & 1 & 1,823 & $10 \mathrm{~m}$ behind target 3 , bullet pocket \\
\hline 7 & 18.5 & 0 & 1 & 4,316 & \\
\hline 7 & 21 & 0 & 1 & 3,176 & $10 \mathrm{~m}$ behind target 4 , bullet pocket \\
\hline 7 & 21 & 13 & 1 & 5,704 & \\
\hline 7 & 21 & 30 & 1 & 3,056 & \\
\hline 7 & 23.5 & 0 & 1 & 3,721 & \\
\hline 7 & 28 & 0 & 1 & 1,880 & \\
\hline 7 & 30.5 & 0 & 1 & 3,186 & $10 \mathrm{~m}$ behind target 6 , bullet pocket \\
\hline 7 & 36 & 0 & 1 & 4,569 & $10 \mathrm{~m}$ behind target 7 , bullet pocket \\
\hline 7 & 36 & 15 & 1 & 10,853 & \\
\hline 7 & 37.5 & 0 & 1 & 6,033 & \\
\hline 7 & 39.5 & 0 & 1 & 3,585 & $10 \mathrm{~m}$ baind target 8 , bullet pocket \\
\hline 7 & 41.5 & 0 & 1 & 3,718 & \\
\hline 7 & 44 & 0 & 1 & 2,142 & $10 \mathrm{~m}$ behind target 9 , bullet pocket \\
\hline 7 & 46.5 & 0 & 1 & 1,692 & \\
\hline 7 & 49 & 0 & 1 & 4,192 & $10 \mathrm{~m}$ behind target 10 , bullet pocket \\
\hline 7 & 49 & 14 & 1 & 4,125 & \\
\hline 7 & 51 & 0 & 1 & 4,741 & \\
\hline 7 & 53 & 0 & 1 & 5,921 & Edge of range \\
\hline 7 & 53 & 12 & 1 & 6,497 & \\
\hline 7 & 53 & 12 & 2 & 6,536 & \\
\hline 7 & 53 & 12 & 3 & 6,542 & \\
\hline 7 & 54 & 0 & 1 & 559 & Base of berm, edge of range \\
\hline 7 & 58 & 0 & 1 & 7,372 & $\begin{array}{l}\text { Sediment in drainage, north end of } \\
\text { berm }\end{array}$ \\
\hline 7 & 60 & 0 & 1 & 20 & Soil pile, north of drainage ditch \\
\hline $\mathrm{Bkg}^{\mathrm{c}} 1$ & -20 & 0 & 1 & 0 & $\begin{array}{l}20 \mathrm{~m} \text { behind firing pad } 10 \text {, edge of } \\
\text { forest }\end{array}$ \\
\hline Bkg 1 & -20 & 15 & 1 & 0 & \\
\hline Bkg 1 & -20 & 30 & 1 & 0 & \\
\hline Bkg 1 & -20 & 45 & 1 & 0 & \\
\hline Bkg 1 & -20 & 60 & 1 & 0 & \\
\hline Bkg 1 & -25 & 0 & 1 & 1,086 & $\begin{array}{l}25 \mathrm{~m} \text { behind firing pad } 10 \text {, edge of } \\
\text { forest }\end{array}$ \\
\hline Bkg 1 & -25 & 0 & 2 & 0 & \\
\hline Bkg 1 & -25 & 0 & 3 & 1,085 & \\
\hline Bkg 1 & -25 & 3 & 1 & 397 & \\
\hline Bkg 1 & -25 & 12 & 1 & 0 & \\
\hline
\end{tabular}


TABLE 9 (Cont.)

\begin{tabular}{cccccc}
\hline Transect & $\begin{array}{c}\text { Locationa } \\
(\mathrm{m})\end{array}$ & $\begin{array}{c}\text { Depth } \\
(\mathrm{cm})\end{array}$ & $\begin{array}{c}\text { Replicate } \\
\text { Number }\end{array}$ & $\begin{array}{c}\mathrm{Pb} \\
\text { Reading } \\
\left(\mathrm{mg} \mathrm{kg}^{-1}\right)\end{array}$ & Notes \\
\hline Bkg 1 & -28 & 0 & 1 & 0 & $\begin{array}{l}28 \mathrm{~m} \text { behind firing pad 10, edge of } \\
\text { forest } \\
\text { Bkg } 1\end{array}$ \\
\hline
\end{tabular}

a Distance from starting point of transect.

b $\mathrm{Pb}$ reading of zero indicates concentration below detection limit.

c Bkg = background sample. 
resulted in mixing the small lead particles and the lead-contaminated soil into the berm during the 15 years that Range 124 has been used for target practice. The use of high-velocity ammunition also may account for the high surface readings and low subsurface readings at Range 124.

The 66 individual XRF readings taken at Range 111, including the replicate readings made at four locations, are listed in Table 10. Distribution of the magnitude of the readings from the 62 different locations and depths is as follows: $60(97 \%)$ were at background level, $2(3 \%)$ were between category $B$ and category $C$ values, and no readings were higher than $600 \mathrm{mg} \mathrm{kg}^{-1}$ (category $\mathrm{C}$ value). Because only two values were above background levels, no defined lead contamination pattern can be established at Range 111.

\subsection{Primary Sample Analytical Results}

\subsubsection{Heavy Motals in Solls}

One objective of this investigation was to assess the degree of heavy-metal contamination in the soils of the three ranges sampled at GTA. Analytical results from the initial soil samples (collected in April 1992) showed that lead and several other heavy metals are present in abovenormal concentrations on all three ranges (Table 5). In July 1992, the primary samples were collected from selected areas of each of the three ranges and analyzed using both the ICP-AES and TCLP methods to provide data on the degree of heavy-metal contamination. Results of the ICP-AES analyses are given in Table 11, and results of the TCLP analyses are shown in Table 12 .

ICP-AES analytical results from Range 122 samples are similar to the analytical results of the initial Range 122 soil samples listed in Table 5. Except for copper and lead, concentrations of the heavy metals are lower than their respective Dutch List category B values. Several samples from the berm face (transect 4) have lead levels greater than $600 \mathrm{mg} \mathrm{kg}^{-1}$ and copper concentrations higher than $500 \mathrm{mg} \mathrm{kg}^{-1}$, the category $\mathrm{C}$ values. Several other samples have both lead and copper concentrations between the category $B$ and category $C$ values. These abovenormal levels of lead and copper were not unexpected, because some handgun ammunition used at this range consists of copper-jacketed lead slugs, and many slugs of this type were observed on the soil surface at Range 122. The TCLP data for Range 122 samples (Table 12) show that concentrations of heavy metals, except for lead, are below the TCLP limits (Table 4) and confirm the results of the initial TCLP results listed in Table 6 . The two berm samples with lead levels above the 5-mg L-1 TCLP limit also had high ICP-AES values.

ICP-AES and TCLP data and the XRF readings for Range 122 show elevated lead levels in samples at some surface locations. Analytical results from both the initial and the primary sample collections show elevated levels of copper in the same samples, but other heavy-metal concentrations are within the normal range for soil. The XRF readings show that the lead 
TABLE 10 X-Ray Fluorescence Readings Taken at Range 111 at GTA during July 1992

\begin{tabular}{|c|c|c|c|c|c|}
\hline Transect & $\begin{array}{l}\text { Locationa } \\
\text { (m) }\end{array}$ & $\begin{array}{l}\text { Depth } \\
(\mathrm{cm})\end{array}$ & $\begin{array}{c}\text { Replicate } \\
\text { Number }\end{array}$ & $\begin{array}{c}\mathrm{Pb} \\
\text { Reading } \\
\left(\mathrm{mg} \mathrm{kg}{ }^{-1}\right)\end{array}$ & Notes \\
\hline 1 & 1 & 0 & 1 & 0 & Top of berm in front of bunker \\
\hline 1 & 1 & 0 & 1 & 12 & \\
\hline 1 & 5 & 0 & 1 & 135 & \\
\hline 1 & 10 & 0 & 1 & 38 & \\
\hline 1 & 15 & 0 & 1 & 0 & \\
\hline 1 & 20 & 0 & 1 & 0 & Bottom of crater \\
\hline 1 & 25 & 0 & 1 & 349 & \\
\hline 1 & 25 & 20 & 1 & 0 & \\
\hline 1 & 30 & 0 & 1 & 72 & \\
\hline 1 & 35 & 0 & 1 & 0 & \\
\hline 1 & 40 & 0 & 1 & 0 & \\
\hline 1 & 45 & 0 & 1 & 114 & \\
\hline 1 & 49 & 10 & 1 & 0 & Top of berm \\
\hline 2 & 1 & 0 & 1 & 12 & Top of berm in front of bunker \\
\hline 2 & 5 & 0 & 1 & 0 & \\
\hline 2 & 10 & 0 & 1 & 132 & \\
\hline 2 & 15 & 0 & 1 & 14 & \\
\hline 2 & 20 & 0 & 1 & 0 & \\
\hline 2 & 25 & 0 & 1 & 80 & \\
\hline 2 & 30 & 0 & 1 & 0 & \\
\hline 2 & 35 & 0 & 1 & 197 & \\
\hline 2 & 40 & 0 & 1 & 15 & \\
\hline 2 & 45 & 0 & 1 & 41 & \\
\hline 2 & 48.5 & 0 & 1 & 0 & Top of berm \\
\hline 3 & 0 & 10 & 1 & 0 & Top of berm \\
\hline 3 & 5 & 0 & 1 & 6 & \\
\hline 3 & 10 & 0 & 1 & 0 & \\
\hline 3 & 10 & 15 & 1 & 0 & \\
\hline 3 & 15 & 0 & 1 & 0 & \\
\hline 3 & 15 & 0 & 2 & 0 & \\
\hline 3 & 25 & 0 & 1 & 80 & \\
\hline 3 & 25 & 0 & 2 & 107 & \\
\hline 3 & 25 & 15 & 1 & 0 & \\
\hline 3 & 30 & 0 & 1 & 0 & \\
\hline 3 & 35 & 0 & 1 & 51 & \\
\hline 3 & 40 & 0 & 1 & 0 & \\
\hline 3 & 45 & 0 & 1 & 0 & \\
\hline 3 & 50 & 0 & 1 & 21 & \\
\hline 3 & 50 & 0 & 2 & 0 & \\
\hline 3 & 55 & 0 & 1 & 0 & \\
\hline 3 & 60 & 0 & 1 & 145 & \\
\hline 3 & 65 & 0 & 1 & 0 & \\
\hline 3 & 73.5 & 0 & 1 & 0 & Top of berm \\
\hline
\end{tabular}


TABLE 10 (Cont.)

\begin{tabular}{|c|c|c|c|c|c|}
\hline Transect & $\begin{array}{l}\text { Location }^{a} \\
(\mathrm{~m})\end{array}$ & $\begin{array}{l}\text { Depth } \\
(\mathrm{cm})\end{array}$ & $\begin{array}{l}\text { Replicate } \\
\text { Number }\end{array}$ & $\begin{array}{c}\mathrm{Pb} \\
\text { Reading } \\
\left(\mathrm{mg} \mathrm{kg}^{-1}\right)\end{array}$ & Notes \\
\hline 4 & 0 & 10 & 1 & 0 & Top of berm \\
\hline 4 & 5 & 0 & 1 & 0 & \\
\hline 4 & 10 & 0 & 1 & 50 & \\
\hline 4 & 15 & 0 & 1 & 0 & \\
\hline 4 & 20 & 0 & 1 & 0 & \\
\hline 4 & 20 & 15 & 1 & 0 & \\
\hline 4 & 25 & 0 & 1 & 65 & \\
\hline 4 & 30 & 0 & 1 & 0 & Top of ridge through open area \\
\hline 4 & 36 & 0 & 1 & 0 & \\
\hline 4 & 40 & 0 & 1 & 0 & \\
\hline 4 & 40 & 10 & 1 & 0 & \\
\hline 4 & 45 & 0 & 1 & 0 & \\
\hline 4 & 45 & 0 & 2 & 0 & \\
\hline 4 & 55 & 0 & 1 & 0 & \\
\hline 4 & 60 & 0 & 1 & 0 & \\
\hline 4 & 65 & 0 & 1 & 8 & \\
\hline 4 & 70 & 0 & 1 & 0 & \\
\hline 4 & 75 & 0 & 1 & 0 & Top of berm \\
\hline $\mathrm{Bkg}^{\mathrm{C}} 1$ & -20 & 13 & 1 & 0 & $20 \mathrm{~m}$ from top of berm \\
\hline Bkg 1 & -34 & 20 & 1 & 118 & $34 \mathrm{~m}$ from top of berm \\
\hline Bkg 2 & 78 & 12 & 1 & 0 & $31 \mathrm{~m}$ from top of berm \\
\hline Bkg 3 & -30 & 8 & 1 & 0 & $30 \mathrm{~m}$ from top of berm \\
\hline Bkg 4 & 92 & 10 & 1 & 0 & $20 \mathrm{~m}$ from top of berm \\
\hline
\end{tabular}

Distance from starting point of transect.

b $\mathrm{Pb}$ reading of zero indicates concentration below detection limit.

${ }^{c}$ Bkg = background sample. 
TABLE 11 Heavy-Metal Concentrations Determined by the ICP-AES Method for Soils Collected at GTA during July 1992

\begin{tabular}{|c|c|c|c|c|c|c|c|c|c|c|c|c|c|}
\hline \multirow[b]{2}{*}{ Range } & \multirow[b]{2}{*}{ Transect } & \multirow[b]{2}{*}{$\begin{array}{l}\text { Location }^{a} \\
\text { (m) }\end{array}$} & \multirow[b]{2}{*}{$\begin{array}{l}\text { Depth } \\
(\mathrm{cm})\end{array}$} & \multicolumn{10}{|c|}{ Heavy Metal Concentration (mg kg-1) } \\
\hline & & & & As & $\mathrm{Ba}$ & Cd & $\mathrm{Cr}$ & Co & $\mathrm{Cu}$ & $\mathbf{P b}$ & $\mathbf{N i}$ & Sn & Zn \\
\hline 122 & 1 & 1 & 0 & $B L^{b}$ & 102 & $\mathrm{BDL}$ & 8.4 & $B D L$ & 152 & 171 & 6.8 & $\mathrm{BDL}$ & 66.8 \\
\hline 122 & 1 & 49 & 0 & BDL & 67.3 & $\mathrm{BDL}$ & 12.2 & 6.3 & 21.7 & 60.6 & 8.2 & $\mathbf{B D L}$ & 39.8 \\
\hline 122 & 1 & 59 & 15 & $\mathrm{BDL}$ & 67.5 & BDL & 10.0 & $B D L$ & 104 & 384 & 5.9 & $\mathrm{BDL}$ & 36.8 \\
\hline 122 & 2 & 15 & 0 & $\mathrm{BDL}$ & 68.9 & $\mathrm{BDL}$ & 9.2 & BDL & 158 & 418 & 5.8 & $\mathrm{BDL}$ & 46.4 \\
\hline 122 & 3 & 110 & 0 & BDL & 68.8 & $\mathrm{BDL}$ & 5.5 & $\mathrm{BDL}$ & 47.8 & 50.0 & 4.7 & $\mathrm{BDL}$ & 24.6 \\
\hline 122 & 4 & 20 & 0 & $\mathrm{BDL}$ & 50.0 & $\mathrm{BDL}$ & 4.9 & $\mathrm{BDL}$ & 104 & 132 & BDL & $B D L$ & 25.0 \\
\hline 122 & 4 & 35 & 0 & $\mathrm{BDL}$ & 46.5 & $\mathrm{BDL}$ & 4.7 & $\mathrm{BDL}$ & 239 & 1,270 & $B D L$ & $\mathrm{BDL}$ & 46.3 \\
\hline 122 & 4 & 50.5 & 0 & $\mathrm{BDL}$ & 51.4 & $\mathrm{BDL}$ & 4.4 & $\mathrm{BDL}$ & 346 & 3,000 & $\mathrm{BDL}$ & $\mathrm{BDL}$ & 56.2 \\
\hline 122 & 4 & 65.3 & 0 & $B D L$ & 48.4 & $\mathrm{BDL}$ & 4.6 & BDL & 294 & 2,830 & $\mathrm{BDL}$ & $\mathrm{BDL}$ & 47.0 \\
\hline 122 & 4 & 65.3 & 13 & $\mathrm{BDL}$ & 49.1 & $\mathrm{BDL}$ & 6.3 & $\mathrm{BDL}$ & 723 & 1,250 & 5.2 & $B D L$ & 78.8 \\
\hline 122 & $\mathrm{Bkg}^{\mathrm{c}} 1$ & -16.5 & 0 & $\mathrm{BDL}$ & 77.2 & $\mathrm{BDL}$ & 6.0 & $\mathrm{BOL}$ & 16.7 & 31.2 & 3.5 & $\mathrm{BDL}$ & 19.1 \\
\hline 122 & Bkg 1 & -16.5 & 30 & $\mathrm{BDL}$ & 70.5 & $\mathrm{BDL}$ & 6.1 & $B D L$ & 17.5 & 35.9 & 4.4 & $\mathrm{BDL}$ & 21.6 \\
\hline 124 & 1 & 1 & 0 & $B D L$ & 225 & $B D L$ & 11.4 & BDL & 155 & 257 & 11.5 & BDL & 56.7 \\
\hline 124 & 1 & 25 & 0 & $B D L$ & 37.7 & 3.5 & 8.0 & $\mathrm{BDL}$ & 283 & 47,200 & 6.0 & $\mathrm{BDL}$ & 68.6 \\
\hline 124 & 1 & 35 & 30 & $\mathrm{BDL}$ & 45.3 & BDL & 7.7 & $\mathrm{BDL}$ & 593 & 8,540 & 5.3 & BDL & 151 \\
\hline 124 & 1 & 36 & 45 & $B D L$ & 38.6 & 1.2 & 8.4 & BDL & 406 & 7,570 & 5.7 & $\mathrm{BDL}$ & 140 \\
\hline 124 & 1 & 39 & 15 & $B D$ & 39.4 & 1.2 & 4.2 & $B D L$ & 511 & 14,800 & $\mathrm{BDL}$ & $B D L$ & 109 \\
\hline 124 & 2 & 5 & 0 & $\mathrm{BDL}$ & 107 & 0.93 & 19.0 & 6.9 & 276 & 650 & 20.1 & $\mathrm{BDL}$ & 90.4 \\
\hline 124 & 4 & 16.5 & 0 & 23.3 & 832 & $\mathrm{BDL}$ & 23.4 & 9.9 & 1,060 & 1,780 & 30.6 & $\mathrm{BDL}$ & 232 \\
\hline 124 & 4 & 57 & 0 & $\mathrm{BDL}$ & 57.0 & BDL & 13.5 & $\mathrm{BDL}$ & 33.1 & 366 & 12.6 & $B D L$ & 43.2 \\
\hline 124 & 6 & 5.5 & 0 & $B D L$ & 40.9 & BDL & 9.6 & BDL & 357 & 5,080 & 10.4 & $\mathrm{BDL}$ & 65.4 \\
\hline 124 & 7 & 36 & 0 & 34.5 & 49.1 & $B D L$ & 7.6 & BOL & 458 & 11,090 & 9.9 & $\mathrm{BDL}$ & 95.8 \\
\hline 124 & 7 & 36 & 15 & $B D L$ & 46.1 & 1.1 & 7.9 & $B D L$ & 5,460 & 10,400 & 8.4 & $B D L$ & 574 \\
\hline 124 & 7 & 51 & 0 & 39.2 & 41.2 & 2.6 & 7.5 & $\mathrm{BOL}$ & 685 & 31,800 & 4.5 & $\mathrm{BDL}$ & 144 \\
\hline 124 & Bkg 1 & -20 & 0 & $B D$ & 56.2 & BDL & 19.4 & 7.9 & 20.5 & 235 & 20.3 & $\mathrm{BDL}$ & 60.1 \\
\hline 124 & Bkg 1 & -20 & 45 & $\mathrm{BDL}$ & 48.5 & $\mathrm{BDL}$ & 11.1 & BDL & 7.4 & 100 & 7.6 & $\mathrm{BDL}$ & 32.9 \\
\hline
\end{tabular}


TABLE 11 (Cont.)

\begin{tabular}{|c|c|c|c|c|c|c|c|c|c|c|c|c|c|}
\hline \multirow[b]{2}{*}{ Range } & \multirow[b]{2}{*}{ Transect } & \multirow[b]{2}{*}{$\begin{array}{l}\text { Location }{ }^{a} \\
(\mathrm{~m})\end{array}$} & \multirow[b]{2}{*}{$\begin{array}{l}\text { Depth } \\
(\mathrm{cm})\end{array}$} & \multicolumn{10}{|c|}{ Heavy Metal Concentration (mg kg ${ }^{-1}$ ) } \\
\hline & & & & As & $\mathrm{Ba}$ & Cd & $\mathrm{Cr}$ & $\infty$ & $\mathrm{Cu}$ & $\mathbf{P b}$ & $\mathrm{Ni}$ & Sn & Zn \\
\hline 111 & 1 & 25 & 0 & 46.7 & 108 & 27.5 & SPOLd & SPOL & 248 & 123 & 53.3 & 24.2 & 1,830 \\
\hline 111 & 1 & 49 & 0 & $\mathrm{BDL}^{\mathrm{b}}$ & 73.1 & 6.0 & 22.3 & $\mathrm{BOL}$ & 65.8 & 81.2 & 25.0 & $\mathrm{BOL}$ & 2,070 \\
\hline 111 & 2 & 20 & 0 & $\mathrm{BDL}$ & 118 & 38.5 & 54.1 & 12.6 & 326 & 110 & 61.5 & $\mathrm{BDL}$ & 2,300 \\
\hline 111 & 2 & 25 & 0 & 31.5 & 82.1 & 131 & SPOL & SPOL & 633 & 108 & 36.0 & 30.4 & 566 \\
\hline 111 & 2 & 48.5 & 0 & $\mathrm{BDL}$ & 37.8 & $\mathrm{BDL}$ & 7.2 & $\mathrm{BDL}$ & 11.0 & 22.2 & 6.2 & $\mathrm{BOL}$ & 56.2 \\
\hline 111 & 3 & 0 & 0 & 91.3 & BDL & 37.2 & SPOL & SPOL & 241 & 71.7 & 64.1 & 29.0 & 978 \\
\hline 111 & 3 & 10 & 0 & 23.2 & 128 & 18.9 & 88.5 & 25.4 & 199 & 92 & 80.9 & $\mathrm{BDL}$ & 1,020 \\
\hline 111 & 3 & 10 & 15 & $\mathrm{BDL}$ & 89.0 & 12.2 & 32.7 & 6.9 & 388 & 68.1 & 34.4 & $\mathrm{BOL}$ & 865 \\
\hline 111 & 3 & 25 & 0 & 57.1 & 102 & 46.0 & SPOL & SPO & 331 & 142 & 53.8 & 67.7 & 1,990 \\
\hline 111 & 3 & 25 & 15 & $\mathrm{BOL}$ & 64.8 & 10.2 & 57.8 & 13.5 & 586 & 56.9 & 54.9 & $\mathrm{BDL}$ & 791 \\
\hline 111 & 3 & 35 & 0 & 61.5 & 92.7 & 144 & SPOL & SPOL & 417 & 143 & 48.6 & 33.1 & 1,110 \\
\hline 111 & 3 & 50 & 0 & 49.4 & 106 & 36.1 & SPOL & SPOL & 324 & 138 & 55.2 & 25.4 & 1,680 \\
\hline 111 & 3 & 60 & 0 & 28.4 & 250 & 66.0 & SPOL & SPOL & 272 & 161 & 33.0 & 31.6 & 525 \\
\hline 111 & 3 & 73.5 & 0 & $\mathrm{BDL}$ & 29.3 & $\mathrm{BDL}$ & 7.8 & $\mathrm{BDL}$ & 6.6 & $\mathrm{BDL}$ & 5.4 & $\mathrm{BDL}$ & 24.4 \\
\hline 111 & 4 & 0 & 10 & $\mathrm{BDL}$ & 40.0 & $\mathrm{BDL}$ & 10.5 & $\mathrm{BDL}$ & 16.4 & 40.7 & 7.5 & BDL & 46.8 \\
\hline 111 & 4 & 20 & 0 & 48.8 & 103 & 58.6 & SPOL & SPO & 436 & 156 & 52.7 & 30.8 & 1,790 \\
\hline 111 & 4 & 20 & 15 & $\mathrm{BDL}$ & 142 & 22.8 & 30.5 & $\mathrm{BOL}$ & 264 & 85.4 & 38.6 & $\mathrm{BDL}$ & 1,600 \\
\hline 111 & 4 & 40 & 0 & $\mathrm{BDL}$ & 86.2 & 96.1 & 27.8 & $\mathrm{BDL}$ & 288 & 104 & 29.6 & $\mathrm{BDL}$ & 558 \\
\hline 111 & 4 & 40 & 10 & $\mathrm{BDL}$ & 79.0 & 1.4 & 7.7 & $B D L$ & 11.4 & 110 & 10.0 & $B D L$ & 60.6 \\
\hline 111 & 4 & 45 & 0 & 45.5 & 99.8 & 128 & SPOL & SPOL & 566 & 123 & 38.2 & 21.6 & 650 \\
\hline 111 & 4 & 60 & 0 & 32.5 & 118 & 60.1 & SPOL & SPO & 481 & 135 & 42.3 & $\mathrm{BDL}$ & 818 \\
\hline 111 & 4 & 75 & 0 & 19.2 & 28.4 & $\mathrm{BDL}$ & SPOL & SPOL & 6.4 & 29.3 & 5.8 & $\mathrm{BDL}$ & 25.1 \\
\hline 111 & Bkg 1 & -20 & 13 & $\mathrm{BDL}$ & 27.0 & $\mathrm{BDL}$ & 6.8 & $\mathrm{BDL}$ & 1.6 & BDL & 6.0 & $\mathrm{BDL}$ & 24.2 \\
\hline 111 & Bkg 2 & 78 & 12 & 23.4 & 29.1 & $\mathrm{BDL}$ & SPOL & SPOL & 5.6 & 27.4 & 6.3 & $B D L$ & 30.5 \\
\hline 111 & Bkg 3 & -30 & 8 & $\mathrm{BDL}$ & 20.5 & $\mathrm{BDL}$ & 8.1 & $\mathrm{BDL}$ & 4.0 & 29.4 & 5.3 & $\mathrm{BDL}$ & 25.1 \\
\hline 111 & Bkg 4 & 92 & 10 & $\mathrm{BDL}$ & 19.9 & $\mathrm{BDL}$ & 5.3 & $\mathrm{BOL}$ & 8.2 & 25.0 & 4.0 & $\mathrm{BDL}$ & 28.2 \\
\hline
\end{tabular}


TABLE 11 (Cont.)

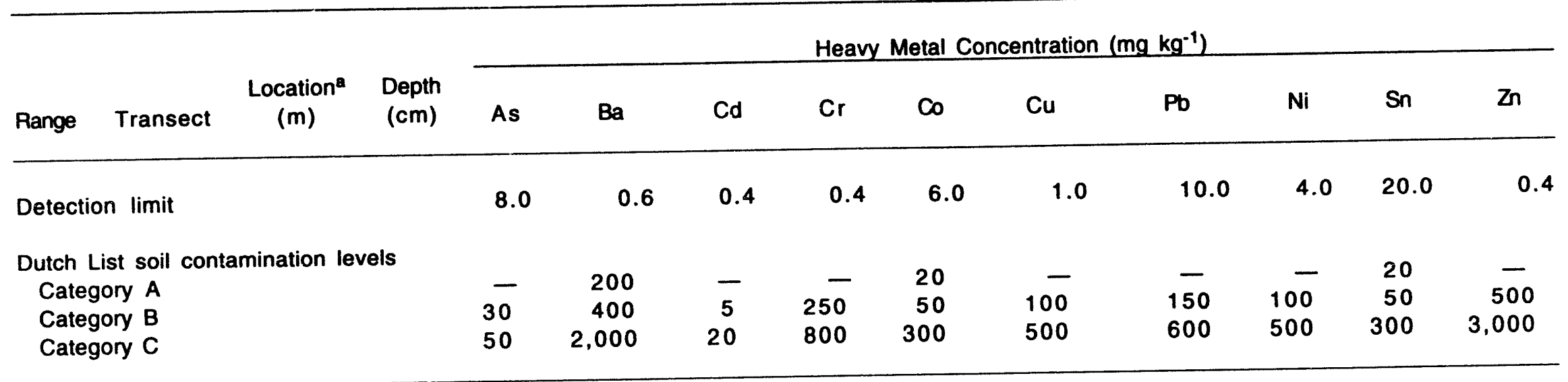

a Distance from starting point of transect.

b $\mathrm{BDL}=$ below detection limit.

${ }^{c} B k g=$ background sample.

d SPOL $=$ spike recovery outside limits of 75 to $125 \%$. 
TABLE 12 Heavy-Metal Concentrations Determined by the TCLP Method for Soils Collected at GTA during July 1992

\begin{tabular}{|c|c|c|c|c|c|c|c|c|c|c|}
\hline \multirow[b]{2}{*}{ Range } & \multirow[b]{2}{*}{ Transect } & \multirow[b]{2}{*}{$\begin{array}{l}\text { Location }^{a} \\
(m)\end{array}$} & \multirow[b]{2}{*}{$\begin{array}{l}\text { Depth } \\
(\mathrm{cm})\end{array}$} & \multicolumn{7}{|c|}{ Heavy Metal Concentration (mg L L-1) } \\
\hline & & & & $\mathrm{Ba}$ & Cd & $\mathrm{Cr}$ & $\mathrm{Cu}$ & $\mathrm{Pb}$ & Sn & Zn \\
\hline 122 & 4 & 20 & 0 & 2.12 & $B D L^{b}$ & BDL & 0.43 & 1.22 & BDL & 0.03 \\
\hline 122 & 4 & 65.3 & 0 & 6.26 & BDL & $\mathrm{BDL}$ & 1.72 & 68.1 & BDL & 0.19 \\
\hline 122 & 4 & 65.3 & 13 & 2.80 & $\mathrm{BDL}$ & $B D L$ & 7.32 & 17.3 & $B D L$ & 0.54 \\
\hline 122 & $B k g^{c} 1$ & -16.5 & 30 & 1.15 & $B D L$ & $B D L$ & $\mathrm{BCL}$ & $\mathrm{BDL}$ & $\mathrm{BDL}$ & $\mathrm{BDL}$ \\
\hline 124 & 1 & 1 & 0 & 38.1 & $\mathrm{BDL}$ & $\mathrm{BDL}$ & 0.73 & 2.37 & 2.66 & 0.40 \\
\hline 124 & 1 & 25 & 0 & 32.0 & $\mathrm{BDL}$ & $\mathrm{BDL}$ & 1.53 & 150 & $\mathrm{BDL}$ & 0.24 \\
\hline 124 & 1 & 45 & 45 & 30.8 & BDL. & BDL & 5.35 & 326 & 2.65 & 1.63 \\
\hline 124 & 3 & 20 & 0 & 54.7 & $B D L$ & $B D L$ & $B D L$ & 1.16 & 2.69 & 0.08 \\
\hline 124 & 4 & 57 & 0 & 19.5 & $\mathrm{BDL}$ & $\mathrm{BDL}$ & $\mathrm{BDL}$ & 1.06 & $B D L$ & $<.01$ \\
\hline 124 & 7 & 49 & 0 & 34.6 & $\mathrm{BDL}$ & $\mathrm{BDL}$ & 4.39 & 513 & BDL & 0.76 \\
\hline 111 & 1 & 25 & 0 & 23.8 & 0.47 & BDL & 0.31 & 0.56 & 1.60 & 16.6 \\
\hline 111 & 1 & 49 & 10 & 23.6 & 0.09 & BOL & 0.05 & $B D L$ & $B D L$ & 19.9 \\
\hline 111 & 2 & 25 & 0 & 20.6 & 2.54 & $B D L$ & 0.46 & $B D L$ & 1.55 & 18.66 \\
\hline 111 & 2 & 48.5 & 0 & 3.62 & $B D L$ & $\mathrm{BDL}$ & $\mathrm{BDL}$ & $\mathrm{BDL}$ & $B D L$ & 1.086 \\
\hline 111 & 3 & 0 & 10 & 21.0 & 0.26 & $\mathrm{BDL}$ & 0.08 & BDL & 1.64 & 23.6 \\
\hline 111 & 3 & 10 & 0 & 24.0 & 0.28 & BDL & 0.19 & 0.56 & 1.54 & 11.0 \\
\hline 111 & 3 & 10 & 10 & 25.0 & 0.17 & $\mathrm{BDL}$ & 0.28 & $\mathrm{BDL}$ & 1.53 & 7.00 \\
\hline 111 & 3 & 25 & 0 & 35.4 & 1.18 & $B D L$ & 1.11 & 1.03 & 3.39 & 42.1 \\
\hline 111 & 3 & 25 & 15 & 79.1 & 0.13 & $B D L$ & 0.10 & 0.88 & 3.28 & 8.20 \\
\hline 111 & 3 & 35 & 0 & 35.7 & 0.50 & BDL & 1.57 & 1.00 & 2.65 & 41.5 \\
\hline 111 & 3 & 50 & 0 & 24.3 & 2.07 & $B D L$ & 4.32 & $\mathrm{BOL}$ & 2.14 & 8.61 \\
\hline 111 & 3 & 60 & 0 & 23.2 & 1.10 & $B D L$ & 0.30 & $\mathrm{BDL}$ & $B D L$ & 3.35 \\
\hline 111 & 3 & 73.5 & 0 & 1.59 & $\mathrm{BDL}$ & $\mathrm{BDL}$ & $\mathrm{BDL}$ & $\mathrm{BOL}$ & $\mathrm{BOL}$ & 0.13 \\
\hline 111 & 4 & 0 & 10 & 5.65 & $B D$ & $\mathrm{BDL}$ & $B D L$ & $\mathrm{BDL}$ & $B D L$ & 0.22 \\
\hline 111 & 4 & 20 & 0 & 23.6 & 0.47 & $\mathrm{BDL}$ & 0.27 & $\mathrm{BDL}$ & 1.51 & 18.3 \\
\hline 111 & 4 & 20 & 15 & 27.1 & 0.32 & $\mathrm{BDL}$ & 0.38 & 0.59 & 1.66 & 14.9 \\
\hline 111 & 4 & 40 & 0 & 23.0 & 1.13 & BDL & 0.25 & $\mathrm{BDL}$ & 1.20 & 2.13 \\
\hline 111 & 4 & 45 & 0 & 23.6 & 2.86 & $\mathrm{BDL}$ & 0.57 & $B D L$ & 1.69 & 3.18 \\
\hline 111 & 4 & 60 & 0 & 23.0 & 0.91 & $\mathrm{BDL}$ & 0.46 & $\mathrm{BDL}$ & 1.36 & 5.15 \\
\hline 111 & 4 & 75 & 0 & 0.56 & $\mathrm{BDL}$ & $\mathrm{BDL}$ & $\mathrm{BDL}$ & $\mathrm{BDL}$ & $\mathrm{BDL}$ & 0.01 \\
\hline 111 & Bkg 1 & -20 & 13 & 0.71 & $\mathrm{BDL}$ & $\mathrm{BDL}$ & $\mathrm{BDL}$ & $\mathrm{BDL}$ & 1.95 & 0.03 \\
\hline 111 & Bkg 1 & -34 & 20 & 0.32 & $\mathrm{BDL}$ & $B D L$ & $\mathrm{BDL}$ & $\mathrm{BDL}$ & $\mathrm{BDL}$ & 0.04 \\
\hline 111 & Bkg 2 & 78 & 12 & 1.87 & $\mathrm{BDL}$ & $\mathrm{BDL}$ & $\mathrm{BDL}$ & $\mathrm{BDL}$ & $\mathrm{BDL}$ & $\mathrm{BDL}$ \\
\hline 111 & Bkg 3 & -30 & 8 & 0.31 & $\mathrm{BDL}$ & $\mathrm{BDL}$ & $\mathrm{BDL}$ & $\mathrm{BDL}$ & $\mathrm{BDL}$ & $\mathrm{BDL}$ \\
\hline 111 & Bkg 4 & 92 & 10 & 2.43 & $B D L$ & $B D L$ & 0.04 & $B O L$ & BDL & 0.07 \\
\hline \multicolumn{2}{|c|}{ Detection limit } & & & 0.25 & 0.05 & 0.15 & 0.02 & 0.50 & 1.00 & 0.02 \\
\hline \multicolumn{2}{|c|}{ TCLP limit } & & & 100.0 & 0.5 & 5.0 & - & 5.0 & - & - \\
\hline
\end{tabular}

a Distance from starting point of transect.

${ }^{b} \mathrm{BDL}=$ below detection limit.

${ }^{c}$ Bkg = background sample. 
contamination is limited to the surface soil, and most of the XRF readings that were higher than $600 \mathrm{mg} \mathrm{kg}^{-1}$ were on the face of the berm. These data suggest that the berm surface soil at Range 122 has lead and possibly copper levels that exceed the regulatory limits. These data also suggest that the lead and potential copper contamination are generally limited to the upper $15 \mathrm{~cm}$ of soil at Range 122. The absence of high concentrations of lead, copper, and other heavy metals below the soil surface suggests that heavy metals are not being leached through or to the lower levels of the soil profile.

Data from ICP-AES and TCLP analyses and XRF readings from Range 124 show that the soil in the berm and surface soil are contaminated with lead. Results of the ICP-AES analyses given in Table 11 show that most of the soil samples from Range 124, including those collected from the trench wall, have lead concentrations higher than the $600 \mathrm{mg} \mathrm{kg}^{-1}$ Dutch List category C value. Several of these same samples have copper levels that are also higher than the category $C$ value of $500 \mathrm{mg} \mathrm{kg}^{-1}$. Many samples with lead and copper levels lower than the category $\mathrm{C}$ value have concentrations that are higher than the category $B$ value. This result suggests that the surface soil and the soil making up the berm is contaminated to some degree with lead and copper. Several samples also have concentrations of arsenic, barium, and zinc that are between the respective category $C$ and category $B$ values. These results are similar to the ICP-AES results from the initial sample collection given in Table 5. TCLP analytical results from Range 124 samples listed in Table 12 show that the levels of heavy metals, except lead, are below the TCLP limits (Table 4). This is consistent with the TCLP data from the initial sample collection that were presented in Table 6 . Heavy-metal contamination to a depth of $75 \mathrm{~cm}$ in the berm is probable because of repeated soil mixing during regular berm maintenance activities. This contamination may be due to disintegration of slugs from high-velocity ammunition. Contamination is probably limited to the upper $15 \mathrm{~cm}$ of soil, because elevated levels of lead and other heavy metals were not observed below the $15-\mathrm{cm}$ depth in the open area of the range. This result suggests that heavy metals are not being leached through or into the lower soil profile.

Review of ICP-AES analytical results from Range 111 samples (Table 11) shows that the concentration of cadmium in a number of samples is higher than the $20 \mathrm{mg} \mathrm{kg}^{-1}$ Dutch List category $\mathrm{C}$ value. Most of the other samples analyzed have cadmium levels higher than the $5 \mathrm{mg} \mathrm{k}_{5}^{-1}$ category B value. Several samples also have arsenic levels higher than the $50 \mathrm{mg} \mathrm{kg}^{-1}$ category $\mathrm{C}$ value and copper concentrations greater than the $500 \mathrm{mg} \mathrm{kg}^{-1}$ category $C$ value. Several additional samples have arsenic, copper, and zinc levels between the category $B$ and category $C$ values. Unlike the other two ranges, Range 111 had only two samples with lead levels higher than the $150 \mathrm{mg} \mathrm{kg}^{-1}$ category B value. These analytical results are similar to the analytical results for the initial samples given in Table 5, except that arsenic is present in elevated concentrations in the primary (July) collection. The TCLP results for samples from Range 111 (Table 12) show that cadmium is present at higher than the $0.5 \mathrm{mg} \mathrm{L}^{-1}$ TCLP limit (Table 4) in five samples. These results are imilar to results from the initial TCLP sample analyses listed in Table 6. The high TCLP values show that a portion of the cadmium at such high soil concentrations can be leached from the soil with simulated rainwater. These data also show that heavy metals are in both surface and subsurface samples over the open area of Range 111. 


\subsubsection{Heavy Metals in Vegetation}

Analytical results for the vegetation samples collected from the three ranges at GTA are shown in Table 13. Comparison of these values with the normal concentration of heavy metals found in plant leaves (Table 1) shows that the chromium, copper, and zinc concentrations are all within the normal range. Tin levels in the vegetation probably do not pose a problem, because all vegetation samples are below the detection limit. However, an assessment cannot be made because published information is not available on the normal concentration of tin in plants.

A few samples from each of the three ranges show barium levels higher than the expected normal range of $10-100 \mathrm{mg} \mathrm{kg}^{-1}$ in plant leaves. These higher levels may be due to the higher proportion of barium in the soil solution, as suggested by the higher proportion of barium compared with other heavy metals extracted by the TCLP procedure (Table 7). These levels of barium are not considered a concern, because they are only slightly above the normal range in plant leaves.

Lead concentrations for vegetation samples collected on the berm (transect 4) at Range 122 are above the normal range of $0.1-5 \mathrm{mg} \mathrm{kg}^{-1}$ in plant leaves. This above-normal level in vegetation is probably due to the above-normal lead concentration in the berm soils at Range 122. Most of the vegetation samples from Range 124 also have elevated lead levels, which may be due to the generally high lead concentration in the surface soil at Range 124 or to external contamination by surface soil or lead particles.

One-half of the vegetation samples collected at Range 111 have cadmium levels above the normal range of $0.05-0.2 \mathrm{mg} \mathrm{kg}^{-1}$ in plant leaves. These elevated levels of cadmium are consistent with the elevated cadmium levels in the soil at this range. The above-normal levels of cadmium could be from plant uptake or from external contamination from soils.

The intake of lead and cadmium by wildlife is probably not a major concern, because the relatively small amount of vegetation contaminated by these heavy metals and available to wildlife as food is limited. There is abundant uncontaminated vegetation around all the ranges. The intake of contaminated plant material as food is probably only a small portion of the total diet of area wildlife.

\subsubsection{Heavy Metals in Surface Water}

Analytical results of the surface water collected at Ranges 122 and 111 are listed in Table 14. Evaluation of the chromium and lead data with regard to the suggested maximum concentration in drinking water is not possible because the detection limits for these heavy metals are higher than the suggested maximum concentration in drinking water (Table 3). Evaluation of the tin and zinc data is also not possible because maximum safe concentrations have not been established at this time. 
TABLE 13 Heavy-Metal Concentrations in Vegetation Collected at GTA during July 1992

\begin{tabular}{|c|c|c|c|c|c|c|c|c|c|}
\hline \multirow[b]{2}{*}{ Range } & \multirow[b]{2}{*}{ Transect } & \multirow{2}{*}{$\begin{array}{l}\text { Location }^{a} \\
\text { (m) }\end{array}$} & \multicolumn{7}{|c|}{ Heavy Metal Concentration (mg kg-1) } \\
\hline & & & $\mathrm{Ba}$ & $\mathrm{Cd}$ & $\mathrm{Cr}$ & $\mathrm{Cu}$ & $\mathrm{Pb}$ & Sn & Zn \\
\hline 122 & 1 & 49 & 115 & 0.04 & $B D L^{b}$ & 1.71 & 2.73 & $\mathrm{BDL}$ & 10.3 \\
\hline 122 & 1 & 63 & 26.9 & BDL & BDL & 0.60 & 2.23 & BDL & 4.96 \\
\hline 122 & 2 & 61 & 31.5 & $\mathrm{BDL}$ & 0.55 & 1.06 & 2.56 & $\mathrm{BDL}$ & 12.5 \\
\hline 122 & 4 & 20 & 30.7 & $\mathrm{BDL}$ & 0.20 & 0.67 & 11.16 & $\mathrm{BDL}$ & 4.19 \\
\hline 122 & 4 & 50.5 & 80.4 & 0.04 & $\mathrm{BDL}$ & 1.67 & 20.57 & $B D L$ & 5.19 \\
\hline 122 & 4 & 65.3 & 35.3 & 0.02 & $\mathrm{BDL}$ & 1.58 & 31.36 & $\mathrm{BDL}$ & 3.77 \\
\hline 122 & 4 & 130 & 35.6 & 0.07 & $\mathrm{BDL}$ & 0.73 & 6.69 & $\mathrm{BDL}$ & 7.61 \\
\hline 122 & $\mathrm{Bkg}^{\mathrm{c}} 1$ & -16.5 & 84.8 & 0.02 & $\mathrm{BDL}$ & 0.49 & 1.24 & $\mathrm{BDL}$ & 1.71 \\
\hline 124 & 1 & 1 & 97.2 & 0.08 & 0.32 & 7.33 & 29.50 & $B D L$ & 10.1 \\
\hline 124 & 1 & 36 & 225 & 0.08 & 0.26 & 5.25 & 90.98 & BDL & 9.19 \\
\hline 124 & 1 & 39 & .70 .6 & 0.04 & 0.26 & 1.02 & 40.90 & $B D L$ & 4.75 \\
\hline 124 & 2 & 1.5 & 69.3 & $\mathrm{BDL}$ & 0.31 & 1.30 & 13.63 & $\mathrm{BDL}$ & 2.70 \\
\hline 124 & 4 & 0 & 39.5 & $\mathrm{BDL}$ & $\mathrm{BDL}$ & 0.48 & 0.74 & $\mathrm{BDL}$ & 1.82 \\
\hline 124 & 4 & 51 & 123 & 0.02 & 0.14 & 0.84 & 4.15 & $\mathrm{BDL}$ & 3.89 \\
\hline 124 & 7 & 51 & 149 & 0.06 & 0.20 & 2.01 & 66.44 & $\mathrm{BDL}$ & 8.00 \\
\hline 124 & Bkg 1 & -16.5 & 60.4 & $\mathrm{BDL}$ & 0.30 & 1.21 & 26.51 & $\mathrm{BDL}$ & 2.98 \\
\hline 111 & 1 & 49 & 130 & 0.04 & 0.20 & 1.19 & 4.96 & $\mathrm{BDL}$ & 3.52 \\
\hline 111 & 3 & 0 & 47.1 & 0.97 & 0.22 & 0.97 & 0.87 & $\mathrm{BDL}$ & 5.49 \\
\hline 111 & 3 & 60 & 44.8 & 1.04 & $\mathrm{BDL}$ & 4.46 & 1.24 & BDL & 17.0 \\
\hline 111 & 4 & 0 & 36.2 & 0.17 & $\mathrm{BDL}$ & 0.90 & 0.74 & $\mathrm{BDL}$ & 5.78 \\
\hline 111 & 4 & 60 & 73.9 & 2.49 & 0.31 & 4.00 & 2.97 & $B D L$ & 13.7 \\
\hline 111 & 4 & 75 & 110 & 0.60 & 0.31 & 1.72 & 1.49 & $\mathrm{BDL}$ & 8.62 \\
\hline 111 & Bkg 1 & -20 & 111 & 0.14 & 0.39 & 1.12 & 1.74 & $B D L$ & 5.06 \\
\hline 111 & Bkg 2 & 78 & 36.1 & 0.29 & $\mathrm{BDL}$ & 0.98 & 1.20 & $\mathrm{BDL}$ & 3.59 \\
\hline Detection & n limit & & 0.13 & 0.01 & 0.13 & 0.01 & 0.33 & 0.66 & 0.06 \\
\hline
\end{tabular}

a Distance from starting point of transect.

b $\mathrm{BDL}=$ below detection limit.

${ }^{c} \mathrm{Bkg}=$ background sample . 
TABLE 14 Heavy-Metal Concentrations in Surface Water Collected at GTA during July 1992

\begin{tabular}{|c|c|c|c|c|c|c|c|c|c|}
\hline \multirow[b]{2}{*}{ Range } & \multirow[b]{2}{*}{ Transect } & \multirow[b]{2}{*}{$\begin{array}{l}\text { Location }^{\mathrm{a}} \\
(\mathrm{m})\end{array}$} & \multicolumn{7}{|c|}{ Heavy Metal Concentration (mg L-1) } \\
\hline & & & $\mathrm{Ba}$ & Cd & $\mathrm{Cr}$ & $\mathrm{Cu}$ & $\mathrm{Pb}$ & Sn & Zn \\
\hline 122 & 4 & North end of berm & 1.10 & 0.03 & $B D L^{b}$ & $\mathrm{BDL}$ & BDL & BDL & 0.19 \\
\hline 111 & 1 & $32 \mathrm{~m}$ south, $0 \mathrm{~m}$ east & 2.30 & 0.04 & BDL & BDL & BDL & BDL & 0.12 \\
\hline 111 & 2 & $10 \mathrm{~m}$ south, $10 \mathrm{~m}$ east & 3.70 & 0.04 & BDL & BDL & BDL & $\mathrm{BDL}$ & $\mathrm{BDL}$ \\
\hline 111 & 3 & $40 \mathrm{~m}$ west, $4 \mathrm{~m}$ north & 2.20 & 0.05 & $\mathrm{BDL}$ & $\mathrm{BDL}$ & $\mathrm{BDL}$ & $\mathrm{BDL}$ & $\mathrm{BDL}$ \\
\hline 111 & 4 & $36 \mathrm{~m}$ west, $1 \mathrm{~m}$ north & 3.80 & 0.04 & $\mathrm{BDL}$ & BDL & $\mathrm{BDL}$ & $\mathrm{BDL}$ & $\mathrm{BDL}$ \\
\hline 111 & 4 & $50 \mathrm{~m}$ west, $7 \mathrm{~m}$ north & 3.00 & $\mathrm{BDL}$ & $\mathrm{BDL}$ & BDL & $\mathrm{BDL}$ & $\mathrm{BDL}$ & 0.16 \\
\hline 111 & 4 & $44 \mathrm{~m}$ west, $0 \mathrm{~m}$ north & 3.70 & 0.05 & $\mathrm{BDL}$ & $\mathrm{BDL}$ & $\mathrm{BDL}$ & $\mathrm{BDL}$ & BDL \\
\hline \multicolumn{3}{|c|}{ Detection limit } & 0.25 & 0.02 & 0.20 & 0.02 & 0.50 & 1.50 & 0.10 \\
\hline \multicolumn{3}{|c|}{$\begin{array}{l}\text { Suggested maximum concentration } \\
\text { in drinking water }\end{array}$} & - & 0.005 & 0.05 & 1.0 & 0.05 & - & 5.0 \\
\hline
\end{tabular}

a Distance from starting point of transect.

${ }^{b} B D L=$ below detection limit.

Inspection of the analytical data from the surface water at both ranges shows that concentrations of barium and cadmium in all samples exceed the suggested maximum drinkingwater concentrations of $0.05 \mathrm{mg} \mathrm{L}^{-1}$ for barium and $0.005 \mathrm{mg} \mathrm{L}^{-1}$ for cadmium. These results may be due to the extractability of barium and the high concentration of cadmium in the soil at Range 111, but there is no apparent reason for the elevated level of cadmium in the water sample from Range 122.

\subsection{Comparison of X-Ray Fluorescence and Laboratory Analytical Data}

Potential saving of both time and cost can be realized by using the XRF method to measure lead and other heavy-metal contamination at firing ranges. The unit used in this investigation was calibrated by the manufacturer for lead in soil. However, the minimum lead detection limit under field conditions and the variation of XRF lead values over a range of concentrations was not available before this investigation. The comparison of XRF and laboratory analytical data discussed below was undertaken to assess the usefulness of the XRF method in future investigations of this type. 


\subsubsection{Lead Data}

Precision and accuracy are two measures of the quality of analytical data produced by a given method. To provide an estimate of the quality of XRF field measurements, two $750-\mathrm{g}$ samples of soil were collected from Range 124. One sample (No. 1) represented soil with an intermediate XRF lead reading, while the second sample (No. 2) represented soil having a high $\mathrm{XRF}$ reading. These samples were air-dried and homogenized, and eight replicate XRF readings were taken. At ANL, four replicates from each sample were analyzed for lead by the ICP-AES method. The field XRF lead readings and corresponding ICP-AES lead values for the two samples from Range 124 are listed in Table 15.

The accuracy of the XRF method is dependent on the concentration of lead in the soil. The percent relative standard deviation for the XRF readings from sample 1 is about $8 \%$, and for sample 2, approximately $10 \%$, which is a very acceptable level of precision for a field method. One ICP-AES outlier value in each sample may indicate the heterogeneity of fine lead particles in the soil that could result from the uneven distribution of lead particles during the disintegration of the slug on impact. For sample 1, the field XRF mean of $1,200 \mathrm{mg} \mathrm{kg}^{-1}$ and the ICP-AES mean of $1,400 \mathrm{mg} \mathrm{kg}^{-1}$ agree satisfactorily if one ICP-AES outlier data point is excluded from the calculation. For sample 2, with a somewhat high lead level, the XRF mean of $5,050 \mathrm{mg} \mathrm{kg}^{-1}$ is substantially lower than the ICP-AES mean of $8,930 \mathrm{mg} \mathrm{kg}^{-1}$, again with one ICP-AES outlier omitted. The XRF readings are expected to be biased toward lower readings on samples with high

TABLE 15 XRF Lead Readings and Corresponding ICP-AES Lead Values for Two Soil Samples Collected from Range 124 at GTA during July 1992

\begin{tabular}{|c|c|c|c|c|}
\hline \multirow[b]{3}{*}{ Replicate Number } & \multicolumn{4}{|c|}{ Lead Concentration $\left(\mathrm{mg} \mathrm{kg}^{-1}\right)$} \\
\hline & \multicolumn{2}{|c|}{ Sample 1} & \multicolumn{2}{|c|}{ Sample 2} \\
\hline & XRF Reading & ICP-AES Result & XRF Reading & ICP-AES Result \\
\hline 1 & 1,270 & 1,310 & 5,099 & 9,260 \\
\hline 2 & 1,050 & 1,420 & 5,276 & 8,900 \\
\hline 3 & 1,165 & $2,570^{a}$ & 4,086 & $15,100^{a}$ \\
\hline 4 & 1,316 & 1,470 & 5,532 & 8,620 \\
\hline 5 & 1,274 & & 5,159 & \\
\hline 6 & 1,167 & & 5,303 & \\
\hline 7 & 1,158 & & 4,707 & \\
\hline 8 & 1,203 & & 5,211 & \\
\hline Mean & 1,200 & 1,400 & 5,050 & 8,930 \\
\hline Standard Deviation & \pm 100 & \pm 70 & \pm 500 & \pm 270 \\
\hline
\end{tabular}

a Outlier excluded from calculations of mean and standard deviation. 
lead concentrations because the number of fluoresced X-rays absorbed by the lead in the sample increases as the concentration of lead in the sample increases.

The XRF readings at 51 locations in the field were compared with the lead concentrations at the same locations as determined by laboratory ICP-AES analysis (Table 11). Of the 51 pairs, 27 had XRF readings of $0 \mathrm{mg} \mathrm{kg}^{-1}$ compared with a mean lead concentration of $93.7 \mathrm{mg} \mathrm{kg}^{-1} \mathrm{by}$ the ICP-AES method. Of the data pairs with XRF readings of $0 \mathrm{mg} \mathrm{kg}^{-1}$, the lowest corresponding ICP-AES lead concentration was $50 \mathrm{mg} \mathrm{kg}^{-1}$ and the highest was $366 \mathrm{mg} \mathrm{kg}^{-1}$ lead. These results suggest that the limit of detection of the portable XRF unit used in this study for the field conditions at GTA was between about 50 and $400 \mathrm{mg} \mathrm{kg}^{-1}$. This limit of detection was acceptable for measuring lead concentration in this study, because it is below the $600 \mathrm{mg} \mathrm{kg}^{-1}$ Dutch List category $\mathrm{C}$ lead value. However, a lower limit of detection would be desirable.

For the 12 samples having XRF readings between 0 and $600 \mathrm{mg} \mathrm{kg}^{-1}$ lead, only two samples had ICP-AES lead concentrations lower than their XRF readings. Of the ten remaining samples in this XRF range, two had ICP-AES lead values higher than $600 \mathrm{mg} \mathrm{kg}^{-1}$ lead. Of the 12 samples with XRF readings higher than $600 \mathrm{mg} \mathrm{kg}^{-1}$, only three had XRF readings higher than their ICP-AES values. The underestimation of lead concentration in this range of XRF readings is expected and is caused by the bias toward lower XRF readings on samples with high lead concentrations. Of the 24 samples having XRF readings higher than $0 \mathrm{mg} \mathrm{kg}^{-1}$, the XRF readings are within $50 \%$ of the XRF reading for only eight samples.

This variation in the degree of agreement between the XRF and ICP-AES results may be due to the nature of the lead contamination. As previously discussed, lead contamination on smallarms ranges usually consists of fine metallic particles that are very heterogeneous in the soil. The somewhat small area exposed for the XRF reading may not be identical to the one gram taken for the ICP-AES analysis. Better correlation between the XRF and ICP-AES results would be required for the field XRF method to be useful as more than a screening tool.

\subsubsection{Other Heavy-Metal Data}

The XRF unit used in this study produced a spectrum of X-rays emitted during each reading, as previously discussed in Section 4.3.2. Each spectrum was copied to a computer and printed later for inspection. On a printed spectrum (Figure 9), the X-axis represents the X-ray energy levels (channels) emitted by the sample, and the $\mathrm{y}$-axis represents the number of $\mathrm{X}$-rays (counts) for an energy level. The first 25 channels of the spectrum are used for identification and other related information and do not represent $\mathrm{X}$-ray energies from the sample. The first peak, up to channel 35 , is from the ${ }^{109} \mathrm{Cd}$ source. The larger peak to the right, at about channels 150 to 160 , is the Compton backscatter peak caused by backscatter from the ${ }^{109} \mathrm{Cd}$ gamma ray source. The lead L-shell emission peaks are at about channels 80 to 100. An algorithm that uses the 


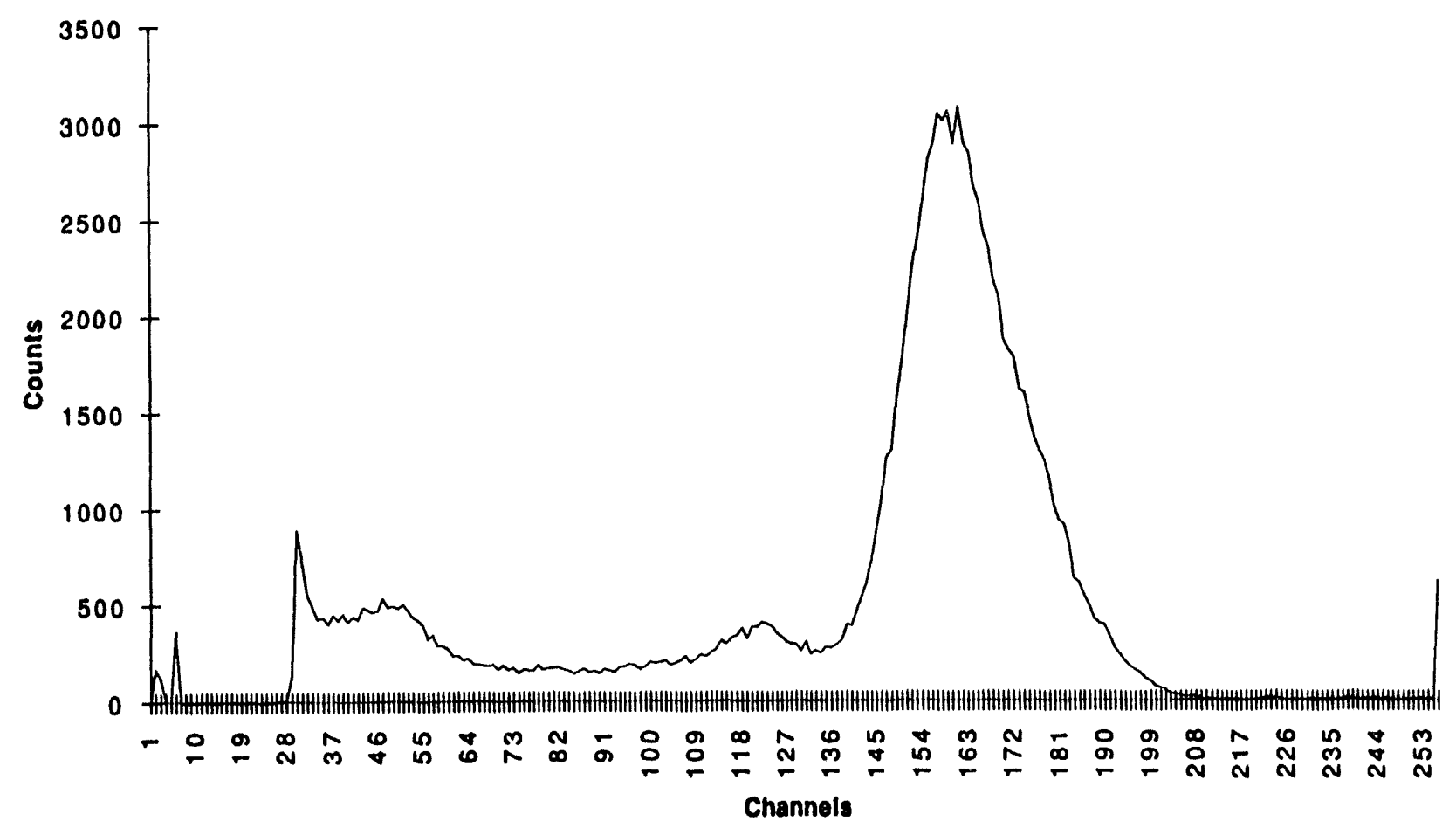

FIGURE 9 XRF Spectrum 1: Sample with $0 \mathrm{mg} \mathrm{kg}^{-1}$ Lead Collected from Range 124 at GTA during July 1992

L-shell emissions and the Compton backscatter is used to identify and quantify lead in the sample. Bands of channels with emissions from chromium, copper, nickel, and zinc appear between the ${ }^{109} \mathrm{Cd}$ peaks and the lead peaks.

The printed spectra of three XRF readings collected from Range 124 at GTA during July 1992 are shown in Figures 9-11. The readings are compared in Table 16 with the heavy-metal concentrations for samples collected at these locations and analyzed by the ICP-AES method. Theoretically, concentrations of heavy metals other than lead can be determined by inspection of the spectrum. In Figures 9-11, it is difficult to distinguish the peaks and, thus, determine the concentration of lead because of the low resolution of the printed spectrum. This poor resolution makes it impossible to identify the peaks and concentrations of chromium, copper, nickel, and zinc. Due to these limitations, inspection and review of individual spectra were not pursued.

\subsection{Potential Heavy-Metal Transport}

Another objective of this investigation was to relate the general soil, geologic, and geochemical conditions at the ranges to the mobility of heavy metals. The physical and chemical characteristics of the soil are important factors influencing the mobility of heavy metals. The analytical results for selected parameters of soil samples collected at the training ranges are shown in Table 17. 


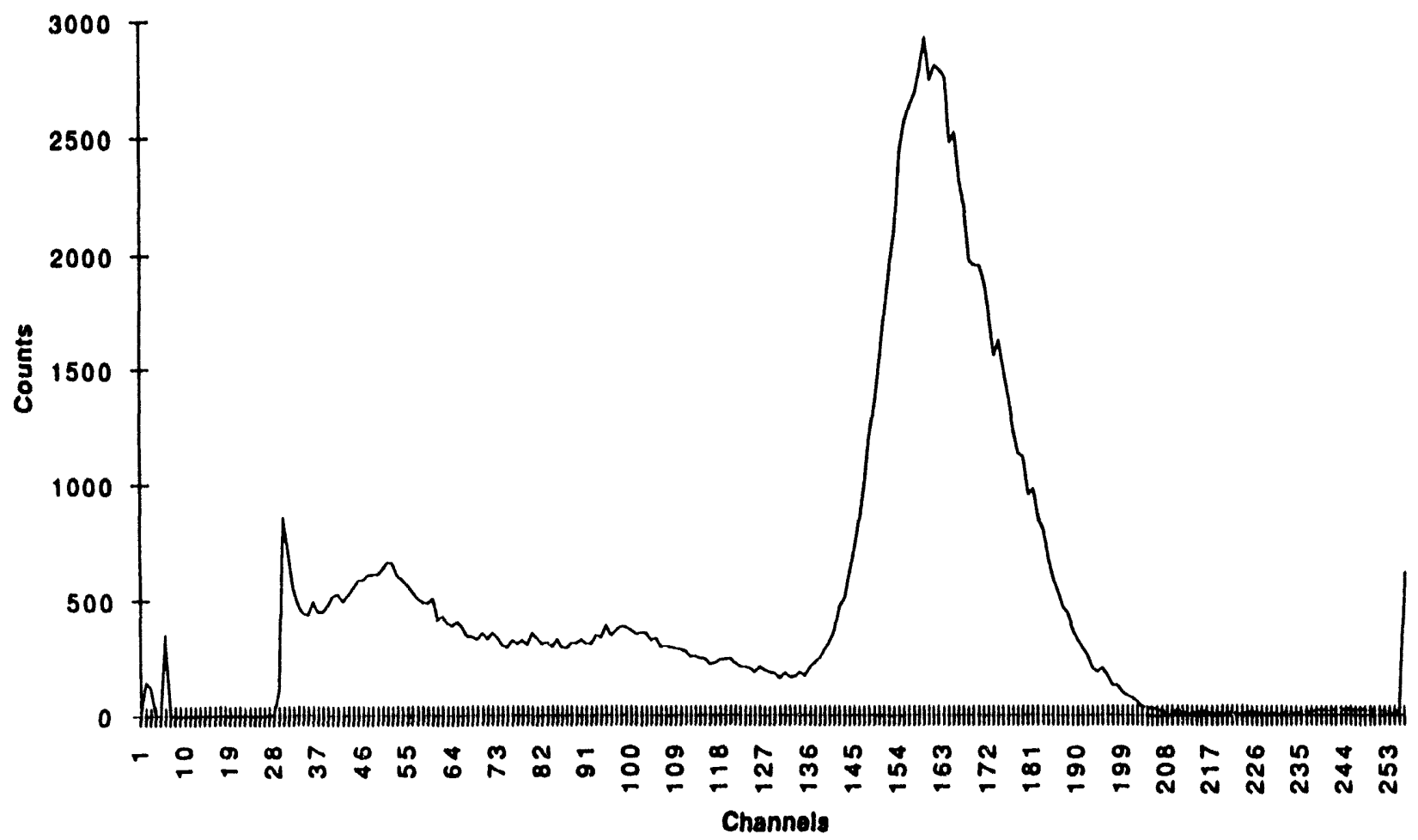

FIGURE 10 XRF Spectrum 2: Sample with $1,796 \mathrm{mg} \mathrm{kg}^{-1}$ Lead Collected from Range 124 at GTA during July 1992

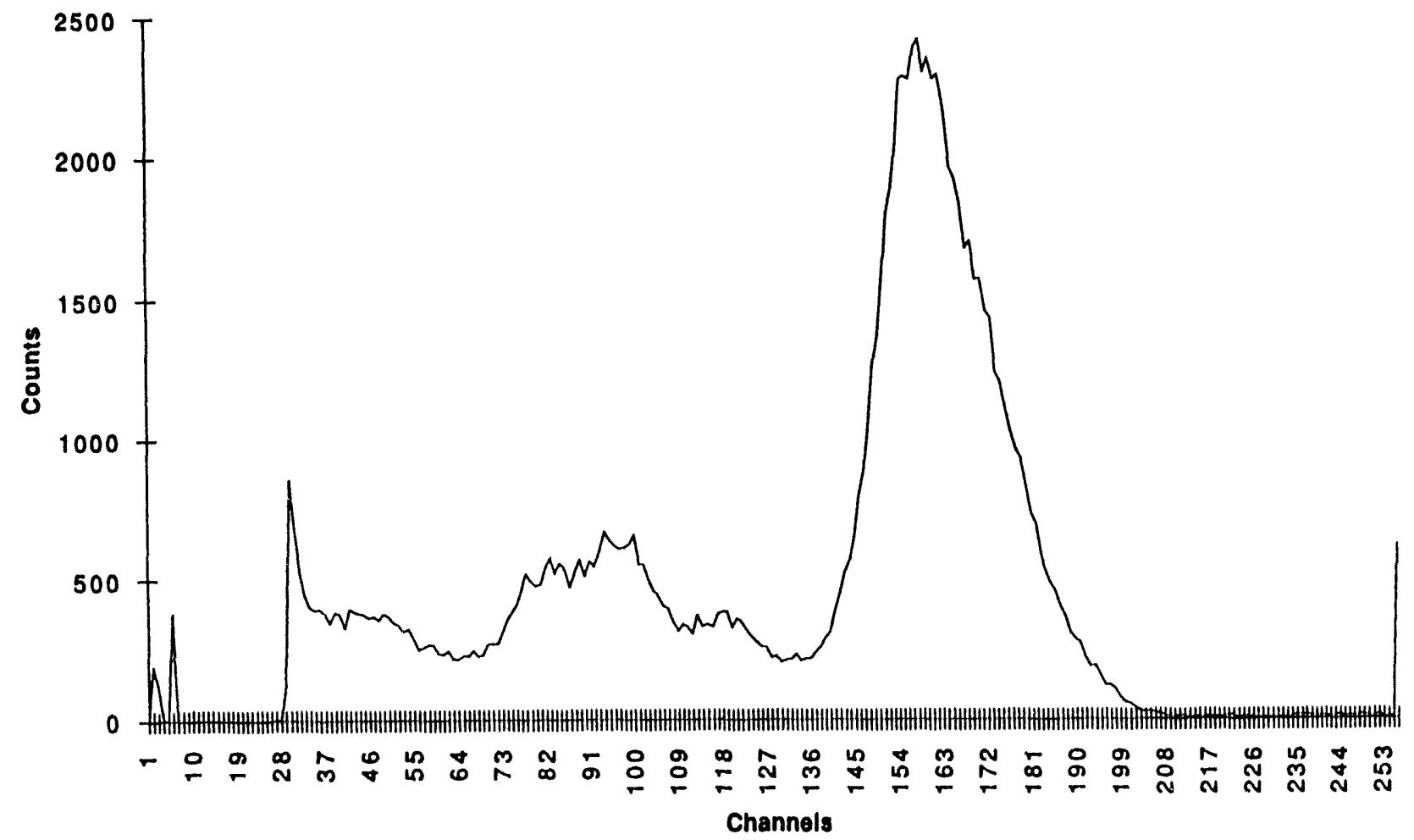

FIGURE 11 XRF Spectrum 3: Sample with $4,569 \mathrm{mg} \mathrm{kg}^{-1}$ Lead Collected from Range 124 at GTA during July 1992 
TABLE 16 Heavy-Metal Concentrations for Samples Collected at XRF Locations from Range 124 at GTA during July 1992

\begin{tabular}{|c|c|c|c|c|c|c|}
\hline \multirow{3}{*}{$\begin{array}{l}\text { Spectrum } \\
\text { Number }\end{array}$} & \multicolumn{6}{|c|}{ Heavy-Metal Concentration (mg kg-1) } \\
\hline & \multirow{2}{*}{$\begin{array}{c}\text { XRF Reading } \\
\mathrm{Pb}\end{array}$} & \multicolumn{5}{|c|}{ ICP-AES Method } \\
\hline & & $\mathrm{Cr}$ & ou & $\mathrm{Pb}$ & $\mathrm{Ni}$ & Zn \\
\hline 1 & 0 & 13.5 & 33.1 & 366 & 12.6 & 43.2 \\
\hline 2 & 1,796 & 23.4 & 1060 & 1,780 & 30.6 & 232 \\
\hline 3 & 4,569 & 7.6 & 458 & 11,090 & 9.9 & 95.8 \\
\hline
\end{tabular}

Soil reaction or $\mathrm{pH}$ is one factor that influences the availability of most heavy metals in soils. Generally, as soil $\mathrm{pH}$ increases, the availability of heavy metals decreases, because more cations are bound to the clay and organic matter in the soil. Liming the soil to raise the $\mathrm{pH}$ is a technique used sometimes to reduce the availability of heavy metals in soils. A review of the $\mathrm{pH}$ values in Table 17 shows that the soils at Ranges 124 and 111 are slightly alkaline. This alkalinity could moderately reduce the availability of heavy metals at these ranges. The soil at Range 122 is slightly acidic, so the availability of heavy metals may be slightly higher as compared with the other two ranges. Considering the above-normal concentrations of some of the heavy metals in the soils at all three ranges, soil $\mathrm{pH}$ is probably not a major factor influencing the availability of heavy metals in these soils.

The percentage of carbon in a soil is an indirect measurement of the organic matter content. The amount of organic matter and the type and amount of clay influence the cation exchange capacity (CEC) of a soil. This capacity is reflected by the two soil samples having about $2 \%$ carbon that also have much higher CEC values than the other samples. The amount and type of clay in soils also influence the CEC. Generally, soils with low proportions of clay, such as the GTA soils, have a lower CEC than soils with more clay. Differences in CEC due to the clay content of the GTA soils are not obvious, because of the minor differences in the clay content. Cations, including heavy metals, are more easily leached from soils with a low CEC than from soils with higher CEC. This finding would suggest that heavy metals could be leached from the GTA soils because of their somewhat low CEC. However, this is also probably a minor factor in the transport of heavy metals from the ranges into the local environment.

Another factor influencing the leaching of heavy metals through the soil profile is soil texture. Coarse-textured soils (sands, loamy sands, and sandy loams) generally have higher water infiltration rates than fine-textured soils (clay, silty clay, and sandy clay). Because of the coarse texture of GTA soils, a high proportion of the rainwater falling on a training range will infiltrate the soil and leach heavy metals lower into the soil profile. However, a finer textured soil will allow a higher proportion of runoff, carrying heavy metals and sediment into adjacent areas. 
TABLE 17 Physical and Chemical Characteristics of Soils Collected at GTA during July 1992

\begin{tabular}{|c|c|c|c|c|c|c|c|c|c|c|}
\hline \multirow[b]{2}{*}{ Range } & \multirow[b]{2}{*}{ Transect } & \multirow{2}{*}{$\begin{array}{l}\text { Location }^{a} \\
\qquad(\mathrm{~m})\end{array}$} & \multirow{2}{*}{$\begin{array}{l}\text { Depth } \\
(\mathrm{cm})\end{array}$} & \multirow[b]{2}{*}{$\mathrm{pH}$} & \multirow{2}{*}{$\begin{array}{c}\text { Carbon } \\
(\%)\end{array}$} & \multirow{2}{*}{$\begin{array}{c}\mathrm{CEC}^{\mathrm{b}} \\
\left(\mathrm{cmol}^{\left.\mathrm{kg}^{-1}\right)}\right.\end{array}$} & \multicolumn{3}{|c|}{$\begin{array}{l}\text { Soil Cor pponent } \\
\text { Concentration } \\
\left(\mathrm{g} \mathrm{kg}^{-1}\right)\end{array}$} & \multirow{2}{*}{$\begin{array}{l}\text { Textural } \\
\text { Class }\end{array}$} \\
\hline & & & & & & & Sand & Silt & Clay & \\
\hline 122 & 1 & 29 & 0 & 5.8 & 1.99 & 12.43 & 750 & 180 & 70 & Sandy loam \\
\hline 124 & 1 & 1 & 15 & 7.1 & 2.20 & 17.57 & 690 & 210 & 100 & Sandy loam \\
\hline 124 & 2 & 20 & 7 & 7.4 & 0.78 & 7.47 & 770 & 160 & 70 & Sandy loam \\
\hline 124 & 4 & 0 & 0 & 7.1 & 1.19 & 6.23 & 810 & 120 & 70 & Loamy sand \\
\hline 124 & 4 & 24 & 60 & 7.7 & 0.23 & 1.69 & 800 & 130 & 70 & Loamy sand \\
\hline 111 & 4 & 40 & 0 & 8.7 & 0.31 & 4.85 & 750 & 130 & 120 & Sandy loam \\
\hline 111 & 4 & 40 & 10 & 8.0 & 0.37 & 4.69 & 800 & 130 & 70 & Loamy sand \\
\hline \multicolumn{4}{|c|}{ Detection limit } & 0.1 & 0.01 & 0.05 & 10 & 10 & 10 & \\
\hline
\end{tabular}

a Distance from starting point of transect.

${ }^{b}$ Cation exchange capacity. 
The physical and chemical characteristics of soils and geochemical factors are important influences on the mobility of heavy metals in the environment. As part of a concurrent study using the soil samples from GTA to determine the amount of heavy metals leached from the soil by various media and methods, soil columns were flushed five times with an amount of distilled water equal to the pore volume. Preliminary results from this experiment show that less than $4 \%$ of the total cadmium content and even smaller amounts of other heavy metals were removed (Peters 1993). This and other column flooding experiments suggest that the heavy metals are not easily leached from the GTA soils.

There is additional evidence that heavy metals are not easily leached into the soil profiles at the three training ranges examined in this study. Both the XRF readings and the analytical data show that lead and other heavy metals are normally limited to the upper $15 \mathrm{~cm}$ of the soil surface. High levels of heavy metals in samples from the trench walls were caused by range maintenance activities, not by leaching. Results of our study show that heavy metals are not contaminating the lower portions of the soil profile.

Another objective of this study was to estimate the geographic extent of local and off-site heavy-metal contamination. A potential method for transporting heavy metals into the adjacent environment is by runoff of water and sediment. The areas around all three ranges are relatively level, so runoff sediment moving out of GTA is not a potential problem. There is some indication that runoff water, carrying sediments, does leave both Ranges 122 and 124 via the drainage ditch in front of the berm. Analytical results from sediments collected in April 1992 suggest sediments contain elevated levels of some heavy metals. Some areas within the local drainage system could have heavy-metal contamination due to sediment accumulation. There is no evidence of surfacewater runoff from Range 111, and it is unlikely there is heavy-metal contamination in adjacent areas caused by sediment accumulation.

Another potential source of off-site heavy-metal contamination is groundwater. Detailed information is limited on the groundwater quality in the area of the three ranges selected for this study. There is an ongoing program to monitor groundwater quality in wells at GTA (Dames and Moore 1992), but the closest well to Ranges 122 and 124 being monitored is at Range 118, about $1.5 \mathrm{~km}(0.9 \mathrm{mi})$ northeast of Range 122 . The depth to water in this well is about $40 \mathrm{~m}(131 \mathrm{ft})$. The latest available analytical results show low concentrations of lead, cadmium, copper, and zinc in the groundwater; concentration levels of all heavy metals are below Dutch List category B values for groundwater, except for copper, which is present at a concentration less than one-half the category $\mathrm{C}$ value. Another well in the monitoring program is a short distance from Range 111. Depth to groundwater in this well is about $80 \mathrm{~m}$ (262 ft). Detectable levels of lead, copper, and zinc are reported for samples collected from this well, but all levels are well below the category B values. It is likely that heavy metals in the groundwater are from natural sources and are not due to the presence of the training ranges. 


\section{Conclusions and Recommeridations}

Potential pollutants were identified by a review of information on the ammunition and weapons used at the three training ranges inventoried in this investigation. This review suggested that arsenic, barium, cadmium, chromium, cobalt, copper, lead, mercury, nickel, tin, and zinc could be deposited in the soils and environs of these ranges. Analytical results from soil samples indicate that concentrations of some heavy metals are above normal and may be of concern at all three training ranges. A review of the hand-grenade components suggested that TNT and RDX residues also could be present at Range 111. The following is a general assessment of the heavymetal status at each of the three ranges included in this investigation.

Results of ICP-AES analyses indicate that most soil samples from Range 122 (handgun range) have lead concentrations that are above the Dutch List category B level $\left(150 \mathrm{mg} \mathrm{kg}^{-1}\right)$, and several samples are above the category $\mathrm{C}$ level $\left(600 \mathrm{mg} \mathrm{kg}^{-1}\right)$. Copper concentrations in some of these soil samples also are above the category B level $\left(100 \mathrm{mg} \mathrm{kg}^{-1}\right)$, but they are below the category $\mathrm{C}$ level $\left(500 \mathrm{mg} \mathrm{kg}^{-1}\right)$. Concentrations of other heavy metals in soil samples from Range 122 are within their normal ranges. Analytical results of TCLP extraction of soil samples show that lead can be leached from soils in concentrations ( $\left.>5 \mathrm{mg} \mathrm{L}^{-1}\right)$ that would cause this soil to be classified as hazardous waste. Soil-sample analytical data and XRF readings show that lead contamination at Range 122 is limited to the surface soil of the berm and the areas directly behind targets .

Analytical results from vegetation samples collected at Range 122 show above-normal lead levels. The source of the lead could be high levels in the soil being taken up by the plants or external contamination by lead particles and soil. In either case, vegetation being consumed by wildlife contains elevated lead levels. The amount of potentially contaminated plant material on the ranges is small compared with the total vegetation in the area. Consequently, the overall concern for elevated lead levels in wildlife diets is minor. The water sample from Range 122 has barium and cadmium levels above the suggested maximum concentrations in drinking water, and a sediment sample from Range 122 has an above-normal concentration of lead, suggesting that lead may be transported from the range along with runoff waters into adjacent drainage ways. The physical and chemical characteristics of the soil at Range 122 suggest that heavy metals are not tightly bound in the soils. Analyses of the soil show that heavy metals are not being leached deeper into the soil profile. Analytical data for the groundwater from a well in the area show that heavy metals are not above the normal concentrations. Range 122 has the lowest heavy-metal contamination of the three ranges included in this study.

ICP-AES results from soil samples collected at Range 124 (rifle range) show that lead and copper concentrations are above the Dutch List category $C$ levels $\left(600 \mathrm{mg} \mathrm{kg}^{-1}\right.$ and $500 \mathrm{mg} \mathrm{kg}^{-1}$, respectively). These results also indicate concentrations above the Dutch List category $\mathrm{B}$ levels for arsenic (30 mg kg-1), barium (400 mg kg-1), tin (50 $\left.\mathrm{mg} \mathrm{kg}^{-1}\right)$, and zinc $\left(500 \mathrm{mg} \mathrm{kg}^{-1}\right)$ in some soil samples. The elevated levels of lead and copper are genuine, because a number of soil samples have consistently high concentrations of these two heavy metals. The arsenic, barium, tin, and zinc levels may be suspect because they occur in only a few samples and are only slightly over normal concentrations. Analyses of TCLP extraction of soil samples indicate that lead is 
leached from contaminated soils at levels $\left(>5 \mathrm{mg} \mathrm{L}^{-1}\right)$ that would cause these soils to be classified as hazardous waste. Soil analytical data and XRF readings show that the soil surface and the interior of the berm are highly contaminated with lead and possibly with copper. This contamination is produced by the type of weapons fired at this range and by regular berm maintenance activities. These data also show that soils below the $15-20 \mathrm{~cm}$ depth on the open area of the range do not contain above-normal concentrations of heavy metals.

Results of the vegetation analysis indicated above-normal concentrations of lead and barium in plants at Range 124. The elevated concentrations may be caused by uptake from high lead and barium levels in the soil or by external contamination of the vegetation. Because of the possibility of introducing contaminated plant materials into local food webs, the above-normal concentrations could be a concern. Only a relatively small amount of vegetation, as compared with the total vegetation available in the area, may be contaminated, so these elevated levels probably do not pose a threat to wildlife. Data indicate a high lead level in the sediment at Range 124, with the possibility of lead being transported by runoff into the adjacent drainage ways along with sediments. Surface water from this range was not available for analysis. Physical and chemical properties of soil at Range 124 were similar to those at Range 122, suggesting that heavy metals are not tightly bound in these soils. However, there is no evidence that heavy metals are being leached into the lower portions of the soil profile at Range 124, nor is there evidence that groundwater in the area is being contaminated by heavy metals from Range 124. Of the three ranges investigated in this study, Range 124 has the highest lead contamination, as well as possible copper contamination.

Results from analyses of soil samples from Range 111 (hand-grenade range) by the ICP-AES method indicate that concentrations of arsenic $\left(50 \mathrm{mg} \mathrm{kg}^{-1}\right)$, cadmium $\left(20 \mathrm{mg} \mathrm{kg}^{-1}\right)$, and copper ( $500 \mathrm{mg} \mathrm{kg}^{-1}$ ) are above the Dutch List category $\mathrm{C}$ levels. Zinc concentrations are also above the category $B$ level $\left(500 \mathrm{mg} \mathrm{kg}^{-1}\right)$ in many soil samples. Concentrations of other heavy metals are generally within the normal range for soils. Results from analyses of TCLP extractions indicate that cadmium is leached from contaminated soils at levels $\left(>0.5 \mathrm{mg} \mathrm{L}^{-1}\right)$ that would cause these soils to be classified as hazardous waste. Analyses for explosives show that residues of TNT and RDX are not present at Range 111.

Vegetation samples from Range 111 show the presence of above-normal concentrations of cadmium and arsenic. The elevated level of cadmium could be a potential concern with respect to wildlife, but the amount of contaminated plant material is small compared with the total volume of vegetation available in the area. Sediments were not available for sampling at Range 111, but standing-water samples did have high levels of both cadmium and barium. Because of the flat topography of Range 111, transport of these contaminates to adjacent areas would not be expected. The physical and chemical characteristics of the soil at Range 111 are similar to those of the other two ranges, suggestir. that heavy metals are not tightly bound in the soils. Analysis of groundwater from the area shows no evidence of contamination. Soil, vegetation, and surfacewater data indicate potentially hazardous levels of cadmium and possibly arsenic at Range 111.

This study also evaluated the effectiveness of a commercially available, hand-held XRF spectrum analyzer for determining lead levels in soil at the three training ranges at GTA. XRF 
readings were compared with laboratory results to evaluate the accuracy and precision of the XRF unit. The detection limit for this unit under field conditions at GTA ranged from 50 to $400 \mathrm{mg} \mathrm{kg}^{-1}$ lead. This limit was acceptable because $600 \mathrm{mg} \mathrm{kg}^{-1}$ lead is the level of concern in this study, but a lower detection limit is highly desirable. Agreement between XRF readings and laboratory results was low, which may have been due to the variable distribution of fine lead particles in the soil. Better correlation between XRF readings and laboratory results is necessary for the XRF unit to be useful as more than a screening tool. However, the hand-held XRF unit is a useful field screening tool for making large numbers of lead readings quickly and inexpensively.

Currently, the only apparent mode of heavy-metal transport into adjacent environments is by runoff waters and sediments at Ranges 122 and 124. This heavy-metal transport could be reduced by the construction of small runoff retention and sediment collection ponds, designed to collect runoff only from the open area and berm face. It is not necessary to retain runoff from the parking lots or from behind the firing lines, because these areas are not contaminated. A runoff retention structure is not necessary at Range 111, because the level topography of the area prevents runoff from occurring.

Additional investigation is needed to determine the extent and depth of cadmium contamination at Range 111 , because a relatively low concentration of cadmium in the surface soil poses a large potential threat to human health and the environment.

Results of this investigation show that there are elevated concentrations of some heavy metals in the surface soil at all three ranges and in the berm soil at Range 124. The heavy metals appear to be bound in the surface soil and are not being leached deeper into the soil profile. However, the immediate remediation of these ranges is neither practical nor necessary at this time. The removal of contaminated soils would accomplish little, because continued training activities would quickly contaminate the surface of the replaced soil. Indeed, moving these contaminated soils would transport heavy metals to other environments. At present, contamination is limited to the surface soil, and data show that heavy metals are not being leached into the lower soil profile or groundwater. The control of runoff waters and sediments would prevent heavy-metal contamination in adjacent areas. Data from this study do indicate that remediation of these ranges will be necessary at the termination of military training activities at the Grafenwöhr Training Area. 


\section{References}

Aaseth, J., and T. Norseth, 1986, "Copper," in Vol. II: Specific Metals, Handbook on the Toxicology of Metals, 2nd ed., L. Friberg et al. (editors), Elsevier, Amsterdam, Netherlands.

Allaway, W.H., 1968, "Agronomic Controls over the Environmental Cycling of Trace Metals," Advances in Agronomy 20:235-274, Academic Press, New York, N.Y.

Anderson, R.A., 1987, "Chromium," in Trace Elements in Human and Animal Nutrition, 5th ed., W. Mertz (editor), Academic Press, New York, N.Y.

Anke, M., B. Groppel, and H. Kronemann, 1984, "Significance of Newer Essential Trace Elements for the Nutrition of Man and Animal," in Vol. 3, Trace Elements Analytical Chemistry in Medicine and Biology, P. Brätter and P. Schramel (editors), Walter de Gruyter, Berlin, Germany.

Baker, D.E., and L. Chesnin, 1975, "Chemical Monitoring of Soils for Environmental Quality and Animal and Human Health," Advances in Agronomy 27:306-374, Academic Press, New York, N.Y.

Baker, D.E., and N.H. Suhr, 1982, "Atomic Absorption and Flame Emission Spectrometry," in Methods of Soil Analysis, Part 2- Chemical and Microbiological Properties, 2nd ed., A.L. Page (editor), American Society of Agronomy, Madison, Wis.

Banwart, W.L., and J.J. Hassett, 1990, "Effects of Soil Amendments on Plant Tolerance and Extractable TNT from TNT Contaminated Soils," in Agronomy Abstracts, American Society of Agronomy, Madison, Wis., p. 33.

Banwart, W.L., et al., 1991, "Plant Uptake of RDX from Spiked Soils," in Agronomy Abstracts, American Society of Agronomy, Madison, Wis., p. 35.

Berlin, M., 1986, "Mercury," in Vol. II: Specific Metals, Handbook on the Toxicology of Metals, 2nd ed., L. Friberg et al. (editors), Elsevier, Amsterdam, Netherlands.

Conrad, D.L., and W.R. Deever, 1992, "Save Test Dollars Using TCLP Alternative," Soils, pp. 8-13, April.

Dames \& Moore International, 1992, Grafenwöhr Milcom Groundwater Sampling, 2nd Sampling Round, February 1992, Project No. 17846-055-420.

Elinder, C.-G., 1986, "Zinc," in Vol. II: Specific Metals, Handbook on the Toxicology of Metals, 2nd ed., L. Friberg et al. (editors), Elsevier, Amsterdam, Netherlands. 
Elinder, C.-G., and L. Friberg, 1986, "Cobalt," in Vol. II: Specific Metals, Handbook on the Toxicology of Metals, 2nd ed., L. Friberg et al. (editors), Elsevier, Amsterdam, Netherlands.

EPA: see U.S. Environmental Protection Agency.

Franson, M.A.H. (editor), 1989, "Part 3000, Determination of Metals," in Standard Methods for the Examination of Water and Wastewater, 17th ed., American Public Health Association, Washington, D.C.

Gee, G.W., and J.W. Bauder, 1982, "Particle-Size Analysis," in Methods of Soil Analysis, Part 1 - Physical and Mineralogical Methods, 2nd ed., A. Klute (editor), American Society of Agronomy, Madison, Wis.

Green, Sgt. M., 1992, personal communication, 51st Ordnance Detachment, Fort Sheridan, Ill.

Heath, J.C., et al., 1991, Environmental Effects of Small Arms Ranges, TN-1836, Naval Facilities Engineering Command, Port Hue, Calif.

Ishinishi, K.T., M. Vahter, and B. Fowler, 1986, "Arsenic," in Vol. II: Specific Metals, Handbook on the Toxicology of Metals, 2nd ed., L. Friberg et al. (editors), Elsevier, Amsterdam, Netherlands.

Jones, J.B., Jr., 1989, Plant Analysis Techniques, Benton Laboratories, Inc., Athens, Ga., pp. 12-13.

Liebig, G.F., Jr., 1966, "Arsenic," in Diagnostic Criteria for Plants and Soils, H.D. Chapman (editor), University of California Citrus Research Center, Riverside, Calif.

Lisk, D.J., 1972, "Trace Metals in Soils, Plants, and Animals," Advances in Agronomy 24:267325, Academic Press, New York, N.Y.

Luckey, T.D., B. Venugopal, and D. Hutcheson, 1975, Heavy Metal Toxicity, Safety and Hormology, Academic Press, New York, N.Y.

Magos, L., 1986, "Tin," in Vol. II: Specific Metals, Handbook on the Toxicology of Metals, 2nd ed., L. Friberg et al. (editors), Elsevier, Amsterdam, Netherlands.

McLean, E.O., 1982, "Soil pH and Lime Requirement," in Methods of Soil Analysis, Part 2Chemical and Microbiological Properties, 2nd ed., A.L. Page (editor), American Society of Agronomy, Madison, Wis. 
Mengel, K., and E.A. Kirkby, 1978, Principles of Plant Nutrition, International Potash Institute, Worblaufen-Bern, Switzerland.

Nelson, D.W., and L.E. Sommers, 1982, "Total Carbon, Organic Carbon, and Organic Matter," in Methods of Soil Analysis, Part 2-Chemical and Microbiological Properties, 2nd ed., A.L. Page (editor), American Society of Agronomy, Madison, Wis.

Norseth, T., 1986, "Nickel," in Vol. II: Specific Metals, Handbook on the Toxicology of Metals, 2nd ed., L. Friberg et al. (editors), Elsevier, Amsterdam, Netherlands.

Peters, R.W., unpublished information (May 1993).

Pratt, P.F., 1966, "Chromium," in Diagnostic Criteria for Plants and Soils, H.D. Chapman (editor), University of California Citrus Research Center, Riverside, Calif.

Reeves, A.L., 1986, "Barium," in Vol. II: Specific Metals, Handbook on the Toxicology of Metals, 2nd ed., L. Friberg et al. (editors), Elsevier, Amsterdam, Netherlands.

Reuther, W., and C.K. Labanauskas, 1966, "Copper," in Diagnostic Criteria for Plants and Soils, H.D. Chapman (editor), University of California Citrus Research Center, Riverside, Calif.

Rhoades, J.D., 1982, "Cation Exchange Capacity," in Methods of Soil Analysis, Part 2- Chemical and Microbiological Properties, 2nd ed., A.L. Page (editor), American Society of Agronomy, Madison, Wis.

Rosenblatt, D.H., et al., 1991, "Organic Explosives and Related Compounds," in Vol. 3, Part G, The Handbook of Environmental Chemistry, O. Hutzinger (editor), Springer-Verlag, Berlin, Germany.

Staatsuitgeverij's-Gravenhage, 1988, Leiraad bodemsanering, afl. 4. "Holländische Liste."

(U.S.) 1990 Code of Federal Regulations, 7-1-90, Vol. 40, Part 261, Appendix II: Toxicity Characteristics Leaching Procedure (TCLP).

USATHAMA: see U.S. Army Toxic and Hazardous Materials Agency.

U.S. Army Toxic and Hazardous Materials Agency, 1990, "Reversed Phase High Performance Liquid Chromatography Method for the Determination of Explosive Residues in Soil," USATHAMA Standard Method SM02, Aberdeen Proving Ground, Md. 
U.S. Environmental Protection Agency, 1986, "Test Methods for Evaluating Solid Waste, Physical/Chemical Methods," SW-846, 3rd ed., Washington, D.C.

Vanselow, A.P., 1966a, "Barium," in Diagnostic Criteria for Plants and Soils, H.D. Chapman (editor), University of California Citrus Research Center, Riverside, Calif.

Vanselow, A.P., 1966b, "Cobalt," in Diagnostic Criteria for Plants and Soils, H.D. Chapman (editor), University of California Citrus Research Center, Riverside, Calif.

Vanselow, A.P., 1966c, "Nickel," in Diagnostic Criteria for Plants and Soils, H.D. Chapman (editor), University of California Citrus Research Center, Riverside, Calif.

Yamagata, N., and I. Sigematsu, 1970, Cadmium Pollution in Perspective, Bulletin 19:1-27, Institute of Public Health, Tokyo, Japan.

Wallihan, E.F., 1966, "Tin," in Diagnostic Criteria for Plants and Soils, H.D. Chapman (editor), University of California Citrus Research Center, Riverside, Calif.

WHO: see World Health Organization.

Williams, J.H., 1980, "Metal Concentrations in Soil and Crop Phytotoxicity," in Reclamation of Contaminated Land, Proceedings of a Society of Chemical Industry Meeting, held in Eastbourne, England, Oct. 22-25, 1979.

Worlá Health Organization, 1984, Guidelines For Drinking-Water Quality, Vol. 1, Recommendations, Geneva, Switzerland. 

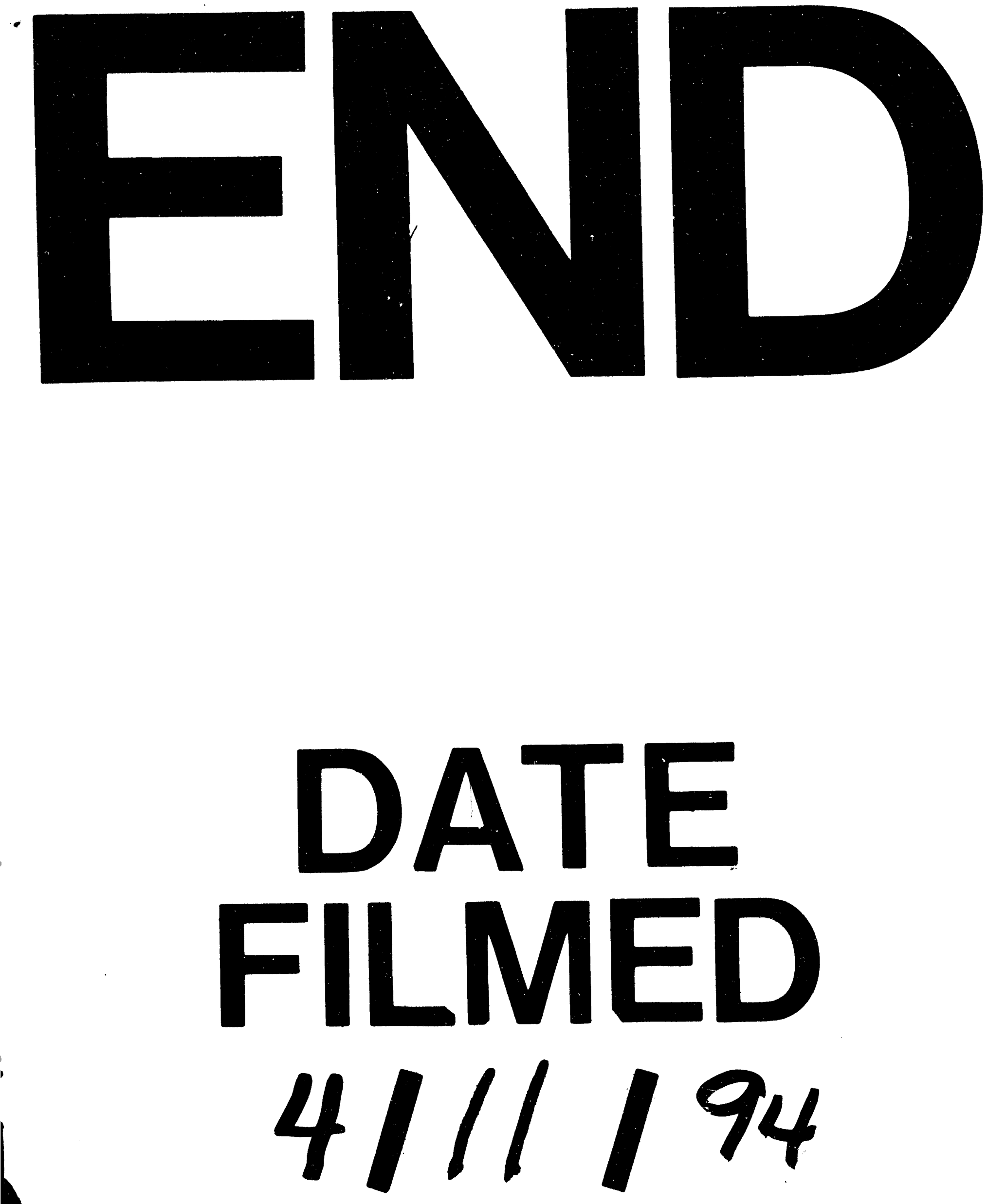

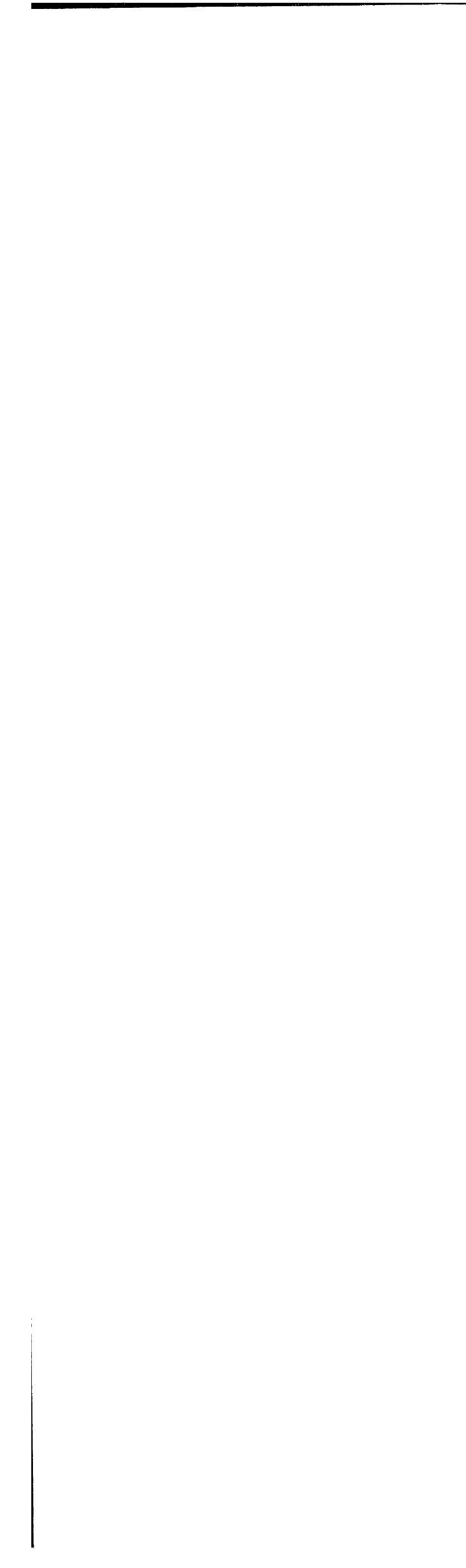